\title{
PROCESSOS DE POLIMERIZAÇÃo \\ E TRANSIÇÃO DE COLAPSO EM POLÍMEROS RAMIFICADOS
}

UBIRACI PEREIRA DA COSTA NEVES

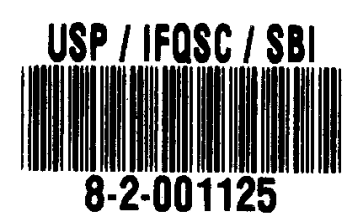

Tese apresentada ao Instituto de Fisica de São Carlos, da Universidade de São Paulo, para obtenção do Título de Doutor em Ciências: Física Básica.

Orientador: Prof. Dr. ROBERTO NICOLAU ONODY

\section{São Carlos}

1997

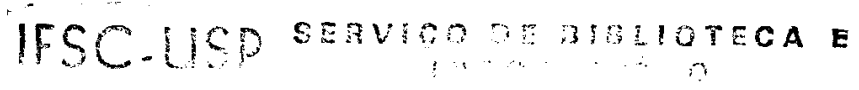


Neves, Ubiraci Pereira da Costa

Processos de Polimerização e Transição de Colapso em Polimeros Ramificados / Ubiraci Pereira da Costa Neves - São Carlos, 1997. $138 p$. 1997.

Tese (Doutorado) - Instituto de Física de São Carlos,

Orientador: Prof. Dr. Roberto Nicolau Onody

1. Polimeros Ramificados. 2. Transição de Colapso. 3. Modelo de Crescimento Cinético. 
A meus pais, Sebastião e Júlia, a meus irmãos, Ubiratan (in memoriam), Ubirajara, Tabajara e Juçara, e a Elisabete Aparecida Galdino. 


\section{AGRADECIMENTOS}

Agradeço aos Professores:

Dr. Roberto Nicolau Onody, meu orientador, pela idealização deste trabalho e orientação, com dinamismo, empenho e competência; pelo apoio e amizade; e pelo curso de Teoria de Transição de Fase e Fenômenos Críticos;

Dr. S. R. Salinas e Dr. J. F. Stilck, pelos esclarecimentos relativos ao método dos aproximantes diferenciais parciais;

Dr. L. S. Lucena, pela salutar discussão relativa a um modelo de crescimento de polimeros ramificados;

Dr. Roland Köberle e Dr. José R. Drugowich de Felício, pela concessão de tempo de CPU na Sunstation Gauss;

Dr. José F. Fontanari, Dr. Josê E. M. Hornos, Dr. Lidério C. Ioriatti Jr., Dr. Luiz Nunes de Oliveira, Dr. Silvestre Ragusa, Dr. Sylvio G. Rosa Júnior e Dr. Vanderlei S. Bagnato, pelos cursos que realizei no mestrado e doutorado.

Agradeço às seguintes instituiçōes:

CNPq (Conselho Nacional de Desenvolvimento Científico e Tecnológico), pelo apoio financeiro;

Centro Nacional de Supercomputação - UFRGS, pelo tempo de CPU no CRAY Y-MP2E/232. 
Manifesto também minha gratidão:

A meus pais, Sebastião P. da Costa Neves Filho e Júlia C. P. da Costa Neves, por possibilitarem que eu permanecesse amparado sob diversos aspectos, principalmente durante a fase de redação e elaboração desta Tese;

A Elisabete Aparecida Galdino, pelo veloz curso de Datilografia Girassol, que me possibilitou digitar este texto com eficiência; pela utilização da impressora HP Deskjet e de manuais do Word e Excel; pela compreensão e por ter-me dedicado constante atenção para com as questōes relativas à minha carreira;

A Ubirajara P. da Costa Neves, por ter facilitado a negociação de um computador 486-DX4 e de uma impressora HP Deskjet, os quais foram utilizados na confecção gráfica desta Tese;

A Diógenes Bosquetti, pelas sugestōes e esclarecimentos relativos à utilização do processador de texto Word 6.0 e pelo empréstimo do manual Word 6 - Passo a Passo;

Aos colegas da pós-graduação, Esmerindo, Márcio, Mauro, Reginaldo e Salviano, por esclarecimentos relativos à utilizaçāo de vários softwares e pela disponibilidade em solucionar eventuais problemas computacionais;

Aos técnicos Cláudio, Valdir e Bruno, pelo esclarecimento de dúvidas e solução de problemas inerentes aos computadores. 


\section{SUMÁRIO}

LISTA DE FIGURAS

viii

LISTA DE TABELAS

$\mathrm{xi}$

RESUMO

xii

ABSTRACT

xiii

1. INTRODUÇÃO

2. ANÁLISE DE EXPANSÕES EM SÉRIES DE POTÊNCIAS

2.1 INTRODUÇÃO

2.2 ANÁLISE DE SÉRIES DE UMA VARIÁVEL 7

2.2.1 Método da Razāo 7

2.2.2 Aproximantes de Padé

2.3 DESENVOLVIMENTO DE MÉTODOS PARA ANÁLISE DE SÉRIES DE DUAS VARIÁVEIS

2.4 APROXIMANTES DE CANTERBURY

2.5 APROXIMANTES DIFERENCIAIS PARCIAIS

2.5.1

Definição dos PDAs

2.5.2

Teoria Linear

16

2.5.3 Curvas Caracteristicas

20

2.5.4

Fidedignidade e Invariância de Euler

22 
3. TRANSIÇÃO DE COLAPSO EM POLÍMEROS

RAMIFICADOS

3.1 INTRODUÇÃO 25

3.2 POLÍMEROS LINEARES 28

3.2.1 Caminhadas Aleatórias 29

3.2.2 Temperatura de Flory $\theta \quad 30$

3.3 POLÍMEROS RAMIFICADOS 32

3.3.1 Realização Experimental 32

3.3.2 Modelos Teóricos 32

3.3.3 Propriedades Termodinâmicas, Geométricas e

Parâmetros Críticos de um Animal na Rede $\quad 35$

3.3.4 Principais Resultados dos Modelos Estudados na

Literatura $\quad 38$

4. ANÁLISE DA TRANSIÇÃO DE COLAPSO EM ANIMAIS NA

REDE ATRAVÉS DE APROXIMANTES DIFERENCIAIS

PARCIAIS $\quad 44$

4.1 INTRODUÇÃO 44

4.2 O MODELO 45

4.3 EXTRAPOLAÇĀO DO DIAGRAMA DE FASES ATRAVÉS DE "FINITE SIZE SCALING" 47

$\begin{array}{lll}4.3 .1 & \text { O Algoritmo BST } & 48\end{array}$

4.3.2 Diagrama de Fases 49

4.4 APLICAÇÃO DOS APROXIMANTES DIFERENCIAIS PARCIAIS 53

4.4.1 Equações Geratrizes $\quad 54$

4.4.2 Formatos dos Conjuntos $M, N, L, J, K$

4.4.3 Resultados Numéricos 57

4.4.3.1 Escolhendo Conjuntos de Rótulos com Formatos Quadrados $\quad 62$

$\begin{array}{lll}\text { 4.4.4 Sumário } & 64\end{array}$ 
5. MODELO DE CRESCIMENTO CINÉTICO 66

5.1 INTRODUÇÃO 66

5.2 MODELO DE CRESCIMENTO CINÉTICO 67

5.2.1 Caminhada de Crescimento Cinético 67

5.2.2 Modelo de Crescimento de Polimeros Ramificados 69

$\begin{array}{lll}\text { 5.2.2.1 Descrição do Modelo } & 70\end{array}$

$\begin{array}{lll}\text { 5.2.3 Linha Critica } b_{c}(c) \text { e Dimensão Fractal } & 72\end{array}$

$\begin{array}{lll}\text { 5.2.4 Criticalidade Auto-Organizada } & 76\end{array}$

6. TOPOLOGIA, DINÂMICA E EFEITOS DE TAMANHO FINITO DE UM MODELO DE CRESCIMENTO CINÉTICO 79

$\begin{array}{lll}6.1 & \text { INTRODUÇÃO } & 79\end{array}$

6.2 TOPOLOGIA E DIMENSÃO FRACTAL 80

6.2.1 O Modelo 80

$\begin{array}{lll}6.2 .2 & \text { Aspectos Topológicos } & 81\end{array}$

6.2.3 Dimensão Fractal 86

$\begin{array}{lll}6.3 & \text { DINÂMICA } & 89\end{array}$

6.3.1 Dependência Temporal da Massa 89

$\begin{array}{lll}\text { 6.3.2 Tempo Médio de Vida } & 91\end{array}$

6.3.3 Estatística de Aglomerados 92

6.3.4 Função de Autocorrelação Temporal 93

6.3.5 Expoente Crítico Dinâmico 94

6.4 EFEITOS DE TAMANHO FINITO 96

$\begin{array}{ll}6.5 & \text { RUGOSIDADE DA SUPERFÍCIE } \\ 6.6 & \text { CONCLUSOES }\end{array}$

6.6 CONCLUSÕES 104

7. SIMULAÇÕES DE UM MODELO DE CRESCIMENTO CINÉTICO COM INTERAÇÕES ATRATIVAS ENTRE SÍTIOS PRIMEIROS VIZINHOS 106

$\begin{array}{lll}7.1 & \text { INTRODUÇÃO } & 106\end{array}$

7.2 MODELO DE CRESCIMENTO CINÉTICO 107 
7.3 UM MÉTODO DE MONTE CARLO

7.4 PARÂMETRO DE ORDEM E COMPRIMENTO DE CORRELAÇÃO

7.5 CONFIGURAÇÕES GEOMÉTRICAS DOS AGLOMERADOS 110

7.6 DIAGRAMA DE FASES 115

$\begin{array}{lll}7.7 & \text { CONCLUSÕES } & 117\end{array}$

8. CONCLUSÕES E PERSPECTIVAS 118

8.1 TRANSIÇÃO DE COLAPSO E SÉRIES 118

8.2 MODELO DE CRESCIMENTO CINÉTICO 121

9. ANEXO: APLICAÇÃO DA TEORIA DE “FINITE SIZE SCALING" AO ESTUDO DE FENÔMENOS CRÍTICOS: MÉTODO DE CUMULANTES

$\begin{array}{lll}9.1 & \text { INTRODUÇÃO } & 124\end{array}$

9.2 FUNÇÃO DE DISTRIBUIÇÃO DE PROBABILIDADE DO PARÂMETRO DE ORDEM 128

9.3 CUMULANTE DA DISTRIBUIÇÃO 132

10. REFERÊNCIAS 136

APÊNDICE: REALIZAÇÃO EXPERIMENTAL DA

TRANSIÇÃO DE COLAPSO EM POLÍMEROS RAMIFICADOS I 


\section{LISTA DE FIGURAS}

Figura 2.1: O comportamento multicritico de um modelo de Heisenberg ferromagnético anisotrópico clássico.

Figura 2.2: Padrão de fluxo das curvas caracteristicas emanando de um ponto multisingular $C$ com expoente "crossover" $\phi<0$.

Figura 3.1: (a) Representação de um monômero; (b) Polímero linear hipotético contendo 4 monômeros; (c) Unidade polifuncional (com funcionalidade $f=4$ ); (d) Exemplo de unidades polifuncionais formando um polimero ramificado.

Figura 3.2: Um animal sobre a rede quadrada com $N=9, B=10$, $P=11, \lambda=1$ e $C=2$.

Figura 4.1: Densidade $\rho$ e compressibilidade isotérmica versus temperatura $T$ para algumas fugacidades fixas: $x=0.001$, $x=0.023$ e $x=0.070$.

Figura 4.2: Diagrama de fases de um modelo de animais em colapso obtido através do algoritmo de extrapolação BST.

Figura 4.3: Expoente $\omega_{\min }$ (que minimiza o erro na extrapolação BST) em funçāo da temperatura extrapolada $T_{\mathrm{c}}$.

Figura 4.4: Ilustração dos formatos dos conjuntos de rótulos $J, L, M, N, K$ apropriados para construção de aproximantes Eulerianos.

Figura 4.5: Padrão de fluxo das trajetórias características de um típico aproximante com ponto multicrítico estável $(\phi>0)$.

60

Figura 4.6: Trajetória crítica correspondente ao mesmo aproximante com ponto multicritico estâvel da Figura 4.4.

Figura 5.1: Duas configurações idênticas são mostradas, com pesos apropriados em cada passo, para um SAW e Um KGW.

Figura 5.2: Exemplo de simulação do modelo de crescimento cinético (generalizado para polimeros ramificados) somente até instante $t=5$.

Figura 5.3: Lei de distribuição de polidispersão.

Figura 5.4: Resultados típicos que mostram o comportamento de $\xi$ em função de $b\left(1000 \leq N_{e} \leq 20000\right)$. 
Figura 5.5: (a) Resultados típicos para o parâmetro de ordem $P_{\infty}$ como função de $b$ e $c(L=300)$; (b) Diagrama de fases $(300 \leq L$ $\leq 5000)$.

Figura 5.6: Fragmento típico de um "polimero" gerado em uma rede $50 \times 50$ com uma distribuição aleatória de impurezas.

Figura 6.1: Um subgrafo conectado sem ciclos (árvoreligação), que não corresponde a nenhuma configuração possivel gerada pelo modelo de crescimento cinético com $b \neq 0 \mathrm{e}$ $c=0$.

Figura 6.2: Parâmetro de ordem $<\rho>$ como função de $b$, para $c=0,0.10,0.20,0.30$ e 0.35 .

Figura 6.3: $\left\langle N_{3}\right\rangle\left\langle N_{3}\right\rangle_{\max }$ versus $b$ para $c=0$, onde $\left\langle N_{3}\right\rangle_{\max }$ é o máximo valor de $\left\langle N_{3}\right\rangle$.

Figura 6.4: Configuração de um aglomerado de sítios conectados gerado em uma simulação do modelo de crescimento cinético com $b=0.5, c=0$ e $L=51$.

Figura 6.5: Gráfico logaritmico de $M=<N>+1$ versus $L$.

88

Figura 6.6(a): Típico gráfico $\log (<N(t)>)$ versus $\log (t)$.

90

Figura 6.6(b): Variação de $\theta$ versus $b$.

Figura 6.7: Tempo médio de vida $T_{f}$ dos aglomerados finitos.

Figura 6.8: Número de aglomerados $(=$ número de aglomerados finitos ativos + número de aglomerados infinitos que ainda não tocaram a fronteira) no instante $t$.

92

Figura 6.9: Função de autcorrelação temporal da massa $\langle C(\tau)>$.

Figura 6.10: Gráfico log-log do tempo de descorrelação $\tau_{D}(L)$ versus comprimento de correlação $\xi(L)$.

95

Figura 6.11: Cumulante de quarta ordem $U_{L}$ versus $b$, para $c=0$ e tamanhos $L=161,181,201,221$ e 241 .

97

Figura 6.12: Expoente $v$ (com barra de erro) em função da concentração de impurezas $c$.

Figura 6.13: Superficie de referência para a medida das funções de correlação de diferença de altura $C_{q}(\Delta r)$.

102

Figura 6.14: Gráfico logarítmico da função de correlação $\left\langle C_{2}(\Delta r)>\right.$ versus $\Delta r$.

Figura 7.1: Um possivel aglomerado no instante $t=3$ e duas hipotéticas configurações $C_{1}$ e $C_{2}$ no instante $t+1$, geradas pela aplicação das regras de crescimento no instante $t$. 
Figura 7.2: Configuração de uma cadeia linear $(b=0)$ que é infinita em $T=0$.

Figura 7.3: Configuração de um aglomerado simulado, com parâmetros $T=0$ e $b=0.5$, numa rede quadrada de tamanho $L=51$ e $\operatorname{com} N_{\mathrm{M}}=400$.

Figura 7.4: Configuração típica de um aglomerado simulado com parâmetros $T=0.5$ e $b=0.01$.

Figura 7.5: Configuração típica de um aglomerado simulado com parâmetros $T=0.5 \mathrm{e} \mathrm{b}=0.03$.

Figura 7.6: Possivel configuração da caminhada de crescimento cinético, reproduzida através do crescimento do aglomerado com $T \rightarrow \infty$ e $b=0$.

Figura 7.7: Configuração de um aglomerado obtido através de uma simulação realizada com parâmetros $T \rightarrow \infty$ e $b=0.05$.

Figura 7.8: Linha crítica no plano $(T, b)$ separando as fases de crescimento finito e infinito.

Figura 9.1: Esboço qualitativo da susceptibilidade $\chi^{\prime}$ de um sistema que sofre uma transição da fase ferromagnética para a fase paramagnética, conforme a temperatura $T$ aumenta.

Figura 9.2: Evolução esquemática da distribuiçāo de probabilidade do parâmetro de ordem $P_{\mathrm{L}}(m)$.

Figura I: Preparaçāo do gel poliacrilamida.

Figura II: Colapso abrupto do gel poliacrilamida.

III

Figura III: Taxa de expansão do volume de um gel quando este é colocado em solventes com diferentes concentraçōes de acetona. 


\section{LISTA DE TABELAS}

Tabela 3.1: Expoente "crossover" $\phi$ para modelos de animais com fugacidade de ciclos e contatos em duas e três dimensões.

Tabela 3.2: Temperatura $T_{\theta}=1 / \beta_{\theta}$ e fugacidade tricritica $x_{t}$ da transição de colapso em modelos de animais com fugacidade de ciclos e contatos, em duas e três dimensões.

Tabela 6.1: Dimensōes Fractais. $\quad 88$

Tabela 6.2: Expoentes Críticos Dinâmicos. 95

Tabela 6.3: Estimativas de $b_{\mathrm{c}}$ e expoentes críticos $v$. 98

Tabela 6.4: Expoentes de Hurst $H$. 103 


\section{RESUMO}

Estudamos o diagrama de fases e o ponto tricrítico da transição de colapso em um modelo de animais na rede quadrada, a partir da expansāo em série da compressibilidade isotêrmica $K_{T}$ do sistema. Como função das variâveis $x$ (fugacidade) e $y=e^{1 / T}$ ( $T$ é a temperatura reduzida), a série $K_{T}$ è analisada utilizando-se a técnica dos aproximantes diferenciais parciais. Determinamos o padrão de fluxo das trajetórias caracteristicas de um tipico aproximante diferencial parcial com ponto fixo estável. Obtemos estimativas satisfatórias para a fugacidade tricritica $x_{t}=0.024 \pm 0.005$ e a temperatura tricritica $T_{t}=0.54 \pm 0.04$. Considerando somente campos de escala lineares, obtemos também o expoente de escala $\gamma=1.4 \pm 0.2$ e o expoente "crossover" $\phi=0.66 \pm 0.08$. Nossos resultados estão em boa concordância com estimativas prévias obtidas por outros métodos. Também estudamos um processo de polimerização ramificada através de simulações computacionais na rede quadrada baseadas em um modelo de crescimento cinético generalizado para se incorporar ramificações e impurezas. A configuração do polimero é identificada com uma árvore-ligação ("bond tree”) a fim de se examinar os aspectos topológicos. As dimensões fractais dos aglomerados ("clusters") são obtidas na criticalidade. As simulações também permitem o estudo da evolução temporal dos aglomerados bem como a determinação das autocorrelações temporais e expoentes criticos dinâmicos. Com relação aos efeitos de tamanho finito, uma técnica de cumulantes de quarta ordem é empregada para se estimar a probabilidade de ramificação crítica $b_{c}$ e os expoentes críticos $v$ e $\beta$. Na ausência de impurezas, a rugosidade da superficie é descrita em termos dos expoentes de Hurst. Finalmente, simulamos este modelo de crescimento cinético na rede quadrada utilizando um método de Monte Carlo para estudar a polimerização ramificada com interações atrativas de curto alcance entre os monômeros. O diagrama de fases que separa os regimes de crescimento finito e infinito é obtido no plano $(T, b)(T$ é a temperatura reduzida e $b$ é a probabilidade de ramificação). No limite termodinâmico, extrapolamos a temperatura $T^{*}=0.102 \pm 0.005$ abaixo da qual a fase é sempre infinita. Observamos também a ocorrência de uma transição de rugosidade na superficie do polimero. 


\section{ABSTRACT}

The phase diagram and the tricritical point of a collapsing lattice animal are studied through an extended series expansion of the isothermal compressibility $K_{T}$ on a square lattice. As a function of the variables $x$ (fugacity) and $y=e^{l / T}$ ( $T$ is the reduced temperature), this series $K_{T}$ is investigated using the partial differential approximants technique. The characteristic flow pattern of partial differential approximant trajectories is determined for a typical stable fixed point. We obtain satisfactory estimates for the tricritical fugacity $x_{t}=0.024 \pm 0.005$ and temperature $T_{t}=0.54 \pm 0.04$. Taking into account only linear scaling fields we are also able to get the scaling exponent $\gamma=1.4 \pm 0.2$ and the crossover exponent $\phi=0.66 \pm 0.08$. Our results are in good agreement with previous estimates from other methods. We also study ramified polymerization through computational simulations on the square lattice of a kinetic growth model generalized to incorporte branching and impurities. The polymer configuration is identified with a bond tree in order to examine its topology. The fractal dimensions of clusters are obtained at criticality. Simulations also allow the study of time evolution of clusters as well as the determination of time autocorrelations and dynamical critical exponents. In regard to finite size effects, a fourthorder cumulant technique is employed to estimate the critical branching probability $b_{c}$ and the critical exponents $v$ and $\beta$. In the absence of impurities, the surface roughness is described in terms of the Hurst exponents. Finally we simulate this kinetic growth model on the square lattice using a Monte Carlo approach in order to study ramified polymerization with short distance attractive interactions between monomers. The phase boundary separating finite from infinite growth regimes is obtained in the $(T, b)$ space $(T$ is the reduced temperature and $b$ is the branching probability). In the thermodynamic limit, we extrapolate the temperature $T^{*}=0.102 \pm 0.005$ below which the phase is found to be always infinite. We also observe the occurrence of a roughening transition at the polymer surface. 


\section{INTRODUÇÃO}

Macromoléculas tais como os ácidos nucleicos (DNA e RNA), as proteinas e os polissacarideos são polimeros de importância fundamental nos processos biológicos. Outros exemplos de polimeros são alguns materiais naturais como a borracha, a madeira e os materiais sintéticos usados na fabricação de plásticos e fibras, todos indispensáveis à civilização atual, essenciais ao vestuário, abrigo, transportes, comunicação e conveniências da vida moderna.

O grande desenvolvimento da ciência dos polimeros e a extensa utilizaçāo dos materiais poliméricos na tecnologia têm contribuído para um interesse cada vez maior em vários problemas da fisica dos polimeros. Esta é uma combinação peculiar de conceitos básicos, idéias e métodos da fisica molecular, termodinâmica, mecânica estatística e fisica do estado sólido.

Os polímeros lineares em solução têm sido objeto de estudo teórico (Flory, 1969; de Gennes, 1975, 1978, 1979; Moore, 1977; Duplantier, 1982; Baumgärtner, 1982) e experimental (Nierlich et al., 1978; Nishio et al., 1979) há aproximadamente meio século. A conhecida caminhada aleatória auto-exclusiva ("self-avoiding walk" SAW) pode descrever uma cadeia de polimero linear em solução diluída num bom solvente, onde os monômeros têm maior afinidade pelo 
solvente do que por monômeros em outros pontos da cadeia. Com a diminuição da temperatura ou da qualidade do solvente, as forças atrativas entre os monômeros tornam-se importantes e o polimero pode colapsar no ponto tricrítico de Flory $\theta$.

Os polimeros ramificados são aqueles que podem apresentar qualquer configuração geométrica incluindo ramos ou ciclos. Experimentalmente, os polimeros ramificados são realizados na forma de gêis, onde há algum tempo atrás uma transição de colapso foi verificada (Tanaka, 1981). Recentemente, um mecanismo de colapso seguido de expansão (o volume varia com um fator $10^{3}$ ) foi encontrado no gel acrilamida, numa mistura água-acetona (Ikehara e Nishi, 1993). Teoricamente, os polímeros ramificados em solução diluída num bom solvente têm sido modelados por animais na rede (aglomerados conectados de sítios vizinhos ocupados). Argumentos do tipo Flory (campo médio) têm sido empregados na obtenção dos expoentes críticos e tricríticos dos polimeros ramificados (Isaacson e Lubensky, 1981). A introdução de interação atrativa (monômero-monômero) entre sítios primeiros vizinhos pode conduzir a um colapso do animal a baixas temperaturas. Evidências desta transição foram fornecidas por muitas técnicas: matriz de transferência em faixas bidimensionais (Derrida e Herrmann, 1983), métodos de Monte Carlo (Dickman e Schieve, 1984; Lam, 1987, 1988) e séries (Gaunt e Flesia, 1990; Madras et al., 1990; Gaunt, 1991; Flesia e Gaunt, 1992; Flesia et al. 1992, 1993). Dhar (1987) provou a existência da transição de colapso num modelo relacionado: o animal direcionado bidimensional.

Um modelo alternativo no estudo da polimerização é o denominado modelo de crescimento cinético (Majid et al., 1984; Herrmann, 1984; Lyklema, 1986). Este é mais realista do que o SAW no sentido de que a extremidade da cadeia é repelida pelos sítios ocupados e, caso existam sítios adjacentes vazios, continua seu crescimento necessariamente. Recentemente, L. S. Lucena, C. Tsallis e colaboradores generalizaram o modelo de crescimento cinético, 
incorporando dois novos parâmetros: a probabilidade de ramificação $b$ e a concentração de impurezas $c$ (Lucena et al., 1994). Este novo modelo de crescimento de polimeros ramificados exibe uma transição finitainfinita (no espaço $(b, c)$ ) que se deve basicamente à competição entre ramificações e obstáculos.

No presente trabalho, nosso objetivo é estudar dois modelos de polimeros ramificados: os animais na rede e o modelo de crescimento cinético generalizado. Primeiramente, consideramos a transiçāo de colapso em um modelo de animais na rede com interações atrativas entre sítios primeiros vizinhos e, para estudar o comportamento multicrítico do sistema, aplicamos um método de análise de séries, os aproximantes diferenciais parciais (Fisher, 1977). Em seguida, estudamos os aspectos topológicos e dinâmicos do modelo de crescimento cinético, analisando os efeitos de tamanho finito do sistema através do emprego de uma técnica de intersecção de cumulantes (Binder, 1981, 1987, 1990) para localizaçāo do ponto crítico e estimativa dos expoentes criticos. Finalmente, incluímos, no sistema, forças atrativas de curto alcance entre os monômeros e, através do desenvolvimento de um método de Monte Carlo, incorporamos um novo parâmetro: a temperatura reduzida $T$. Obtemos a linha de transição finita-infinita no plano $(T, b)$.

Nos tópicos abaixo, apresentamos o conteúdo principal de cada um dos próximos capitulos desta Tese e de seus elementos de pós-texto (anexo, referências e apêndice).

Capitulo 2: consideramos o problema da análise assintótica de séries de potências (Guttmann, 1989); nosso principal objetivo ê estudar a teoria dos aproximantes diferenciais parciais, introduzidos por Fisher (1977) em resposta à necessidade de um método que permitisse investigar um comportamento multicritico complicado ao analisar séries de duas (ou mais) variáveis.

Capitulo 3: apresentamos um breve retrospecto do estudo dos polímeros lineares, onde definimos o ponto de Flory $\theta$ da transição de 
colapso de cadeias em solução; abordamos o problema da transição de colapso em polimeros ramificados, definindo os modelos de animais na rede, suas propriedades termodinâmicas, geométricas e seus parâmetros críticos; apresentamos também uma ampla visão dos principais resultados dos modelos estudados na literatura.

Capitulo 4: empregamos a teoria dos aproximantes diferenciais parciais no estudo do comportamento multicrítico da expansão em série da compressibilidade isotérmica $K_{T}(x, y)$ ( $x$ é a fugacidade e $\left.y=e^{1 / T}\right)$ de um modelo de animais na rede quadrada (com interações atrativas entre sitios primeiros vizinhos); o método, aplicado pela primeira vez neste sistema, nos permite estimar o ponto tricrítico e os expoentes da transição de colapso, obtendo ainda o padrão de fluxo das trajetórias caracteristicas (Onody e Neves, 1996a).

Capitulo 5: descrevemos o modelo de crescimento cinético em sua forma original (Majid et al., 1984) e também na forma generalizada por Lucena et al. (1994) para incorporar a possibilidade de ramificações e a presença de impurezas; mostramos os principais resultados obtidos por Lucena et al., dentre os quais a curva critica separando as fases finita e infinita no espaço $(b, c)$; apresentamos ainda como a criticalidade auto-organizada do sistema pode ser atingida através de uma regra dinâmica global, proposta recentemente por Andrade et al. (1996).

Capitulo 6: estudamos novos aspectos do modelo de crescimento cinético generalizado, sua topologia e dinâmica, e aplicamos uma teoria fenomenológica de "finite size scaling" (método de intersecção cumulantes - Binder, 1981, 1987, 1990) para obter as probabilidades de ramificação criticas $b_{c}$ e para estimar os expoentes criticos $\beta \mathrm{e} v$; descrevemos a rugosidade da superficie do polimero em termos dos expoentes de Hurst (Neves e Onody, 1995).

Capitulo 7: incluimos, no modelo de crescimento cinético, forças atrativas de curto alcance entre os monômeros e, atravês do emprego de 
um método de Monte Carlo, introduzimos a temperatura reduzida $T$ no sistema; no plano $(T, b)$, obtemos o diagrama de fases que separa os regimes de crescimento finito e infinito; verificamos que a transição de rugosidade na superficie do aglomerado deve manifestar-se em todas as temperaturas (Onody e Neves, 1996b).

Capitulo 8: apresentamos as conclusões e perspectivas; primeiramente, propomos uma enumeração de animais na rede generalizada para o caso em que há dois tipos de sítios ocupados, que poderá ser aplicada no estudo de heteropolímeros; com relação ao estudo da polimerização ramificada através do modelo de crescimento cinético, propomos o cálculo de funções termodinâmicas do sistema (calor específico e compressibilidade isotérmica) no "ensemble grand canônico", com a introdução do parâmetro fugacidade, ao lado da temperatura.

Anexo: abordamos a teoria de "finite size scaling" e estudamos um método de intersecção de cumulantes (Binder, 1981, 1987, 1990); considerando que na criticalidade a função de distribuição do parâmetro de ordem apresenta uma mudança substancial, mostramos como este método pode localizar o ponto crítico de um sistema e estimar os expoentes criticos.

Referências: são apresentadas em ordem alfabética de autor, de acordo com o sistema de chamada alfabético.

Apêndice: apresentamos a realização experimental da transição de colapso em polímeros ramificados; descrevemos os resultados das experiências desenvolvidas com o gel poliacrilamida, onde há algum tempo atrâs uma transição de colapso foi detectada pelo grupo liderado por T. Tanaka, no M.I.T.. 


\section{ANÁLISE DE EXPANSÕES EM SÉRIES DE POTÊNCIAS}

\subsection{INTRODUÇÃO}

Expansões em séries de potências podem ser desenvolvidas em muitos modelos de rede para várias dimensões. Estas expansões podem ser utilizadas no cálculo das propriedades do modelo, particularmente na região crítica.

Neste capítulo, consideramos o problema da análise assintótica de séries de potências (Guttmann, 1989), com especial interesse no método dos aproximantes diferenciais parciais (Fisher, 1977).

Inicialmente, descrevemos brevemente dois métodos para análise de séries de uma única variável, o método da razão (Domb e Sykes, 1956) e os aproximantes de Padé (Padé, 1892). Em seguida, apresentamos os aproximantes de Canterbury (Chisholm, 1973), que se constituem numa generalização dos aproximantes de Padé, para funções de duas variáveis. Finalmente, abordamos a teoria dos aproximantes diferenciais parciais, introduzidos por Fisher em resposta à necessidade de um método que permitisse investigar um comportamento multicrítico complicado ao analisar séries de duas (ou mais) variáveis.

Aplicamos o método dos aproximantes diferenciais parciais em um problema fisico real no capitulo 4. Em particular, estudamos a 
transição de colapso em polímeros ramificados (Onody e Neves, 1996a) e utilizamos a técnica na análise da expansão em série da compressibilidade isotérmica do sistema, $K_{T}(x, y)$, como função das variáveis fugacidade $x$ e peso de Boltzmann $y$.

\subsection{ANÁLISE DE SÉRIES DE UMA VARIÁVEL}

Próximo ao ponto crítico onde ocorre uma transição de fase, o comportamento de uma função termodinâmica do sistema, $f(z)$, é tipicamente expresso por

$$
f(z) \approx A\left(1-\frac{z}{z_{c}}\right)^{-\lambda}, \quad\left(z \rightarrow z_{c}^{-}\right)
$$

As constantes $A, z_{c}$ e $\lambda$ são chamadas, respectivamente, amplitude da singularidade, ponto crítico e expoente crítico. A forma assintótica (2.1) corresponde ao termo de ordem dominante e, em muitos casos, termos de correção também devem ser considerados (Guttmann, 1989).

Os parâmetros $A, z_{c}$ e $\lambda$ podem ser determinados através de uma análise da expansão em série de potências de $f(z)$. Considere que a expansão de Taylor de $f(z)$, em torno de $z=0$, seja conhecida até determinada ordem, isto é,

$$
f(z)=\sum_{n=0}^{\infty} a_{n} z^{n}
$$

com $a_{n}$ conhecido para $n=0,1, \cdots, N$.

Suponhamos que, na expansāo (2.2), possamos definir o limite $z_{0}=\lim _{n \rightarrow \infty}\left|a_{n}\right|^{-1 / n}$. Então, a série converge para $|z|<z_{0}$ e diverge para $|z|>z_{0}$. Correspondentemente, deve haver no minimo uma singularidade (ponto não analítico) sobre o círculo de convergência $|z|=z_{0}$.

\subsubsection{MÉTODO DA RAZÃO}

O método da razão (Domb e Sykes, 1956, 1957) é geralmente usado para determinar a singularidade que reside no eixo real e é 
dominante. Suponha que a singularidade dominante de alguma função $f(z)$ esteja sobre o eixo real positivo em $z=z_{0}=z_{c}$. A aplicação do método consiste no cálculo das razões de coeficientes sucessivos,

$$
r_{n}=\frac{a_{n}}{a_{n-1}}=\frac{1}{z_{c}}\left(1+\frac{\lambda-1}{n}+O\left(\frac{1}{n^{2}}\right)\right),
$$

que variam linearmente com $1 / n$ conforme $n \rightarrow \infty$ (ver Guttmann, 1989). A intersecção em $1 / n=0$ conduz ao valor de $z_{c}$, enquanto que a inclinação permite estimar $\lambda$.

\subsubsection{APROXIMANTES DE PADÉ}

Os aproximantes de Padé (Padé, 1892) foram introduzidos na fisica por Baker e Gammel (1961) e primeiramente aplicados aos fenômenos criticos por Baker (1961). Ao contrário do método da razão, os aproximantes de Padé permitem estudar simultaneamente diversas singularidades que residem em qualquer local do plano complexo $z$.

O aproximante de Padé $[L, M]$ de uma função $f(z)$, cuja expansão em série é dada por (2.2), é a razão de um polinômio $P_{L}(z)$ de grau $L$ por um polinômio $Q_{M}(z)$ de grau $M$,

$$
[L, M] \equiv \frac{P_{L}(z)}{Q_{M}(z)} \equiv \frac{p_{0}+p_{1} z+\ldots+p_{L} z^{L}}{1+q_{1} z+\ldots+q_{M} z^{M}} .
$$

Os coeficientes $p_{0}, p_{1}, \ldots, p_{L}$ e $q_{1}, q_{2}, \ldots, q_{M}$ são escolhidos tal que a expansão de $[L, M]$ concorde com a expansão de $f(z)$ até ordem $L+M$, ou seja,

$$
f(z)=[L, M]+O\left(z^{L+M+1}\right)
$$

Como mostrado por Baker (1965), os coeficientes assim escolhidos são únicos. O método direto é geralmente usado para gerar os aproximantes de Padé. Os coeficientes de $z^{L+1}$ até $z^{L+M}$ em (2.5) fornecem $M$ equações lineares simultâneas para $q_{1}, q_{2}, \ldots, q_{M}$. A substituição da solução deste 
sistema nas $L+1$ equações lineares obtidas ao equacionar os coeficientes de $z^{0}$ até $z^{L}$ em (2.5) conduz, então, aos coeficientes de $p_{0}$ até $p_{L}$. Na prática, a solução das equaçōes matriciais correspondentes é feita no computador e envolve inversão de matrizes.

Se a expansão em série de $f(z)$ é conhecida até ordem $z^{N}$, então os aproximantes $[L, M]$ podem ser distribuídos numa tabela de Padé, com $L+M \leq N$. Os aproximantes diagonais $[n, n]$, ou qualquer seqũência diagonal próxima $[n+j, n]$, convergem mais rapidamente.

Considere $f(z)$ dada por (2.1) com $A=A(z)$ analítica em $z=z_{c} \mathrm{e}$ defina $A_{c}=A\left(z_{c}\right)$. Então,

$$
f(z) \approx A_{c}\left(1-\frac{z}{z_{c}}\right)^{-\lambda}\left[1+O\left(1-\frac{z}{z_{c}}\right)\right] .
$$

Segue que a derivada logaritmica

$$
D(z) \equiv \frac{d}{d z} \ln f(z) \approx \frac{-\lambda}{\left(z-z_{c}\right)}\left[1+O\left(z-z_{c}\right)\right], \quad\left(z \rightarrow z_{c}\right),
$$

tem somente um pólo simples em $z_{c}$ (Baker, 1961). Uma vez que os aproximantes de Padé podem representar pólos simples exatamente, os aproximantes da série $D(z)$, conhecidos como aproximantes Dlog Padé, devem convergir mais rapidamente do que os da série $f(z)$, os quais podem apresentar um ponto de ramificaçāo. Se um aproximante tem um pólo na vizinhança de $z_{c}$, sua localização fornecerá uma estimativa de $z_{c}$, enquanto o correspondente resíduo será uma estimativa de $-\lambda$.

\subsection{DESENVOLVIMENTO de métodos PaRA ANÁlise de SÉRIES DE DUAS VARIÁVEIS}

Chisholm e seus colaboradores generalizaram os aproximantes de Padé, desenvolvendo aproximantes para a análise de séries de duas ou mais variáveis (Chisholm, 1973; Chisholm e McEwan, 1974; Chisholm e Jones, 1975; Chisholm e Roberts, 1976). O desenvolvimento de tais aproximantes tornou-os subseqüentemente conhecidos como aproximantes de Canterbury (ver seção 2.4). Contudo, deve-se observar 
que, para que a aplicação do método de Padé seja bem sucedida, é sempre preferivel considerar a derivada logaritmica de modo a converter a função com uma singularidade algébrica simples em uma função racional.

O comportamento singular mais simples que se pode esperar em uma função de duas variáveis é

$$
f(x, y) \approx A(y)\left[x_{c}(y)-x\right]^{-\gamma},
$$

onde $A(y)$ varia suavemente. Neste caso, a derivada de $\ln f(x, y)$ em relação a $x$ produz uma função racional e, assim sendo, pode-se esperar que tais aproximantes de Canterbury (seção 2.4) representem a funçāo razoavelmente bem. Mesmo isto requer que a linha crítica $x_{c}(y)$ varie suavemente e seja não singular. Entretanto, os casos interessantes onde duas linhas criticas encontram-se num ponto multicrítico, ou onde a única linha crítica termina num ponto, originam tipos de descontinuidades que os aproximantes de Canterbury não podem representar. Fisher (1977) então desenvolveu o método dos aproximantes diferenciais parciais (ver seção 2.5) para analisar funções com este tipo de comportamento crítico.

Funções de uma única variável apresentam comportamento contínuo e suave exceto no ponto singular, onde observa-se uma singularidade de lei de potência. Para funções de duas variáveis, o comportamento esperado é uma linha singular, ao invés de um ponto, tal que

$$
f(x, y) \approx A(x, y)\left[x-x_{c}(y)\right]^{-\gamma}+B(x, y) \quad, \quad x \rightarrow x_{c}(y)^{-},
$$

onde $A, B$ e $x_{c}$ são funções analíticas de seus argumentos. Este tipo de comportamento pode ser analisado fixando-se sucessivos valores de $y \mathrm{e}$ aplicando-se qualquer um dos métodos padrões para uma única variável. Outro comportamento esperado, o mais tipico, corresponde à situação onde $f(x, y)$ possui duas linhas singulares distintas, provavelmente com expoentes criticos distintos, que se encontram num ponto multisingular. Este comportamento, conforme veremos na seção 2.5, será analisado pelo método dos aproximantes diferenciais parciais. 
Apresentamos, em seguida, a definição dos aproximantes de Canterbury e um estudo dos aproximantes diferenciais parciais. Como aproximantes de duas variáveis, ambos são definidos a partir de uma expansão em série de dupla potência

$$
f(x, y)=\sum_{m, n=0}^{\infty} f_{m, n} x^{m} y^{n}
$$

onde um determinado conjunto de coeficientes de ordem mais baixa é conhecido. Nos fenômenos críticos, as variáveis $x$ e $y$ tipicamente denotam temperatura e campo magnético. A generalização para mais de duas variâveis é conceitualmente óbvia, mas algebricamente complexa.

\subsection{APROXIMANTES DE CANTERBURY}

O aproximante de Canterbury $C\left(n_{1}, n_{2}, m_{1}, m_{2}\right)$, definido a partir da expansão (2.10), é dado por

$$
C\left(n_{1}, n_{2}, m_{1}, m_{2}\right)=\frac{\sum_{\alpha=0}^{m_{1}} \sum_{\beta=0}^{m_{2}} a_{\alpha \beta} x^{\alpha} y^{\beta}}{\sum_{\gamma=0}^{m_{1}} \sum_{\delta=0}^{m_{2}} b_{\gamma \delta} x^{\gamma} y^{\delta}},
$$

onde os coeficientes $a_{\alpha \beta}$ e $b_{\gamma \delta}$ são escolhidos de modo que o aproximante reproduza os coeficientes originais da série (2.10) até a ordem mais alta possivel. A determinação dos coeficientes não é única sem restrição adicional. Quando $n_{1}=n_{2}=n$ e $m_{1}=m_{2}=m$, o aproximante é denominado diagonal e denotado por $C(n, m)$. Se uma variável for igualada a zero, o aproximante deve reduzir ao correspondente aproximante de Padé da série reduzida.

\subsection{APROXIMANTES DIFERENCIAIS PARCIAIS}

Fisher (1977) introduziu o conceito dos aproximantes diferenciais parciais (PDAs) para estudar os fenômenos multicriticos. Um exemplo típico de função que exibe singularidade de caráter multicrítico é a expansão em sêrie da susceptibilidade em torno do ponto bicrítico que 
descreve o "crossover" Ising-Heisenberg-XY, num ferromagneto clássico tridimensional. Fisher e Kerr (1977) testaram a técnica numericamente neste exemplo, analisando a susceptibilidade total de um modelo de Heisenberg anisotrópico com acoplamentos entre primeiros vizinhos $J_{\|}=J_{z z} \geq 0$ e $J_{\perp}=J_{x x}=J_{y y} \geq 0$, como função das variáveis $x=J_{\|} / k_{B} T$ e $y=J_{\perp} / k_{B} T$. A Figura 2.1 mostra o comportamento multicritico deste modelo. Para $J_{\|}>J_{\perp}$, espera-se um comportamento do tipo Ising, com expoente $\gamma_{I}=1.24$, ao longo da curva crítica $x_{c}^{I}(y)$. Para $J_{\|}<J_{\perp}$, esperase um comportamento do tipo XY, com $\gamma_{X Y}=1.32$, ao longo da curva critica $x_{c}^{X Y}(y)$. Somente para $J_{\|}=J_{\perp}$, sobre o ponto multisingular $\left(x_{c}, y_{c}\right)$ onde as duas curvas se encontram, ocorre um comportamento do tipo Heisenberg, com $\gamma_{H}=1.39$.

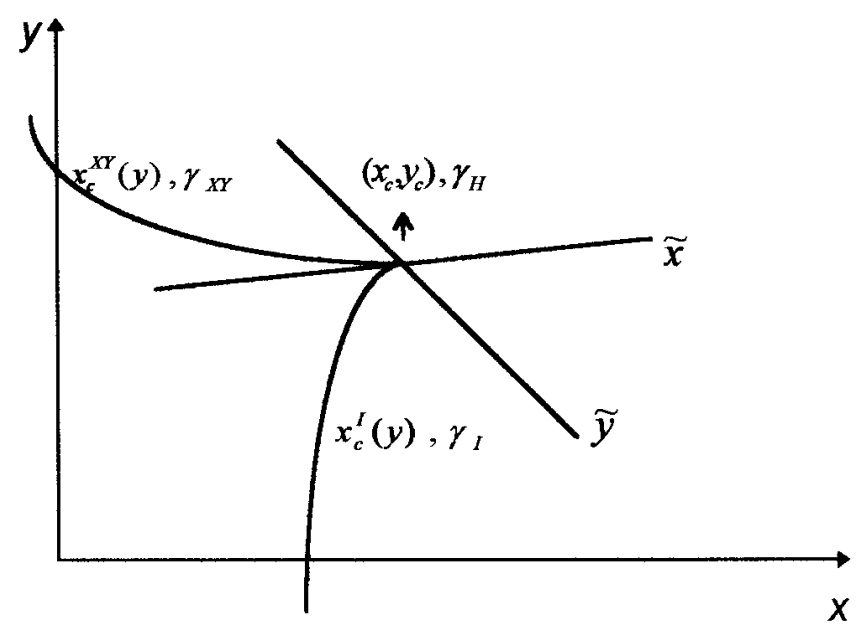

Figura 2.1: 0 comportamento multicritico de um modelo de Heisenberg ferromagnético anisotrópico clássico, com $x=J_{\|} k_{B} T$ e $y=J_{\perp} / k_{B} T$. Ao longo da linha $x_{c}^{\prime}(y)$, espera-se comportamento do tipo lsing, ao longo de $x_{c}^{X Y}(y)$, espera-se comportamento do tipo $X Y$ e no ponto $\left(x_{c}, y_{c}\right)$ espera-se comportamento do tipo Heisenberg.

Na vizinhança de um ponto multicritico $\left(x_{c}, y_{c}\right)$, espera-se (Fisher e Nelson, 1974) um comportamento de escala da forma

$$
f(x, y) \approx\left(x-x_{c}\right)^{-\gamma} Z\left(\frac{y-y_{c}}{\left(x-x_{c}\right)^{\phi}}\right)+B(x, y),
$$


onde $Z(z)$ é uma função de escala da variâvel $z=\left(y-y_{c}\right) /\left(x-x_{c}\right)^{\phi}$, $B(x, y)$ ê um termo analítico ("background") e $\gamma$ e $\phi$ são expoentes. No exemplo considerado, $\gamma=\gamma_{H}$, enquanto que $\phi$ é um expoente “crossover" que não se relaciona de modo simples com $\gamma_{H}, \gamma_{I}$ ou $\gamma_{X Y}$.

A forma de escala assintótica mais geral, apropriada ao caso em que os eixos de escala não são paralelos aos eixos $x$ e $y$, é dada por

$$
f(x, y) \approx|\widetilde{x}|^{-\gamma} Z\left(\frac{\tilde{y}}{|\widetilde{x}|^{\phi}}\right)+B(x, y) \quad,
$$

onde $\widetilde{x}$ e $\widetilde{y}$ são os novos eixos ou campos de escala lineares, definidos pelas combinaçōes lineares

$$
\widetilde{x}=\Delta x-\frac{\Delta y}{e_{2}} \quad \text { e } \quad \tilde{y}=\Delta y-e_{1} \Delta x,
$$

com $\Delta x=x-x_{c}$ e $\Delta y=y-y_{c}$. As constantes $e_{1}$ e $e_{2} \neq 0$ representam, respectivamente, as inclinaçōes dos eixos de escala $\widetilde{x}(\tilde{y}=0)$ e $\tilde{y}$ $(\widetilde{x}=0)$. Os expoentes $\gamma$ e $\phi$ são, respectivamente, o expoente de escala e o expoente "crossover". $Z(z)$ é a função de escala da variável $z=\widetilde{y} /|\widetilde{x}|^{\phi}$ e $B(x, y)$ é um termo analitico.

Para exemplificar o significado dos eixos de escala, considere a função teste $f_{t}=\left(1-x-\frac{1}{2} y\right)^{-3 / 2}\left(1-2 x-\frac{1}{5} y\right)^{-1 / 2}$, com duas linhas de singularidades. Além de ter sido usada por Roberts et al. (1975) em seu estudo dos aproximantes de Canterbury, esta função foi representada exatamente pelos aproximantes diferenciais parciais, no primeiro teste detalhado do método dos PDAs, desenvolvido por Stilck e Salinas (1981). Como possivel opção, fazemos $\widetilde{x}=\left(1-x-\frac{1}{2} y\right)$ e $\widetilde{y}=\left(1-2 x-\frac{1}{3} y\right)$, de modo que $f_{t}=\widetilde{x}^{-3 / 2} \widetilde{y}^{-1 / 2}$, ou seja, $f_{t}$ apresenta comportamento dado por (2.13), com $Z(z)=z^{-1 / 2}$ e $2 \gamma-\phi=3$. O ponto multicritico é obtido igualando-se as equações (2.14) a zero, o que neste caso fornece $\left(x_{c}, y_{c}\right)=\left(\frac{3}{8}, \frac{5}{4}\right)$. Os eixos de escala $\widetilde{x}(\widetilde{y}=0)$ e $\widetilde{y}(\widetilde{x}=0)$ são as retas de inclinações $e_{1}=-10$ e $e_{2}=-2$. A outra possivel opção consiste em 
trocar $\tilde{x}$ e $\tilde{y}$, o que conduz a $e_{1}=-2$ e $e_{2}=-10, \operatorname{com} Z(z)=z^{-3 / 2}$ e $2 \gamma-3 \phi=1$. Em casos simples como este, os eixos de escala são paralelos aos "loci" de singularidades da função. Em casos mais gerais, um eixo de escala é tangente à curva crítica no ponto multicrítico.

Os PDAs fornecem um meio de extrapolar a informação contida nos coeficientes de uma dada série de dupla potência. Constituem-se também na ferramenta apropriada para o estudo de funções que apresentam muitas singularidades. Em particular, é possível extrair estimativas fidedignas dos pontos multisingulares e de seus expoentes de escala (Stilck e Salinas, 1981; Chen et al., 1982; Fisher e Styer,1982; Styer e Fisher, 1983; Barma e Fisher, 1985; Randeria e Fisher, 1988; Guttmann, 1989).

\subsubsection{DEFINICÃO DOS PDAS}

O aproximante diferencial parcial, de uma função $f(x, y)$, é a solução $F(x, y) \equiv F_{K: M N L J}(x, y)$, da equação

$$
Q_{M}(x, y) \frac{\partial F(x, y)}{\partial x}+R_{N}(x, y) \frac{\partial F(x, y)}{\partial y}=P_{L}(x, y) F(x, y)+U_{J}(x, y),
$$

que satisfaz condições de contorno apropriadas. Aqui, os polinômios

$$
\begin{gathered}
Q_{M}(x, y)=\sum_{\left(m, m^{\prime}\right) \in M} q_{m, m^{\prime}} x^{m} y^{m^{\prime}} \quad, \quad R_{N}(x, y)=\sum_{\left(n, n^{\prime}\right) \in N} r_{n, n^{\prime}} x^{n} y^{n^{\prime}}, \\
P_{L}(x, y)=\sum_{\left(l, l^{\prime}\right) \in L} p_{l, l^{\prime}} x^{l} y^{l^{\prime}} \quad \text { e } \quad U_{J}(x, y)=\sum_{\left(j, j^{\prime}\right) \in J} u_{j, j^{\prime}} x^{j} y^{j^{\prime}},
\end{gathered}
$$

contém somente potências definidas pelos conjuntos de rótulos ("label sets"): $M \supset\left(m, m^{\prime}\right), \quad N \supset\left(n, n^{\prime}\right), \quad L \supset\left(l, l^{\prime}\right)$ e $J \supset\left(j, j^{\prime}\right)$. Os coeficientes $q_{m, m^{\prime}}, r_{n, n^{\prime}}, p_{l, l^{\prime}}$ e $u_{j, j^{\prime}}$ são obtidos resolvendo-se equaçōes algébricas lineares inerentes à imposição de que a expansão em série de $F(x, y)$ reproduza a série conhecida 


$$
f(x, y)=\sum_{\left(i, i^{\prime}\right) \in I} f_{i, i^{\prime}} x^{i} y^{i^{\prime}}
$$

até determinada ordem. Os coeficientes $f_{i, j^{\prime}}$ são conhecidos somente para $\left(i, i^{\prime}\right)$ pertencentes a um conjunto de rótulos finito $I$, denominado conjunto de indices ("index set"). As equações geratrizes para os coeficientes polinomiais são obtidas substituindo-se $F(x, y)$ por $f(x, y)$ em (2.15) e igualando-se os coeficientes de mesma potência em ambos os lados da equação, para todas as ordens $x^{k} y^{k^{\prime}}$ tais que $\left(k, k^{\prime}\right)$ pertença a um conjunto escolhido $K$, denominado conjunto de rótulos das igualdades ("matching label set"). Assim, se as equações forem linearmente independentes, o número de elementos de $K$ deve ser igual ao número de elementos de $J, L, M$ e $N$ menos um. Isto significa que a cardinalidade de $K$ está especificada, mas não seu formato.

A restrição apropriada de elementos dos conjuntos $J, K, L, M$ e $N$ conduz a uma variedade de casos particulares do método dos PDAs, incluindo os aproximantes de Canterbury $(M=N=\varnothing)$ e os PDAs homogêneos, obtidos ao fazer $J=\varnothing$ (caso em que $B(x, y)$ deve ser desprezivel). No caso de uma única variável $x$ (no limite $y \rightarrow 0$ ) e se $U_{J}=0$, a equação diferencial parcial $(2.15)$ reduz-se a

$$
\frac{1}{F(x)} \frac{d F(x)}{d x}=\frac{P_{L}(x)}{Q_{M}(x)} .
$$

Esta é justamente a equação para obtenção do aproximante de Padé da derivada logarítmica (Dlog Padé) de uma função de uma única variável (seção 2.2.2). 


\subsubsection{TEORIA LINEAR}

O método mais apropriado para resolver a equação diferencial parcial (2.15) é através de integração ao longo das curvas características. Seja $\tau$ um parâmetro de fluxo e considere $x=x(\tau, z)$ e $y=y(\tau, z)$ como funçōes de $\tau$ e de um parâmetro contínuo $z$, que será definido de uma forma mais precisa adiante. A trajetória característica rotulada por $z$ satisfaz às equações

$$
\frac{\partial x}{\partial \tau}=Q_{M}(x, y) \quad \text { e } \quad \frac{\partial y}{\partial \tau}=R_{N}(x, y)
$$

onde subentende-se que as derivadas parciais com relação a $\tau$ são tomadas com $z$ fixo. A troca de $\tau$ por $-\tau$ em (2.19) conduz à mesma característica no plano $(x, y)$, embora isto permita escolher $\tau$ crescente para um dado sentido de integração sobre a curva. Sobre a curva característica, a equaçāo diferencial (2.15) pode ser escrita como

$$
\frac{\partial F}{\partial \tau}=P_{L}(x, y) F(x, y)+U_{J}(x, y)
$$

Um ponto fixo das equaçōes de fluxo (2.19) é denominado ponto multisingular $C \equiv\left(x_{c}, y_{c}\right)$ e determinado pelo zero comum de $Q_{M}$ e $R_{N}$ :

$$
Q_{M}\left(x_{c}, y_{c}\right)=R_{N}\left(x_{c}, y_{c}\right)=0 .
$$

A partir da linearização de (2.19) e (2.20), na vizinhança de $\left(x_{c}, y_{c}\right)$, pode-se demonstrar que o aproximante $F(x, y)$ assume a forma de escala de $f(x, y)$ tal como em (2.13), obtendo-se assim as expressōes para o cálculo dos expoentes $\gamma$ e $\phi$. Para isto, é conveniente definir os coeficientes 


$$
\begin{array}{lll}
U_{0}=U_{J}\left(x_{c}, y_{c}\right) & , & P_{0}=P_{L}\left(x_{c}, y_{c}\right) \\
Q_{1}=\left.\frac{\partial Q_{M}(x, y)}{\partial x}\right|_{x=x_{c}, y=y_{c}}, & Q_{2}=\left.\frac{\partial Q_{M}(x, y)}{\partial y}\right|_{x=x_{c}, y=y_{c}}, \\
R_{1}=\left.\frac{\partial R_{N}(x, y)}{\partial x}\right|_{x=x_{c}, y=y_{c}} & \text { e } & R_{2}=\left.\frac{\partial R_{N}(x, y)}{\partial y}\right|_{x=x_{c}, y=y_{c}},
\end{array}
$$

e então escrever as expansões de Taylor dos polinômios $U_{J}, P_{L}, Q_{M}$ e $R_{N}$ em torno do ponto multicrítico,

$$
\begin{aligned}
& U_{J}(x, y)=U_{0}+O(\Delta x, \Delta y), \\
& P_{L}(x, y)=P_{0}+O(\Delta x, \Delta y), \\
& Q_{M}(x, y)=Q_{1} \Delta x+Q_{2} \Delta y+O\left(\Delta x^{2}, \Delta x \Delta y, \Delta y^{2}\right), \\
& R_{N}(x, y)=R_{1} \Delta x+R_{2} \Delta y+O\left(\Delta x^{2}, \Delta x \Delta y, \Delta y^{2}\right),
\end{aligned}
$$

$\operatorname{com} \Delta x=x-x_{c}$ e $\Delta y=y-y_{c}$.

As equaçōes de fluxo (2.19), quando truncadas até ordem linear, podem ser reduzidas à forma diagonal se forem escritas em termos das variáveis $\tilde{\boldsymbol{x}}$ e $\tilde{y}$. Ou seja,

$$
\frac{\partial \widetilde{x}}{\partial \tau}=\lambda_{1} \tilde{x} \quad \text { e } \quad \frac{\partial \widetilde{y}}{\partial \tau}=\lambda_{2} \tilde{y}
$$

onde $\lambda_{1}$ e $\lambda_{2}$ são autovalores, enquanto que $\tilde{x}=\Delta x-\left(\Delta y / e_{2}\right)$ e $\tilde{y}=\Delta y-e_{1} \Delta x$ são justamente os campos de escala lineares (ver (2.14)).

Demonstramos, em seguida, a forma diagonal (2.24), calculando os autovalores $\lambda_{1}, \lambda_{2} \mathrm{e}$ as inclinações $e_{1}, e_{2}$ dos eixos de escala. Inicialmente, invertendo as equações (2.14) obtemos

$$
\Delta x=\frac{e_{2} \tilde{x}+\tilde{y}}{\Delta e} \quad \text { e } \quad \Delta y=\frac{e_{2}\left(e_{1} \tilde{x}+\tilde{y}\right)}{\Delta e},
$$

onde $\Delta e=e_{2}-e_{1} \neq 0$. Derivando, então, as equações (2.14), parcialmente com relação a $\tau$ e substituindo as equações de fluxo (2.19) $\operatorname{com} Q_{M} \mathrm{e}$ $R_{N}$ truncados até ordem linear (equaçōes (2.23)), escrevemos

$$
\begin{aligned}
& \frac{\partial \widetilde{x}}{\partial \tau}=\frac{\partial x}{\partial \tau}-\frac{1}{e_{2}} \frac{\partial y}{\partial \tau}=\left(Q_{1}-\frac{R_{1}}{e_{2}}\right) \Delta x+\left(Q_{2}-\frac{R_{2}}{e_{2}}\right) \Delta y, \\
& \frac{\partial \widetilde{y}}{\partial \tau}=\frac{\partial y}{\partial \tau}-e_{1} \frac{\partial x}{\partial \tau}=\left(R_{1}-e_{1} Q_{1}\right) \Delta x+\left(R_{2}-e_{1} Q_{2}\right) \Delta y .
\end{aligned}
$$

A substituição de (2.25) em (2.26) fornece 


$$
\begin{aligned}
& \frac{\partial \widetilde{x}}{\partial \tau}=\frac{1}{\Delta e}\left(e_{2} Q_{1}+e_{1} e_{2} Q_{2}-R_{1}-e_{1} R_{2}\right) \tilde{x}+\frac{1}{e_{2} \Delta e}\left(e_{2} Q_{1}+e_{2}^{2} Q_{2}-R_{1}-e_{2} R_{2}\right) \tilde{y} \\
& \frac{\partial \tilde{y}}{\partial \tau}=-\frac{e_{2}}{\Delta e}\left(e_{1} Q_{1}+e_{1}^{2} Q_{2}-R_{1}-e_{1} R_{2}\right) \tilde{x}-\frac{1}{\Delta e}\left(e_{1} Q_{1}+e_{1} e_{2} Q_{2}-R_{1}-e_{2} R_{2}\right) \tilde{y}
\end{aligned}
$$

Para que estas equações sejam reduzidas à forma diagonal (2.24), devemos impor que o coeficiente de $\tilde{y}$ em (2.27) e o de $\tilde{x}$ em (2.28) sejam nulos, obtendo daí equações quadráticas para $e_{1}$ ou $e_{2}$ :

$$
Q_{2} e_{i}^{2}+\left(Q_{1}-R_{2}\right) e_{i}-R_{1}=0 \quad, \quad(i=1,2) .
$$

Os demais coeficientes devem ser identificados respectivamente com os autovalores $\lambda_{1}$ e $\lambda_{2}$, cujas expressões, simplificadas atravês da utilização de (2.29), são dadas por:

$$
\lambda_{1}=Q_{1}-\frac{R_{1}}{e_{2}} \quad, \quad \lambda_{2}=R_{2}-e_{1} Q_{2} .
$$

Nos casos de interesse prático, $e_{1}$ e $e_{2}$ serão ambos reais e distintos. Assumindo-se que $\left(Q_{1}-R_{2}\right)^{2}+4 R_{1} Q_{2}>0$, a equação quadrática (2.29), com indice $i=1$ ou 2, possui duas soluções reais $e^{+} \mathrm{e} e^{-}$. As inclinaçōes dos eixos de escala $e_{1}$ e $e_{2}$ podem então ser estimadas através das soluções $e^{+}$e $e^{-}$da equação quadrática. Em principio, pode-se escolher a inclinação $e_{1}$ do eixo $\tilde{x}$ igual a $e^{+}$e a inclinação $e_{2}$ do eixo $\tilde{y}$ igual a $e^{-}$ ou vice-versa. Valores reais de $e_{1}$ e $e_{2}$ implicam em $\lambda_{1}$ e $\lambda_{2}$ também reais.

A integração das equações de trajetória (2.24) fornece

$$
\widetilde{x} \approx \widetilde{x}_{0} e^{\lambda_{1}\left(\tau-\tau_{0}\right)} \quad, \quad \tilde{y} \approx \tilde{y}_{0} e^{\lambda_{2}\left(\tau-\tau_{0}\right)},
$$

onde $\widetilde{x}_{0}, \widetilde{y}_{0}$ e $\tau_{0}$ são constantes de integração e o simbolo $\approx$ reconhece que somente termos lineares foram mantidos em (2.23) ao escrever (2.24). A eliminação de $\tau$ fornece a trajetória assintótica

$$
\frac{\tilde{y}}{|\widetilde{x}|^{\phi}} \approx \frac{\widetilde{y}_{0}}{\left|\widetilde{x}_{0}\right|^{\phi}} \equiv \eta \quad,
$$

onde o expoente "crossover" é definido por

$$
\phi=\frac{\lambda_{2}}{\lambda_{1}} \text {. }
$$


A razão $\eta$ das constantes de integração permite rotular uma trajetória assintoticamente próxima ao ponto multicrítico $C$ e, portanto, é uma função do parâmetro $z$. Quando $\phi$ é positivo, todas as trajetórias características atingem $C$ no limite $\tau \rightarrow-\infty$ (para $\lambda_{i}>0$ ). Está claro que, para $\frac{1}{2}<\phi<2$, as trajetórias assintóticas dadas pela equação (2.32), com exceção das trajetórias especiais correspondentes a $\widetilde{x}=0$ e $\tilde{y}=0$, aproximam-se dos eixos de escala mais lentamente do que quadraticamente. Deveras, numa taxa determinada somente por $\phi$. Neste caso, $z$ pode ser definido como

$$
z=\lim _{\tau \rightarrow-\infty} \frac{\widetilde{y}(\tau, z)}{|\widetilde{x}(\tau, z)|^{\phi}},
$$

onde os limites são tomados ao longo das trajetórias assintóticas. A trajetória especial rotulada por $z=0$ corresponde assintoticamente ao eixo $\tilde{y}=0$ e é denominada trajetória principal $\Pi$.

Quando $\phi>0$ não se encontrar no intervalo $\left[\frac{1}{2}, 2\right]$, os termos quadráticos que foram desprezados em (2.24) são dominantes e a aproximação linear aqui utilizada não é válida (Randeria e Fisher, 1988). No caso em que $\phi<0$, somente duas trajetórias atingem $C$, enquanto todas as demais afastam-se da vizinhança de $C$ conforme $\tau \rightarrow-\infty$. Estes dois casos requerem a análise de campos de escala nāo lineares.

O ponto multicrítico $C$ pode ser classificado de acordo com $o$ comportamento das trajetôrias de fluxo em sua vizinhança imediata. Quando $\phi>0$, as trajetórias convergem para $C$, que ê denominado ponto estável (se $\lambda_{1}<0$ e $\lambda_{2}<0$ ) ou ponto instável (se $\lambda_{1}>0$ e $\lambda_{2}>0$ ). Quando $\phi<0, C$ é denominado ponto de sela ("saddle point"). Se $\lambda_{1}$ e $\lambda_{2}$ forem complexos, $C$ é denominado ponto espiral.

Observemos que definir um ponto multisingular como sendo estável ou instável é apenas uma questão do sinal de $\tau$ na equação (2.24). 
Por outro lado, o ponto de sela corresponde a um expoente crossover $\phi$ negativo, que governa somente as correções de escala (Barma e Fisher, 1985). O ponto espiral corresponde a uma singularidade não física.

Em vista de tais circunstâncias, aceitaremos a restrição $\frac{1}{2}<\phi<2$. Na região linear, a equação $(2.20)$ que governa o fluxo de $F(x, y)$ sobre uma trajetória caracteristica reduz-se a

$$
\frac{\partial F}{\partial \tau}=P_{0} F+U_{0}
$$

cuja solução geral é dada por

$$
F=F_{0}(z) e^{P_{0} t}-U_{0} / P_{0},
$$

onde $F_{0}(z)$ é uma constante de integração. De (2.31) obtemos $e^{P_{0} \tau}=|\widetilde{x}|^{P_{0} / \lambda_{1}}\left|\widetilde{x}_{0}\right|^{-P_{0} / \lambda_{1}} e^{P_{0} \tau_{0}}$ que substituído em (2.36) permite eliminar $\tau$ :

$$
F=F_{0}(z)|\widetilde{x}|^{P_{0} / \lambda_{1}}\left|\widetilde{x}_{0}\right|^{-P_{0} / \lambda_{1}} e^{P_{0} \tau_{0}}-U_{0} / P_{0}
$$

Identificando-se

$$
\begin{gathered}
\gamma=-\frac{P_{0}}{\lambda_{1}}, \\
B_{0}=-U_{0} / P_{0}, \\
Z(z)=F_{0}(z)\left|\widetilde{x}_{0}\right|^{-P_{0} / \lambda_{1}} e^{P_{0} \tau_{0}},
\end{gathered}
$$

e notando-se que no limite assintótico $z=\widetilde{y} /|\widehat{x}|^{\phi}$, demonstramos finalmente que o aproximante assume a forma de escala

$$
F(x, y)=|\widetilde{x}|^{-\gamma} Z\left(\frac{\widetilde{y}}{|\widetilde{x}|^{\phi}}\right)+B_{0}
$$

A função de escala $Z(z)$ depende essencialmente das condições de contorno impostas na equação diferencial parcial (2.15), uma vez que estas encontram-se contidas em $F_{0}(z)$. O cálculo de $Z(z)$ para um dado aproximante $F(x, y)$ envolve um desenvolvimento além da teoria linear.

\subsubsection{CURVAS CARACTERÍSTICAS}

A integração da equação diferencial parcial (2.15) requer a escolha de condições de contorno apropriadas. O método das 
características é recomendado para esta integração, sendo abordado em qualquer texto de análise numérica (como, por exemplo, Ortega e Poole, 1981).

Por este método, determina-se inicialmente as curvas ou trajetórias caracteristicas $x=x(\tau, z)$ e $y=y(\tau, z)$, através da integração numérica das equaçōes diferenciais (2.19). Para um dado ponto inicial, a integração conduz a uma determinada curva característica (rotulada por z). Entāo, integra-se (2.20) ao longo de cada curva característica para obter o aproximante e em seguida estimar a função de escala.

As condições de contorno são impostas ao longo do “locus” $\rho$, definido como sendo a trajetória no plano $x y$ onde $F(x, y)$ é conhecido. Expressemos o "locus" $\rho$ em termos das coordenadas $(\tau, z)$ através de $\tau=\tau_{\rho}(z)$, onde $\tau_{\rho}(z)$ é o valor de $\tau$ no qual a curva caracteristica especificada por $z$ intercepta $\rho$. Então, $F_{\rho}(z) \equiv F\left(x\left(\tau_{\rho}(z), z\right), y\left(\tau_{\rho}(z), z\right)\right)$ é o valor conhecido do aproximante sobre o ponto de intersecção de $\rho$ com a curva característica de rótulo $z$.

No caso de aproximantes homogêneos $\left(U_{J}(x, y)=0\right)$, a solução de (2.20) pode ser escrita como

$$
F(x, y)=F_{\rho}(z) \exp \left[\int_{\tau_{\rho}(z)}^{\tau} P\left(x^{\prime}, y^{\prime}\right) d \tau^{\prime}\right]
$$

onde a integraçāo é realizada ao longo da trajetória característica $\left\{x^{\prime}=x\left(\tau^{\prime}, z\right), y^{\prime}=y\left(\tau^{\prime}, z\right)\right\}$.

A Figura 2.2 ilustra $\mathrm{o}$ padrão de fluxo de trajetórias caracteristicas emanando do ponto multicrítico $C \equiv\left(x_{c}, y_{c}\right)$ numa situação em que $\phi>0$. Tais curvas interceptam o "locus" $\rho$, onde as condições de contorno são conhecidas. A trajetoria principal $\Pi$, especificada por $z=0$, é tangente ao eixo de escala $\tilde{y}=0$. Uma curva característica de especial interesse corresponde ao "locus" singular $x_{\sigma}(y)$ onde $F(x, y)$ é não analítica. Em muitas aplicações práticas, 
haverá pelo menos um "locus" singular. Por exemplo, se $x$ e $y$ denotam respectivamente a temperatura inversa $1 / T$ e a pressão $p$ de um fluido simples, então $C$ poderia representar o ponto crítico $\left(T_{c}, p_{c}\right)$ da coexistência liquido-gás: o "locus" singular corresponderia então à fronteira de fases $p=p_{\sigma}(T)$ onde gás e líquido coexistem para $T<T_{c}$ (ou $\left.x>x_{c}\right)$.

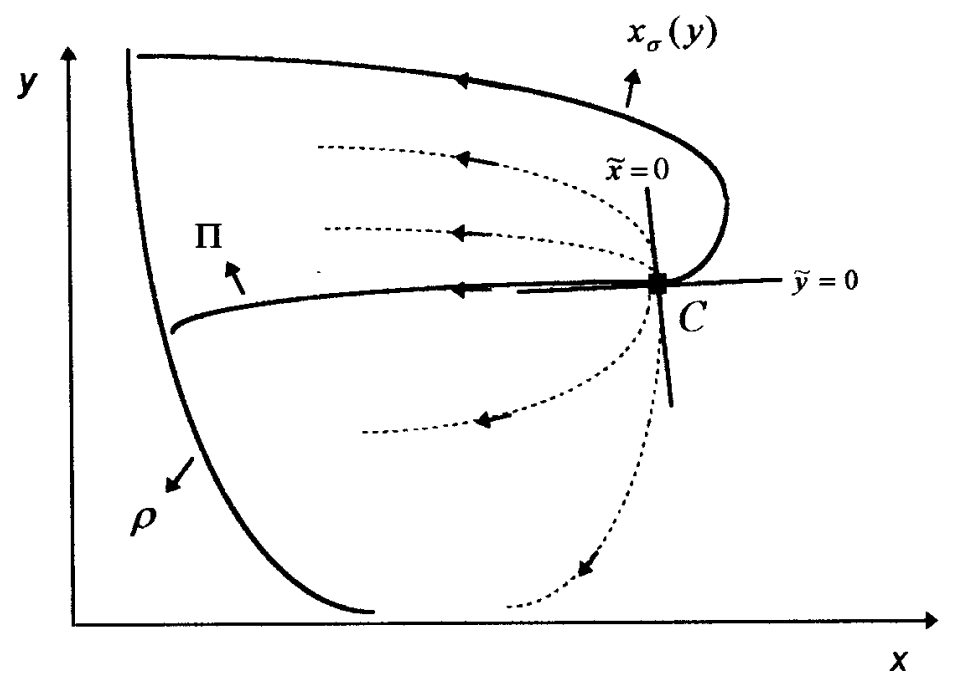

Figura 2.2: Padrăo de fluxo das curvas características (linhas tracejadas) emanando de um ponto multisingular $C$ com expoente "crossover" $\phi>0$. As linhas contínuas vermelhas representam a trajetória principal II e o "locus" singular $x_{\sigma}(y)$. A curva em verde $\rho$ é o "locus" onde as condiçōes de contorno são impostas. Os segmentos de reta em azul representam os eixos de escala.

\subsubsection{FIDEDIGNIDADE E INVARIÂNCIA DE EULER}

$\mathrm{Na}$ aplicação do método dos PDAs, é necessário escolher as potências não nulas dos conjuntos de rótulos polinomiais $M, N, L, J$ e do conjunto de rótulos das igualdades $K$. Critérios importantes para a escolha de tais conjuntos estão contidos em teoremas concernentes às propriedades de fidedignidade ("faithfulness") e de invariancia dos PDAs (ver Fisher e Styer, 1982; Styer e Fisher, 1983). 
Um aproximante $F(x, y)$ é fidedigno se cada coeficiente $F_{i, i^{\prime}}$ de sua expansão em série $F(x, y)=\sum_{i, i^{\prime}} F_{i, i^{\prime}} x^{i} y^{i^{\prime}}$ for igual a cada coeficiente $f_{i, r^{\prime}}$ da série conhecida $f(x, y)$ (expressão (2.17)), para todo $f_{i, i^{\prime}}$ utilizado no cálculo de $F(x, y)$. Fidedignidade é claramente uma propriedade desejável para um aproximante. Através da imposição de condições de contorno apropriadas e da escolha de um conjunto $K$ de formato apropriado, é possível assegurar esta propriedade. Devido à caracteristica pela qual a fidedignidade depende das condições de contorno utilizadas, a escolha dos conjuntos de rótulos torna-se um exercício sutil.

Uma outra propriedade importante é a invariância de aproximantes sob transformações de variáveis. Considere que a função $f(x, y)$ seja submetida à mudança de variáveis inversiva, $x=X(\bar{x}, \bar{y})$, $y=Y(\bar{x}, \bar{y})$, ou $x \rightarrow \bar{x}=\bar{X}(x, y), \quad y \rightarrow \bar{y}=\bar{Y}(x, y)$, tornando-se uma nova função $\bar{f}(\bar{x}, \bar{y}) \equiv f(X(\bar{x}, \bar{y}), Y(\bar{x}, \bar{y}))=f(x, y)$. Então, tanto podemos calcular o aproximante $F(x, y)$ da função $f(x, y)$, quanto o aproximante $\bar{F}(\bar{x}, \bar{y})$ de $\bar{f}(\bar{x}, \bar{y})$. Em principio, $\bar{F}(\bar{x}, \bar{y})$ não é necessariamente igual a $F(x, y)$. Contudo, é verdade que podemos considerar a igualdade numérica de $\bar{F}(\bar{x}, \bar{y})$ e $F(x, y)$ como uma propriedade de um aproximante superior (Baker, 1961). Tal aproximante é invariante sob a transformação especificada por $\bar{X}(x, y)$ e $\bar{Y}(x, y)$ e portanto não pode ser melhorado através de uma transformação da série antes da aproximação. Da mesma maneira, todos os pontos $(x, y)$ equivalentes sob a transformação, que podem formar um grande conjunto, são tratados de um modo equivalente no processo da aproximação; logo, a natureza de um aproximante invariante e suas propriedades de convergência são limitadas pela estrutura intrinseca de singularidade da função e não por um "acidente" na escolha da forma particular das variáveis usadas na expansão em série da função (Baker, 1975). A superioridade de aproximantes invariantes de uma variável, especificamente os 
aproximantes de Padé diagonais e quase diagonais, é amplamente confirmada por experiência numérica prática (Hunter e Baker, 1973). Uma experiência mais limitada e não menos impressiva, com os aproximantes diferenciais parciais (Chen et al., 1982), também confirma a superioridade prática dos aproximantes invariantes. Há duas classes de transformações lineares homogêneas que admitem PDAs invariantes, as rotaçōes generalizadas, $x \rightarrow \bar{x}=a_{11} x+a_{12} y$ e $y \rightarrow \bar{y}=a_{21} x+a_{22} y \quad$ (com $\left.a_{11} a_{22}-a_{12} a_{21} \neq 0\right)$, e as transformaçōes de Euler $x \rightarrow \bar{x}=A x /(1+B x)$ e $y \rightarrow \bar{y}=A^{\prime} y /\left(1+B^{\prime} y\right)\left(\operatorname{com} A, A^{\prime} \neq 0\right)$.

A invariância de Euler, propriedade importante pela qual o aproximante é invariante sob transformações de Euler, depende da escolha apropriada dos conjuntos de rótulos $M, N, L, J$ e $K$, estando sujeita a certas restrições complicadas entre os mesmos (Styer e Fisher, 1983). Em nosso estudo, consideraremos aproximantes em conformidade ou quase em conformidade com as exigências para invariância de Euler, os quais fornecem estimativas mais estáveis e confiáveis para as propriedades da função em questão.

Ao aplicarmos a técnica dos PDAs no estudo da transição de colapso em polímeros (capítulo 4), escolhemos os formatos dos conjuntos $M, N, L, J$ e $K$ baseados em critérios de fidedignidade e invariância de Euler específicos para a série analisada (Fisher e Styer, 1982; Styer e Fisher, 1983). Nosso estudo, tal como nos cálculos práticos desenvolvidos por Fisher (1977), Fisher e Kerr (1977) e Chen et al. (1982), tende a confirmar a expectativa de que aproximantes Eulerianos ou quase Eulerianos fornecem estimativas mais estáveis e confiáveis. 


\section{3. tRansição de COLAPSO EM POLímeros RAMIFICADOS}

\subsection{INTRODUÇÃo}

Polimeros são macromoléculas, com peso molecular da ordem de $10^{3}$ a $10^{6}$, provenientes de encadeamento de moléculas pequenas. A substância simples que dá origem ao polímero é chamada monômero. $\mathrm{O}$ processo de crescimento (polimerização) pode dar origem a cadeias lineares, ramificadas ou ainda reticuladas. Por exemplo, a polimerização do monômero de etileno $\left(\mathrm{H}_{2} \mathrm{C}=\mathrm{CH}_{2}\right)$ forma o plástico polietileno, constituído de cadeias lineares.

Os polimeros lineares consistem de seque ências muito longas de unidades de monômeros (ver Figuras 3.1(a) e 3.1(b)). Unidades polifuncionais, tais como a indicada na Figura 3.1(c), conduzem à formação de polimeros ramificados, como o representado na Figura $3.1(\mathrm{~d})$.

Os polímeros lineares têm sido estudados por muito tempo tanto teoricamente (Flory, 1969; de Gennes, 1975, 1978, 1979; Moore, 1977; Duplantier, 1982; Baumgärtner, 1982) quanto experimentalmente (Nierlich et al., 1978; Nishio et al., 1979). Uma cadeia de polimero linear 


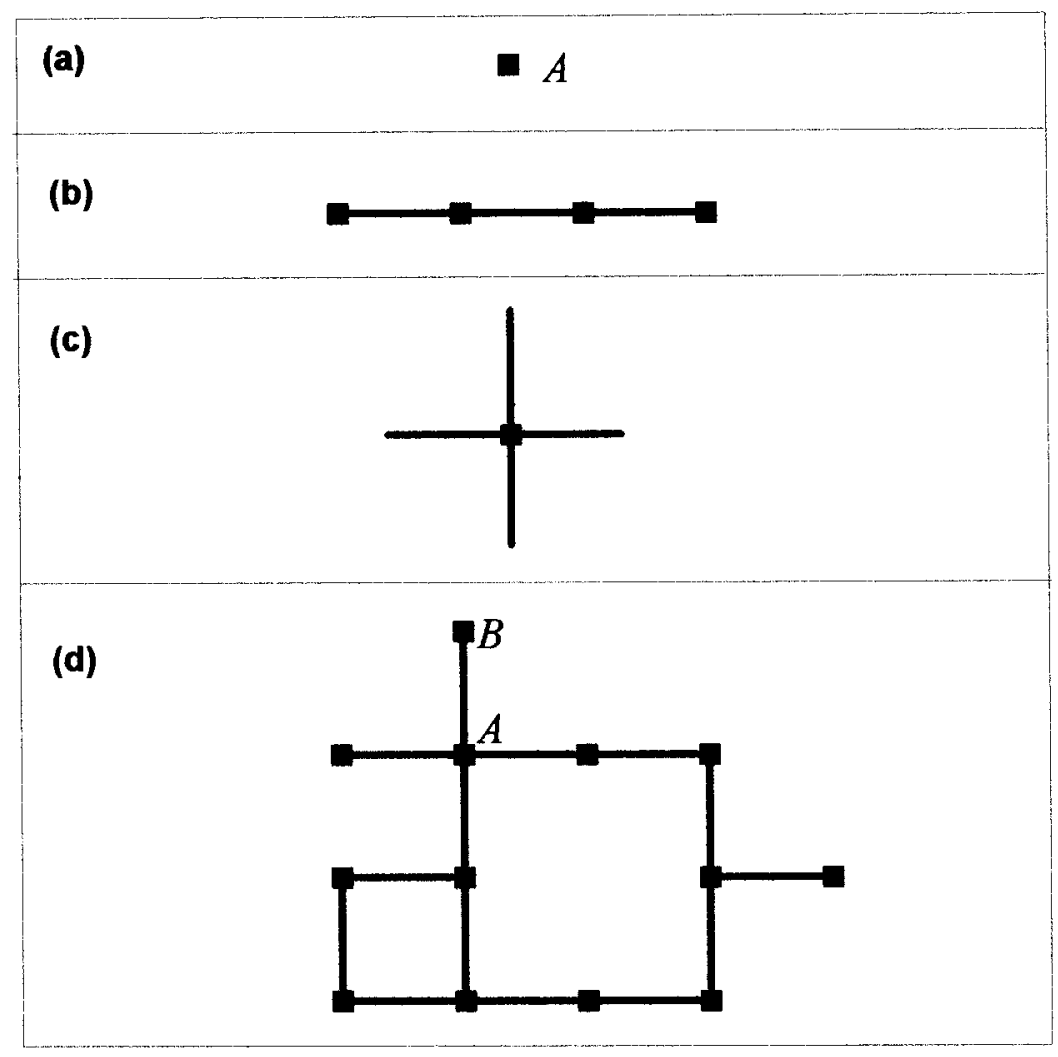

Figura 3.1: (a) Representação de um monômero $A$; (b) Polímero linear hipotético contendo 4 monômeros; (c) Unidade polifuncional (com funcionalidade $f=4$; (d) Exemplo de unidades polifuncionais formando um polímero ramificado; neste caso, temos uma estrutura com mais de um tipo de monômero $(A$, em vermelho, e $B$, em verde) denominada heteropolimero; observe que a estrutura é ramificada e apresenta dois ciclos fechados ("loops").

em solução diluída num bom solvente pode ser representada por uma caminhada aleatória auto-exclusiva numa rede regular. Conforme será visto na seção seguinte, neste regime as interações são devidas ao efeito do volume excluído. Com a diminuição da temperatura ou da qualidade do solvente, as forças atrativas, induzidas por interações com o solvente, tornam-se importantes e o polimero pode colapsar no ponto tricritico de Flory $\theta$.

Polímeros ramificados em solução diluída num bom solvente podem ser modelados por animais na rede. Por definição, estes animais sāo aglomerados (“clusters”) conectados de sitios vizinhos ocupados, incluindo ramos ou “loops”. A introdução de interação atrativa monômero-monômero entre sítios primeiros vizinhos pode conduzir a um colapso do animal a baixas temperaturas. Os polimeros ramificados 
têm sua realização experimental na forma de géis, onde há algum tempo atrás um colapso foi verificado experimentalmente (Tanaka, 1981). Recentemente, um mecanismo de colapso combinado com expansão (o volume muda por um fator $10^{3}$ ) foi encontrado no gel acrilamida, numa mistura água-acetona (Ikehara e Nishi, 1993). Evidências teóricas desta transição foram fornecidas por muitas técnicas: matriz de transferência em faixas bidimensionais (Derrida e Herrmann, 1983), métodos de Monte Carlo (Dickman e Schieve, 1984; Lam, 1987, 1988) e séries (Gaunt e Flesia, 1990; Madras et al., 1990; Gaunt, 1991; Flesia e Gaunt, 1992; Flesia et al. 1992, 1993). Dhar (1987) provou a existência da transição de colapso num modelo relacionado: o animal direcionado bidimensional.

Argumentos como os de Flory (campo médio) têm sido aplicados para obter os expoentes críticos e tricríticos dos polímeros ramificados (Isaacson e Lubensky, 1981). Entretanto, a dimensão crítica superior $\left(d_{c}\right)$ e a dimensão tricrítica superior $\left(d_{t}\right)$ são: $d_{c}=8$ e $d_{t}=6$ para polímeros ramificados (Lubensky e Isaacson, 1979); enquanto que $d_{c}=4$ e $d_{t}=3$ para polimeros lineares. Conseqüentemente, em dimensões fisicas, é muito provável que os expoentes de Flory para polímeros ramificados nāo sejam tão bons quanto os obtidos para polimeros lineares.

Além de ser bons modelos para polímeros ramificados, os animais na rede também aparecem em outras situações fisicas como DLA em equilíbrio (Wessel e Ball, 1992) e no estudo de vesículas (Fisher et al., 1991). O colapso de animais na rede pode ser conduzido por diferentes agentes: o número de pares interagentes de sítios primeiros vizinhos no animal, o número de ciclos ou o número de contatos (sítios primeiros vizinhos não diretamente conectados por uma ligação). Os dois primeiros são equivalentes (Gaunt e Flesia, 1990) e há recentes alegações sobre a determinação exata dos expoentes críticos (Vanderzande, 1993). Acredita-se que os modelos de contatos não 
pertençam à mesma classe de universalidade que os modelos de pares ou ciclos (Gaunt, 1991).

No presente capitulo, apresentamos um breve retrospecto do estudo dos polimeros lineares, onde definimos o ponto de Flory $\theta$ da transição de colapso de cadeias em solução. Em seguida, abordamos o problema da transição de colapso em polímeros ramificados: sua realização experimental (Apêndice) e os modelos teóricos de animais na rede. Definimos os modelos de animais para a transição de colapso, suas propriedades termodinâmicas, geométricas e seus parâmetros críticos. Finalmente, apresentamos uma ampla visão dos principais resultados dos modelos estudados na literatura.

No capítulo seguinte, consideramos um modelo de animais na rede e utilizamos os aproximantes diferenciais parciais para estudar o comportamento multicrítico da compressibilidade isotérmica do sistema, na transição de colapso (Onody e Neves, 1996a).

\subsection{POLímeros lineares}

A estatística de polimeros lineares em solução tem sido objeto de estudo há aproximadamente meio século. Um retrospecto de grande parte deste estudo encontra-se disponivel na literatura (Flory, 1969; de Gennes, 1979). Um problema que tem atraído grande atenção dos pesquisadores é a transição de colapso de uma cadeia em solução: com a diminuição da temperatura (ou da qualidade do solvente), o polimero pode colapsar no ponto de Flory $\theta$. Este fenômeno tem sido estudado tanto teoricamente quanto experimentalmente, possivelmente devido à sua conexão com "folding" de proteinas.

Descrevemos as caminhadas aleatórias como modelos de cadeias poliméricas lineares. Em seguida, apresentamos alguns resultados importantes da teoria de campo médio devida a Flory e Huggins, os quais conduzem à definição da temperatura tricrítica $\theta$ onde ocorre a 
transição de colapso. Durante muito tempo, a teoria Flory e Huggins foi o único método de interpolaçāo para explicar o que acontece entre as fases colapsada e estendida das cadeias poliméricas em solução.

\subsubsection{CAMINHADAS ALEATÓRIAS}

Uma das idealizaçōes mais simples de uma cadeia de polímero flexivel consiste em substituí-la por uma caminhada aleatória ("random walk") numa rede periódica. Tal caminhada inicia-se na origem e, após uma sucessão de $N$ passos, termina num ponto $\vec{r}$ da rede. Cada passo é dado, com igual probabilidade, em direção a qualquer um dos sítios primeiros vizinhos ${ }^{1}$. A distância quadrática média $\left\langle\vec{r}^{2}\right\rangle$, entre as extremidades da cadeia, é linear em $N$,

$$
\left\langle\vec{r}^{2}\right\rangle=R_{0}^{2}=a^{2} N \quad,
$$

onde $a$ é o comprimento de cada passo. Qualitativamente, caracterizamos uma cadeia ideal como sendo aquela que possui o tamanho $R_{0} \sim N^{1 / 2}$ de uma caminhada aleatória simples.

Experimentos com espalhamento de luz mostram que o tamanho $R$ de uma cadeia real em solução diluída varia conforme $R \sim N^{0.6}$. Existem estudos numéricos muito precisos para as cadeias reais, onde cada cadeia é ainda representada por uma caminhada aleatória, mas com a diferença de que agora a caminhada não pode se interceptar. Esta é a denominada caminhada aleatória auto-exclusiva ("selfavoiding random walk"). A cada passo da caminhada auto-exclusiva, a cadeia move-se de um ponto da rede em direção a qualquer um dos sítios primeiros vizinhos, interrompendo o crescimento se o sítio escolhido já tiver sido visitado. Neste caso, a distância quadrática média

1 Aparentemente, esta descrição foi iniciada por Orr (1947). 
entre as extremidades da cadeia é denotada por $R_{F}^{2}=<\vec{r}^{2}>$ e obedece à lei de escala

$$
R_{F} \approx a N^{v},
$$

onde $v$ é um expoente universal: $v \approx 3 / 5$ em $d=3$ dimensões; $v \approx 3 / 4$ em $d=2$ dimensões; e $v=1$ em uma dimensão.

As cadeias reais em solução diluída em bom solvente têm as mesmas características universais que as caminhadas aleatórias numa rede. Assim, cadeias poliméricas diluídas em bom solvente encontramse expandidas: seu tamanho $R_{F}\left(R_{F} \approx a N^{3 / 5}\right.$ em $\left.d=3\right)$ é maior do que o de uma cadeia ideal $\left(R_{0}=a N^{1 / 2}\right)$. Em solução concentrada, a densidade de cadeias é alta e a conclusão correta (primeiramente compreendida por Flory) é a de que tais cadeias comportam-se como as ideais. Experimentos em soluções concentradas mostram que: em $d=3$, as cadeias estão entrelaçadas e apresentam um raio $R_{0}$; em $d=2$, as cadeias (sobre camadas adsorvidas) estão fortemente segregadas, com um tamanho ainda comparável a $R_{0}$.

\subsubsection{TEMPERATURA DE FLORY $\theta$}

$\mathrm{Na}$ teoria de Flory-Huggins (campo médio), é conveniente representar as cadeias poliméricas na rede por caminhadas aleatórias auto-exclusivas. O número médio de passos em cada caminhada é denotado por $N$. Os sítios assim visitados são ocupados por monômeros, enquanto os demais são preenchidos, cada qual, por uma molécula de solvente. A fração de sítios ocupados por monômeros é denotada por $\Phi$. Interações entre a cadeia e o solvente são sempre caracterizadas pelo parâmetro de Flory $\chi(T)$, que é uma função decrescente da temperatura $T$. O comportamento de um bom (mau) solvente ocorre quando os contatos entre monômero e solvente são mais (menos) favorecidos do que os contatos monômero-monômero. 
No modelo acima considerado, a energia livre $F$ da mistura contém duas componentes: um termo de entropia que descreve quantos arranjos de cadeias podem existir na rede para um dado $\Phi$ e um termo descrevendo as interações entre moléculas interagentes. A expansão de $F$ para baixas concentrações $\Phi$, por sítio, é escrita como

$$
\left.\frac{F}{T}\right|_{\text {sitio }}=\frac{\Phi}{N} \ln \Phi+\frac{v}{2 a^{3}} \Phi^{2}+\frac{1}{6} \Phi^{3}+\cdots,
$$

onde $a^{3}$ é o volume de uma célula unitária e $v=a^{3}[1-2 \chi(T)]$ é denominado parâmetro de volume excluído. $\mathrm{O}$ primeiro termo do lado direito da expressão é proveniente da entropia da mistura. O segundo termo, proporcional a $\Phi^{2}$, é interpretado como o que define a interação efetiva entre pares de monômeros diluídos. Seu coeficiente $1-2 \chi(T)$ contém duas contribuições: uma parte $[-2 \chi(T)]$ que está relacionada às interaçōes entre sítios adjacentes e uma outra parte (1) que expressa a existência de repulsões estéricas entre os monômeros a pequenas distâncias (o que é representado pela proibição de que dois monômeros estejam sobre o mesmo sítio da rede).

A temperatura particular $T=\theta$ (temperatura de Flory), na qual $\chi(T)=1 / 2$, corresponde a um parâmetro de volume excluído $v=0$, o que significa um exato cancelamento entre a repulsão estérica e a atração (van der Waals) entre os monômeros. Portanto, em $T=\theta$ as cadeias diluídas são aproximadamente ideais. À temperatura $T>\theta$, o parâmetro $\chi(T)$ corresponde ao regime de bom solvente: $\chi(T)<1 / 2$. Neste regime, $v>0$ e o efeito de volume excluído reflete-se pelo dominio das repulsões estéricas: as cadeias tendem a se expandir. A $T<\theta$ ocorre o regime de mau solvente $(\chi(T)>1 / 2)$ : as cadeias separadas tendem a se tornar mais compactas do que as ideais devido à sua propensão à segregação. Esta estrutura colapsada ocorre somente em sistemas diluídos. 


\subsection{POLÍMEROS RAMIFICAdOS}

\subsubsection{REALIZAÇÃO EXPERIMENTAL}

Experimentalmente, os polimeros ramificados são realizados em géis. Há algum tempo atrás uma transição de colapso foi verificada no gel poliacrilamida, pelo grupo liderado por T. Tanaka, no M.I.T.. No Apêndice, descrevemos os resultados das experiências desenvolvidas com este gel.

\subsubsection{MODELOS TEÓRICOS}

Aglomerados conectados de sítios ocupados em uma rede constituem um bom modelo para polímeros ramificados em solução diluída em bom solvente. Estes aglomerados são subgrafos conectados de uma rede e são denominados animais na rede ("lattice animals"). Os animais incorporam o efeito do volume excluído que é importante em solventes diluídos. Descrevem o limite de altas temperaturas dos polimeros ramificados, quando os efeitos de volume excluído dominam sobre a afinidade entre monômeros. A introdução de interações atrativas monômero-monômero entre sítios primeiros vizinhos conduz a um colapso do animal na rede a baixas temperaturas.

Cada animal pode ser classificado de acordo com o seu: número de sítios ocupados $(N)$; número de ligaçōes $(B)$; número de pares de sitios primeiros vizinhos $(P)$; número de contatos $(\lambda)$, onde um contato é definido como um par de sítios primeiros vizinhos não conectados por uma ligação; número de ciclos ou "loops" $(C)$. Por exemplo, a Figura 3.2 ilustra um animal na rede quadrada com $N=9, B=10, P=11, \lambda=1 \mathrm{e}$ $C=2$. 


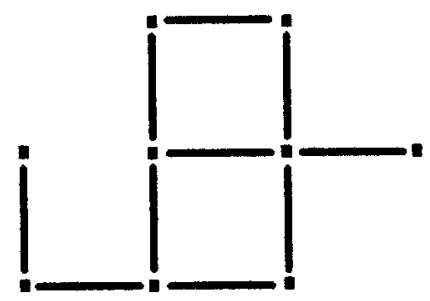

Figura 3.2: Um animal sobre a rede quadrada com $N=9, B=10, P=11, \lambda=1$ e $C=2$.

São sempre válidas as relaçōes

$$
\begin{gathered}
P=B+\lambda \quad \text { e } \\
B=C+N-1 \quad
\end{gathered}
$$

Esta última é conhecida como relaçāo de Euler. Podemos demonstrá-la a partir da construção de um animal na rede. Inicialmente, ocupamos um sitio da rede $(N=1, B=0, C=0)$. Adicionamos uma ligação conectando este sitio a um sítio primeiro vizinho, que é então ocupado $(N=2, B=1, C=0)$. O crescimento continua de tal modo que, a cada etapa, adicionamos ao animal uma nova ligação com a condição de que esta ocupe: (a) um segmento entre um sítio ocupado e um vazio ou; (b) um segmento entre dois sitios ocupados (contato). No caso (a), o referido sítio vazio é então ocupado e os números $N$ e $B$ são acrescidos, cada qual, de uma unidade, enquanto $C$ permanece constante. No caso (b), o contato desaparece, um novo ciclo no animal é completado e os números $C$ e $B$ são acrescidos, cada qual, de uma unidade, enquanto $N$ permanece constante. Assim, se $\Delta Q$ simbolizar a variaçāo de uma certa quantidade $Q$ (que classifica o animal), entre duas etapas quaisquer do crescimento, concluímos que: $\Delta B=\Delta C+\Delta N=\Delta(C+N)$. Isto implica que $B=C+N+\kappa$, onde $\kappa$ é uma constante. Substituindo-se, por exemplo, $N=1, B=0, C=0$ (que corresponde a um animal com um único sítio ocupado), obtemos $\kappa=-1$. 
Há dois tipos básicos de animais definidos em termos da ausência ou presença de contatos: o animal-sitio ("site animal") ou animal fortemente embebido na rede é aquele que não possui contatos $(\lambda=0) \mathrm{e}$ portanto corresponde a um grafo conectado da rede onde entre dois vértices adjacentes existe necessariamente uma ligação; o animalligação ("bond animal”) ou animal fracamente embebido é aquele que pode ou nâo possuir contatos e portanto corresponde a um subgrafo conectado onde entre dois vértices adjacentes pode ou não existir uma ligação.

As árvores na rede ("lattice trees") são definidas como sendo animais que não possuem ciclos $(C=0)$. Uma árvore-sitio ("site tree") é um animal-sítio sem ciclos e uma árvore-ligação ("bond tree") é um animal-ligaçāo sem ciclos.

A introduçāo de pesos de Boltzmann nos animais na rede conduz a quatro modelos básicos, que correspondem aos pesos $e^{\beta P}, e^{\beta B}, e^{\beta C} \mathrm{e}$ $e^{\beta \lambda}$, onde $\beta=1 / k_{B} T_{K}, T_{K}$ é a temperatura absoluta e $k_{B}$ é a constante de Boltzmann. Nestes modelos de rede relacionados, o colapso do animal é conduzido essencialmente por algum tipo de fugacidade $\left(e^{\beta \mu}\right)$ de primeiros vizinhos ou de ciclos. A função de partição de um modelo é calculada sobre configuraçōes de animais com tamanho fixo e o tamanho de um animal pode ser medido pelo seu conteúdo de sítios $(N)$ ou pelo seu conteúdo de ligações $(B)$. Este fato e a consideração de que um animal pode ainda ser fracamente ou fortemente embebido geram quatro possiveis subdivisões para cada um dos quatro modelos básicos. Resultam, portanto, dezesseis modelos. Seguindo a notação de Gaunt e Flesia (1990), estes modelos são identificados por letras minúsculas quando os animais são fracamente embebidos (modelo-p, -b, -c, - $\lambda$ ) ou por letras maiúsculas quando os animais são fortemente embebidos (modelo-P, -B, -C, $-\Lambda$ ). Uma letra precedida do símbolo' simboliza um modelo cujo tamanho do animal é medido pelo conteúdo de ligações, caso contrário, o tamanho do animal é medido pelo conteúdo de sítios. Por exemplo, o modelo- $\lambda^{\prime}$ corresponde a animais com fugacidade de 
contatos, fracamente embebidos e com tamanhos iguais ao número de ligações.

Um outro modelo possivel é o de árvores na rede (modelo-t), no qual não existe distinção entre medir o tamanho através de $N$ ou $B$, pois neste caso $C=0$ e a relação de Euler é trivial: $B=N-1$.

\subsubsection{PROPRIEDADES TERMODINÂMICAS, GEOMÉTRICAS E PARÂMETROS CRÍTICOS DE UM ANIMAL NA REDE}

Consideremos o modelo-P de animais na rede e expressemos suas funções termodinâmicas com o formalismo da mecânica estatística. $O$ procedimeno é análogo para os demais modelos.

A função de partição do modelo-P é calculada como

$$
Z_{N}(T ; \mathrm{P})=\sum_{P} A(N, P) e^{P / T} \quad,
$$

onde $A(N, P)$ é o número de animais com $N$ sítios e $P$ pares de sítios primeiros vizinhos e $T=k_{B} T_{K} /|\varepsilon|$ é a temperatura reduzida $(\varepsilon<0$ é o potencial atrativo entre primeiros vizinhos que será expresso em unidades de energia tais que $|\varepsilon|=1)$. Temperaturas negativas são interpretadas como correspondentes ao setor de interações repulsivas. A soma em (3.6) é realizada sobre todos os possíveis números de pares para um animal de tamanho $N$.

A função geratriz (função de "grand-partição") pode então ser construída como

$$
G(x, T)=1+\sum_{N=1}^{\infty} Z_{N}(T ; \mathrm{P}) x^{N},
$$

onde $x=e^{\beta \mu}$ è a fugacidade $(x<1)$, com $\mu$ simbolizando o potencial quimico.

A energia livre por unidade de sítio para um animal de tamanho $N$ fixo é definida como 


$$
f_{N}=-\frac{T}{N} \ln Z_{N}
$$

O calor especifico $c_{N}$ (por sítio) é calculado através de

$$
\frac{c_{N}}{k_{B}}=-T \frac{\partial^{2} f_{N}}{\partial T^{2}}
$$

ou em termos das flutuações de energia,

$$
\frac{c_{N}}{k_{B}}=\frac{\left\langle P^{2}\right\rangle-\langle P\rangle^{2}}{N T^{2}}
$$

Rigorosamente, o calor especifico verdadeiro deveria ser calculado tomando-se primeiramente o limite $N \rightarrow \infty$ em (3.8) para obter a energia livre $f$ e somente então diferenciando $f$. Contudo, é presumivelmente verdade que o resultado assim obtido é o mesmo que o proposto em (3.9) ou (3.10) (Gaunt e Flesia, 1990).

No "ensemble grand-canônico", a densidade $\rho(x, T)$ é proporcional ao número médio de sítios dos animais e pode ser obtida derivando-se a funçāo geratriz:

$$
\rho(x, T) \propto\langle N\rangle=\frac{x}{G(x, T)} \frac{\partial G(x, T)}{\partial x}
$$

A compressibilidade isotérmica $K_{T}(x, T)$ do sistema pode ser identificada com as flutuações na densidade (ver, por exemplo, Stanley, 1971):

$$
K_{T}(x, T) \propto\left\langle N^{2}\right\rangle-\langle N\rangle^{2}=x \frac{\partial \rho(x, T)}{\partial x}
$$

A propriedade geométrica mais importante de um animal é o valor médio $\langle R>$, onde $R$ é a medida de algum comprimento característico (por exemplo, raio de giração do animal, distância entre as extremidades). Para $N \rightarrow \infty$, numa determinada temperatura, o comportamento esperado deste comprimento médio é 


$$
\langle R\rangle \sim N^{v}
$$

Portanto, a massa $N$ do animal obedece à equação $N \propto\langle R\rangle^{D_{F}}$, onde $D_{F}=1 / v$ é a sua dimensão fractal. Tal como ocorre com as cadeias lineares, espera-se também uma transição de colapso para os animais na rede. No limite termodinâmico e à temperatura de transição $T_{\theta}$, a estrutura dos animais muda de compacta para ramificada e o expoente $v$ deve também mudar. Acima de $T_{\theta}$, o expoente $v$ deve ser igual ao dos animais na rede usuais ( $v \approx 0.64$ em $d=2$ dimensões). Abaixo de $T_{\theta}, o$ animal está colapsado e $v=1 / d=1 / 2$. Exatamente em $T_{\theta}$, o expoente $v$ assume um valor diferente $v=v_{1}$.

Derrida e Herrmann (1983) apresentaram evidências para o comportamento singular do calor específico $c$ de um animal no limite termodinâmico,

$$
c \sim\left|T-T_{\theta}\right|^{-\alpha},
$$

onde $\alpha$ é um expoente crítico.

As correlações das flutuações térmicas próximas ao ponto de colapso são representadas por um comprimento de correlação térmico $\xi_{T}$ que diverge como

$$
\xi_{T} \sim\left|T-T_{\theta}\right|^{-\nu_{2}}
$$

Para $N$ finito, o gráfico do calor específico $c_{N}$ como função da temperatura $T$ apresenta um máximo na temperatura $T_{m}(N)$ que, de acordo com a teoria de "finite-size scaling", tem um comportamento de escala dado por

$$
T_{m}(N)=T_{\theta}-a N^{-\phi},
$$

onde $a$ é uma constante $\mathrm{e}$ 


$$
\phi=\frac{v_{1}}{v_{2}}
$$

é o expoente “crossover” (Derrida e Herrmann, 1983; Dickman e Schieve, 1984; Lam, 1987).

O expoente do calor específico $\alpha$ pode ser relacionado ao expoente "crossover", partindo-se do fato de que, próxima ao ponto de colapso, a energia livre $f$ no limite $N \rightarrow \infty$ diverge como (Derrida e Herrmann, 1983):

$$
f \sim\left(\xi_{T}\right)^{-D_{P}} \sim\left|T-T_{\theta}\right|^{\nu_{2} D_{P}}
$$

Das equações (3.9) e (3.14) conclui-se que $f \sim\left|T-T_{\theta}\right|^{2-\alpha}$. Portanto, temos

$$
2-\alpha=v_{2} D_{F} \quad
$$

onde lembramos que $D_{F}=1 / v_{1}$ no ponto de colapso. Utilizando (3.17) segue a relação de escala:

$$
2-\alpha=\frac{1}{\phi}
$$

\subsubsection{PRINCIPAIS RESULTADOS DOS MODELOS ESTUDADOS NA LITERATURA}

Dos modelos de animais na rede apresentados na seção 3.3.2, cinco são triviais no sentido de que o calor específico (calculado a partir das expressões (3.6),(3.8) e (3.9)) é igual a zero. Os modelos triviais, facilmente identificados, são: modelos $-\Lambda,-\Lambda^{\prime},-\mathrm{P}^{\prime},-\mathrm{B}^{\prime}$, e $-\mathrm{b}^{\prime}$. Os quatro primeiros correspondem a animais sem contatos $(\lambda=0)$ : para os modelos- $\Lambda$ e $-\Lambda^{\prime}, Z_{N}(T ; \Lambda)$ e $Z_{B}\left(T ; \Lambda^{\prime}\right)$ sāo constantes; para os modelos$\mathrm{P}^{\prime}$ e $-\mathrm{B}^{\prime}$, de (3.4) temos $P=B$ e portanto $Z_{B}\left(T ; \mathrm{P}^{\prime}\right)=Z_{B}\left(T ; \mathrm{B}^{\prime}\right) \propto e^{B / T}$, o que implica $f_{N} \propto T$ e $c_{N}=0$. O modelo-b', embora com contatos, tem uma funçāo de partição também proporcional a $e^{B / T}$ e $c_{N}=0$. 
Além disto, há modelos equivalentes, com o mesmo calor específico. Os modelos-P e -B são ambos equivalentes ao modelo- $\mathrm{C}$. Desde que $P=B$ para animais fortemente embebidos, segue que $Z_{N}(T ; \mathrm{P})=Z_{N}(T ; \mathrm{B})$. A equivalência com o modelo-C é obtida relacionando-se as funções de partição através da utilização da relação de Euler (3.5):

$$
Z_{N}(T ; \mathrm{B})=\sum_{B} A(N, B) e^{B / T}=e^{(N-1) / T} \sum_{C} A(N, C) e^{C / T}=e^{(N-1) / T} Z_{N}(T ; \mathrm{C})
$$

Tomando-se o logaritmo do primeiro e último membros da expressão acima, multiplicando-se por $-T / N$ e identificando-se as energias livres (dadas por (3.8)) de ambos os modelos, resulta

$$
f_{N}(T ; \mathrm{B})=f_{N}(T ; \mathrm{C})+N^{-1}-1 .
$$

Ou seja, os calores específicos (dados por (3.9)) são iguais.

Os modelos-b e -c são equivalentes. A demonstração deste fato é análoga à anterior, uma vez que a relação de Euler não envolve contatos. Também são equivalentes os modelos- $\mathrm{p}^{\prime} \mathrm{e}-\lambda^{\prime}$, onde $B$ é fixo e a relação $P=B+\lambda$ permite relacionar $Z_{B}\left(T ; \mathrm{p}^{\prime}\right)=e^{B / T} Z_{B}\left(T ; \lambda^{\prime}\right)$, daí obtendo a igualdade dos calores específicos. Portanto, são sete os modelos não triviais independentes,

$$
\text { modelos-C, }-\mathrm{C}^{\prime},-c,-\mathrm{c}^{\prime},-\lambda,-\lambda^{\prime} \text { e } \mathrm{p},
$$

à parte do modelo-t de árvores na rede $(C=0)$.

Na literatura, os modelos têm sido estudados por vários métodos (matriz de transferência, Monte Carlo, séries). As Tabelas 3.1 e 3.2 fornecem, respectivamente, o expoente “crossover" e o ponto da transição de colapso obtidos para modelos e redes diferentes (em $d=2 \mathrm{e}$ $d=3$ ).

Derrida e Herrmann (1983) estudaram o modelo-P na rede quadrada através de cálculos exatos utilizando matrizes de transferência em faixas bidimensionais com comprimentos $n \times \infty$. 
Obtiveram o diagrama de fases no plano $x-T$. O ponto da transição de colapso foi identificado como um ponto tricrítico e calculado utilizando renormalização fenomenológica. Os valores obtidos para a temperatura de colapso tricrítica $T_{t}$ e a fugacidade tricrítica $x_{t}$ são: $T_{t}=T_{\theta}=0.535 \pm 0.005$ e $x_{t}=0.0230 \pm 0.0004$. A extrapolação $(N \rightarrow \infty)$ dos expoentes $v_{1}=0.5095 \pm 0.0030$ e $v_{2}=0.775 \pm 0.025$ permitiu calcular o expoente "crossover" $\phi=0.657 \pm 0.025$ e o expoente $\alpha=2-\phi^{-1} \approx 0.48$.

Dickman e Schieve (1984) estudaram o modelo-B (equivalente aos modelos- $\mathrm{P}$ e $-\mathrm{C}$ ) em redes bidimensionais utilizando um método de Monte Carlo para estimar o número de animais envolvidos no cálculo da função de partição. O gráfico do calor específico (calculado através das flutuações de energia para animais de diferentes tamanhos), em função da temperatura, exibe um pico. Conforme o tamanho $N$ aumenta, a temperatura $T_{m}(N)$ onde ocorre o máximo do calor especifico também aumenta e o pico torna-se mais alto e estreito. Apesar de a temperatura critica não ter sido extrapolada para $N \rightarrow \infty$, o resultado na rede quadrada $\left(T_{m}(N=100)=0.542 \pm 0.005\right)$ é consistente com $T_{\theta}$ obtido por Derrida e Herrmann. Para a rede triangular $T_{m}(N=61)=0.90 \pm 0.01$ e para a rede $\mathrm{FCC}, T_{m}(N=19) \approx 1.09$. Uma caracteristica surpreendente nos gráficos do calor específico é a presença de um pico secundário menor, a baixas temperaturas. Com o aumento de $N$, este pico diminui em magnitude, torna-se mais estreito e tende a temperaturas menores, onde os animais quase não têm sítios vazios dentro de sua região perimetral. Presumivelmente, este pico secundário corresponde a uma transição de rugosidade na superficie do animal. A temperatura em que ocorre esta transição deve tender a zero conforme $N \rightarrow \infty$.

Na rede cúbica simples, o modelo-B foi estudado por Lam (1987, 1988) utilizando o mesmo método de Monte Carlo de Dickman e Schieve. Os picos nos gráficos do calor especifico versus temperatura permitiram extrapolar $T_{\theta}$ e $\phi$ e tais estimativas foram depois melhoradas utilizando-se uma análise de escala: $T_{\theta} \approx 0.854$ e $\phi \approx 0.814$. 
Madras et al. $(1988,1990)$ consideraram modelos de animais e árvores, com fugacidade de ciclos ou contatos, calculando limites rigorosos para a dependência da energia livre em função de $\beta$. Também obtiveram dados exatos de enumeração de animais, utilizando métodos combinatoriais inventados por Sykes (1986) e implementados computacionalmente por Martin (1990). Os dados foram publicados em uma tabela que apresenta o número de animais com $N$ vértices, $B$ ligações e $\lambda$ contatos, para as redes quadrada (até $N=19$ ) e cúbica simples (até $N=17$ ).

Foram Chang e Shapir (1988) quem propuseram a fugacidade de ciclos e estudaram os modelos-C e $-c^{\prime}$ utilizando dados exatos de enumeraçāo de animais. A estimativa do expoente "crossover" para o modelo-C em três dimensões é $\phi \approx 1$ (em conflito com $\phi \approx 0.814$ estimado por Lam através de um método de Monte Carlo).

Gaunt e Flesia (1990) consideraram o modelo-C na rede quadrada e utilizaram a enumeração exata de animais (até $N=19$ ) para, a partir da função de partição, calcular a energia livre e através de diferenciaçāo numérica, obter o calor específico do modelo. Os gráficos do calor específico versus temperatura para diferentes tamanhos apresentam picos da transição de colapso e apontam o surgimento de um pico secundário, o da transição de rugosidade, conforme já observado por Dickman e Schieve utilizando um método de Monte Carlo e animais de tamanhos maiores (até $N=100$ ).

Os modelos de contatos foram abordados por Gaunt (1991) e Flesia e Gaunt (1992) através de estudos numéricos do calor específico baseados em dados de enumeração exatos. Os três modelos- $\lambda$, $-\lambda^{\prime}$, -t (de contatos) apresentam o mesmo expoente $\phi=0.60 \pm 0.03$ em $d=2$ e $\phi=0.82 \pm 0.03 \mathrm{em} d=3$. As estimativas do ponto de transição de colapso para estes modelos de contatos nas redes quadrada, cúbica e BCC são apresentadas na Tabela 3.2. 
Vanderzande (1993) propôs o valor exato $\phi=2 / 3$ para o modelo de ciclos em $d=2$, utilizando argumentos que mostram que a transição de colapso em animais é descrita pelo modelo de Potts com 0 -estado tricritico.

Em suma, têm sido estudadas duas classes básicas de modelos: em uma delas o colapso é conduzido por uma fugacidade de ciclos e, na outra, por uma fugacidade de contatos. Os resultados (Tabela 3.1) indicam que os modelos de ciclos e contatos estão provavelmente em classes de universalidade diferentes, mas as evidências ainda não são conclusivas. Além disso, as estimativas de $T_{\theta}$ (Tabela 3.2) sugerem que um sistema bidimensional colapsa a uma temperatura menor do que um sistema tridimensional. O número de coordenação da rede é também importante. Por exemplo, ao diminuir a temperatura, espera-se que um animal tridimensional na rede $\mathrm{BCC}$ colapse antes do que um na rede cúbica simples, pois há mais sítios primeiros vizinhos na rede BCC.

\begin{tabular}{|c|c|c|}
\hline & $\phi \quad(d=2)$ & $\phi \quad(d=3)$ \\
\hline $\begin{array}{l}\text { Modelos de Clclos } \\
\text { (Modelos }-C=-B=-P \text { ) }\end{array}$ & $\begin{array}{c}0.657 \pm 0.025 \quad[\mathrm{SQ}, \mathrm{MT}] \\
2 / 3 \quad[--, \mathrm{EX}]\end{array}$ & $\begin{array}{cc}0.814 & {[\mathrm{SC}, \mathrm{MC}]} \\
1 & {[-, \mathrm{SE}]}\end{array}$ \\
\hline $\begin{array}{l}\text { Modelos de Contatos } \\
\text { (Modelos }-\lambda,-\lambda,-t)\end{array}$ & $0.60 \pm 0.03 \quad[-, \mathrm{SE}]$ & $0.82 \pm 0.03 \quad[\mathrm{SQ}, \mathrm{SE}]$ \\
\hline
\end{tabular}

Tabela 3.1: Expoente "crossover" ф para modelos de animais com fugacidade de ciclos e contatos em duas e três dimensōes. Para cada estimativa, estão indicados entre colchetes: a rede utilizada, quadrada (SQ) ou cúbica simples (SC); o método empregado, matriz de transferência (MT), Monte Carlo (MC), séries (SE) obtidas a partir de dados exatos de enumeração de animais, ou se o resultado é exato (EX). 


\begin{tabular}{|c|c|c|}
\hline Modolo do doro & $T_{\theta}, x_{t} \quad(\alpha=2)$ & $T \theta \quad(a-3)$ \\
\hline Modelos $-\mathbf{C}=-\mathbf{B}=-\mathbf{P}$ & $\begin{array}{c}T_{\theta}=0.535 \pm 0.005 \quad[\mathrm{SQ}, \mathrm{MT}] \\
x_{t}=0.0230 \pm 0.0004\end{array}$ & $0.854 \quad[\mathrm{SC}, \mathrm{MC}]$ \\
\hline Wodelos do Contentos & $2 \theta \quad(d-2)$ & 16 $(a-3)$ \\
\hline Modelo- $\lambda$ & $2.6 \pm 0.4 \quad[\mathrm{SQ}, \mathrm{SE}]$ & $\begin{array}{ll}3.3 \pm 3.3 & {[\mathrm{SC}, \mathrm{SE}]} \\
4.4 \pm 0.2 & {[\mathrm{BCC}, \mathrm{SE}]}\end{array}$ \\
\hline Modelo- $\lambda$ ' & $2.2 \pm 0.5 \quad[\mathrm{SQ}, \mathrm{SE}]$ & $\begin{array}{ll}2.8 \pm 2.4 & {[\mathrm{SC}, \mathrm{SE}]} \\
3.1 \pm 0.2 & {[\mathrm{BCC}, \mathrm{SE}]}\end{array}$ \\
\hline Modelo-t & $2.0 \pm 0.4 \quad[\mathrm{SQ}, \mathrm{SE}]$ & $\begin{array}{ll}2.9 \pm 2.5 & {[\mathrm{SC}, \mathrm{SE}]} \\
3.0 \pm 0.9 & {[\mathrm{BCC}, \mathrm{SE}]}\end{array}$ \\
\hline
\end{tabular}

Tabela 3.2: Temperatura $T_{\theta}=1 / \beta_{\theta}$ e fugacidade tricrítica $x_{t}$ da transição de colapso em modelos de animais com fugacidade de ciclos e contatos, em duas e três dimensóes. Para cada estimativa, estāo indicados entre colchetes: a rede utilizada, quadrada (SQ), cúbica simples (SC) ou BCC; o método empregado, matriz de transferência (MT), Monte Carlo (MC) ou séries (SE) obtidas a partir de dados exatos de enumeração de animais. 
Obtiveram o diagrama de fases no plano $x-T$. O ponto da transição de colapso foi identificado como um ponto tricrítico e calculado utilizando renormalização fenomenológica. Os valores obtidos para a temperatura de colapso tricritica $T_{t}$ e a fugacidade tricrítica $x_{t}$ são: $T_{t}=T_{\theta}=0.535 \pm 0.005$ e $x_{t}=0.0230 \pm 0.0004$. A extrapolação $(N \rightarrow \infty)$ dos expoentes $v_{1}=0.5095 \pm 0.0030$ e $v_{2}=0.775 \pm 0.025$ permitiu calcular o expoente "crossover" $\phi=0.657 \pm 0.025$ e o expoente $\alpha=2-\phi^{-1} \approx 0.48$.

Dickman e Schieve (1984) estudaram o modelo-B (equivalente aos modelos-P e -C) em redes bidimensionais utilizando um método de Monte Carlo para estimar o número de animais envolvidos no cálculo da função de partição. O gráfico do calor específico (calculado através das flutuações de energia para animais de diferentes tamanhos), em função da temperatura, exibe um pico. Conforme o tamanho $N$ aumenta, a temperatura $T_{m}(N)$ onde ocorre o máximo do calor específico também aumenta e o pico torna-se mais alto e estreito. Apesar de a temperatura crítica não ter sido extrapolada para $N \rightarrow \infty$, o resultado na rede quadrada $\left(T_{m}(N=100)=0.542 \pm 0.005\right)$ é consistente com $T_{\theta}$ obtido por Derrida e Herrmann. Para a rede triangular $T_{m}(N=61)=0.90 \pm 0.01$ e para a rede FCC, $T_{m}(N=19) \approx 1.09$. Uma caracteristica surpreendente nos gráficos do calor específico é a presença de um pico secundário menor, a baixas temperaturas. Com o aumento de $N$, este pico diminui em magnitude, torna-se mais estreito e tende a temperaturas menores, onde os animais quase não têm sítios vazios dentro de sua região perimetral. Presumivelmente, este pico secundário corresponde a uma transição de rugosidade na superficie do animal. A temperatura em que ocorre esta transição deve tender a zero conforme $N \rightarrow \infty$.

Na rede cúbica simples, o modelo-B foi estudado por Lam (1987, 1988) utilizando o mesmo método de Monte Carlo de Dickman e Schieve. Os picos nos gráficos do calor específico versus temperatura permitiram extrapolar $T_{\theta}$ e $\phi$ e tais estimativas foram depois melhoradas utilizando-se uma análise de escala: $T_{\theta} \approx 0.854$ e $\phi \approx 0.814$. 


\section{ANÁlise da tranSIÇÃO dE COLAPSO EM ANIMAIS NA REDE ATRAVÉS DE APROXIMANTES DIFERENCIAIS PARCIAIS}

\subsection{INTRODUÇÃO}

No presente capítulo, estudamos a transição de colapso em polímeros ramificados utilizando um modelo de animais-sítio na rede quadrada, onde cada par de vértices primeiros vizinhos tem uma energia de interação atrativa. Conforme vimos no capítulo 3 , este modelo de pares (modelo-P) é equivalente a modelos onde o colapso do animal é conduzido por uma fugacidade de ciclos.

A partir de dados exatos de enumeração dos animais, construimos a função geratriz do modelo, discutindo o comportamento de algumas de suas propriedades termodinâmicas, bem como indicando a presença do ponto tricrítico da transição de colapso. Utilizamos um algoritmo de extrapolação simples (BST) para, no limite termodinâmico, obtermos o diagrama que separa as fases colapsada e expandida.

Empregamos a teoria dos aproximantes diferenciais parciais (PDAs), abordada no capítulo 2, no estudo do comportamento multicritico da expansão em série da compressibilidade isotérmica do sistema, $K_{T}(x, y)$, onde $x$ é a fugacidade e $y=e^{1 / T}(T$ denota a 
temperatura reduzida). O método dos PDAs nos permite estimar o ponto tricritico e os expoentes da transição de colapso, obtendo ainda o padrão de fluxo das trajetórias características. Obtemos as seguintes estimativas: fugacidade tricritica $x_{t}=0.024 \pm 0.005$; temperatura tricrítica $T_{t}=0.54 \pm 0.04$; expoente de escala $\gamma=1.4 \pm 0.2 \mathrm{e}$; expoente "crossover" $\phi=0.66 \pm 0.08$ (Onody e Neves, 1996a). Nossas estimativas estão em muito boa concordância com os valores obtidos por outras técnicas (Derrida e Herrmann, 1983; Vanderzande, 1993). Além disto, a estimativa do expoente $\gamma$, associado ao comportamento multicrítico dominante de $K_{T}(x, y)$, é um resultado novo. O expoente "crossover" $\phi$ está relacionado ao expoente $\alpha$ do calor específico através da relação de escala $\alpha=2-\phi^{-1} \approx 0.48$.

Acreditamos que a principal importância deste trabalho concerne à aplicação da técnica dos PDAs, que permanece ainda como um método relativamente pouco utilizado. Pela primeira vez, os PDAs são utilizados para estudar o comportamento multicrítico de uma função termodinâmica do referido modelo, permitindo assim estimar o ponto tricrítico e os expoentes da transição de colapso. Neste sentido, os cálculos são interessantes e potencialmente instrutivos.

\subsection{O MODELO}

Investigamos a transição de colapso em polímeros ramificados bidimensionais. Consideramos o modelo-P na rede quadrada. Conforme definido na seção 3.3.2, este é um modelo de animais com tamanho medido pelo número de vértices $N$, com $P$ pares de vértices adjacentes interagentes e que estão fortemente embebidos na rede (o número de contatos é $\lambda=0$, e portanto, o número de pares $P$ coincide com o número de ligações $B$ ). Cada par de sítios primeiros vizinhos tem uma energia atrativa.

Dados exatos relativos à enumeração dos animais nas redes quadrada e cúbica simples foram recentemente publicados em uma 
tabela por Madras et al. (1990). Os animais foram classificados pelo seu número de vértices (até $N=19$ na rede quadrada), ligações e contatos. Desta tabela, podemos obter o número $A(N, P)$ de animais-sítio com $N$ vértices, $P$ pares de sítios adjacentes $(P=B)$ e, que não possuem contatos $(\lambda=0)$. A partir desta enumeração e de acordo com (3.6) e (3.7), construímos uma série para a função geratriz,

$$
\begin{aligned}
& G(x, y(T))=1+\sum_{N=1}^{19} \sum_{P=0}^{18} A(N, P) x^{N}[y(T)]^{P}=, \\
& 1+x+2 x^{2} y+6 x^{3} y+x^{4} y^{3}(y+18)+\cdots
\end{aligned}
$$

exata até ordens $x^{19}$ e $y^{18}$, onde $x$ ê a fugacidade $(x<1)$ e $y=y(T)=e^{1 / T}$ ( $T$ é a temperatura reduzida). $O$ setor $T>0$ ou $y>1$ corresponde às interações atrativas. A série foi truncada até ordem 18 na variável $y$ por um motivo simples: animais com tamanho $N \geq 20$ não contribuem para ordens $P \leq 18$ na variável $y$.

Estudamos o comportamento singular da função de "grand partição” $G(x, y(T))$ via compressibilidade isotérmica do sistema. A partir da função geratriz e de acordo com as equaçōes (3.11) e (3.12), definimos $^{1}$ a densidade $\rho$ e a compressibilidade isotérmica $K_{T}$ do sistema:

$$
\begin{gathered}
\rho=\frac{x}{G(x, y(T))} \frac{\partial G(x, y(T))}{\partial x} \mathrm{e} \\
K_{T}=x \frac{\partial \rho}{\partial x} .
\end{gathered}
$$

As fórmulas (4.2) e (4.3) podem ser calculadas exatamente utilizando-se computação algébrica ("Waterloo Maple Software”). A substituição $y=e^{1 / T}$ permite expressá-las como funções de $x$ e $T$. O grâfico das propriedades termodinâmicas $\rho$ e $K_{T}$ como funções da temperatura $T$, para algumas fugacidades $x$ com valores fixos, é

1 As constantes de proporcionalidade em (3.11) e (3.12) foram identificadas como iguais a 1 , pois são irrelevantes na anâlise do comportamento multicritico de $K_{T}$. 
apresentado na Figura 4.1. Para pequenos valores de $x$, a densidade $\rho$ (parâmetro de ordem) tende a apresentar um salto descontínuo (típico de uma transição de fase de primeira ordem). Conforme $x$ aumenta, $\rho$ evolui para um comportamento contínuo. Esta mudança de comportamento é um indício da presença da temperatura tricrítica. Além disto, a compressibilidade isotérmica também tende a exibir, no limite termodinâmico, uma mudança em seu comportamento, de singularidade tipo delta para singularidade de lei de potência.

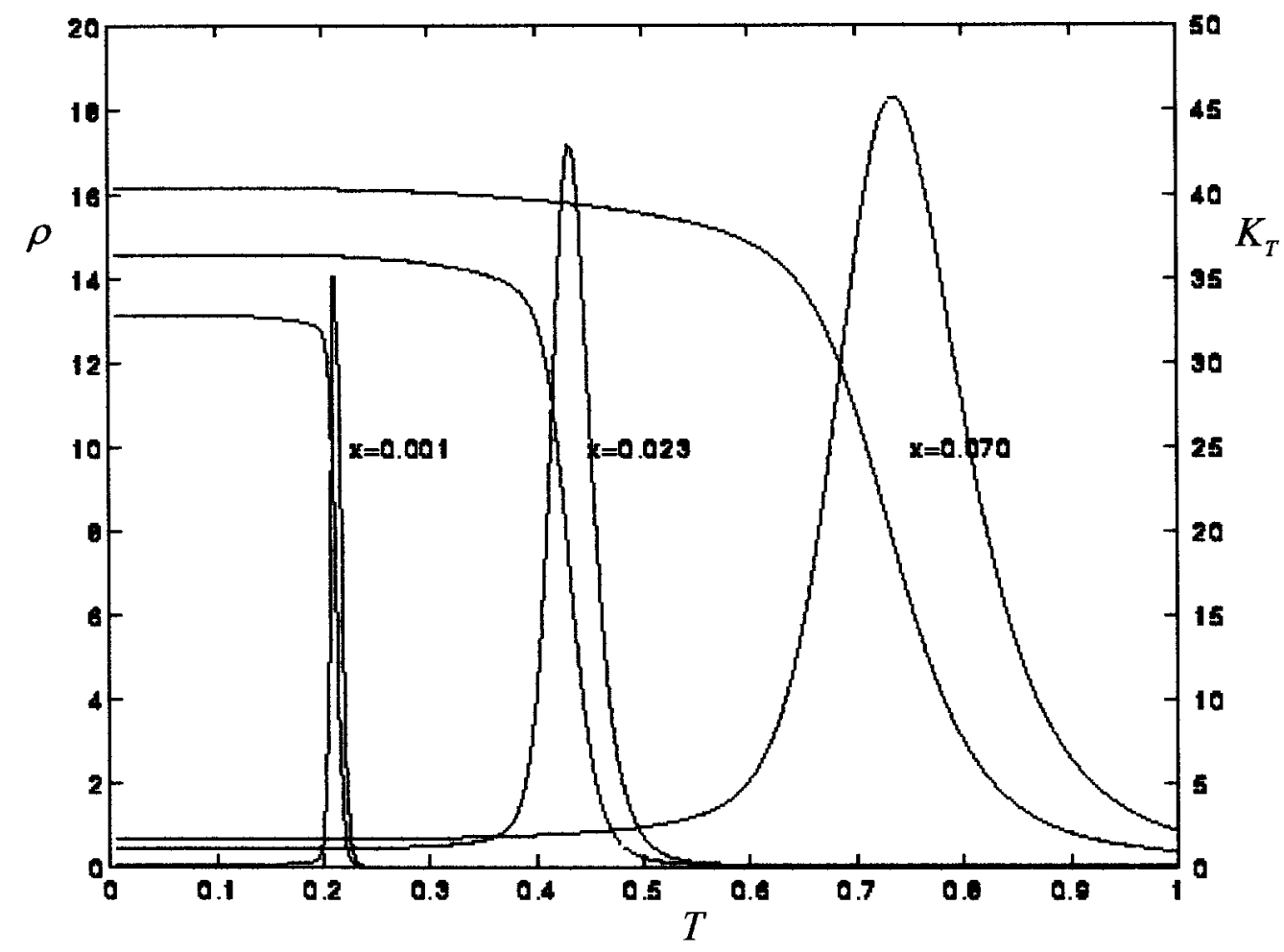

Figura 4.1: Densidade $\rho$ (linhas azuis) e compressibilidade isotérmica $K_{T}$ (linhas vermelhas) versus temperatura $T$ para algumas fugacidades fixas: $x=0.001, x=0.023 \mathrm{e}$ $x=0.070$. O gráfico foi obtido utilizando-se animais-sítio com tamanhos até $N=19$.

\subsection{EXTRAPOLAÇÃO dO diagrama dE FASES ATRAVÉS DE “FINITE SIZE SCALING"}

A teoria de "finite size scaling" procura descrever como fenômenos coletivos de longa escala, associados com o início de grandes flutuações 
próximas aos pontos críticos, manifestam-se em pequenas amostras. Para diferentes tamanhos de rede, as quantidades fisicas podem ser obtidas e seus valores convenientemente estendidos utilizando-se algum algoritmo de extrapolação confiável.

Dois algoritmos são comumente utilizados na extrapolação de sequências (Henkel e Schūtz, 1988): o algoritmo VBS, devido a van den Broeck e Schwartz (1979) e; o algoritmo BST, devido a Bulirsh e Stoer (1964). Conforme veremos nesta seção, utilizamos o algoritmo BST para, a partir de uma sequência de temperaturas relativas a sistemas finitos, extrapolarmos a temperatura crítica no limite termodinâmico. Isto nos permitirá traçar o diagrama de fases do modelo de animais em estudo. A escolha do algoritmo BST é devida a dois motivos: este não requer uma sequência consecutiva de dados finitos, isto ê, é mais flexivel que o algoritmo VBS e; sua convergência é mais rápida e menos sensivel a erros de arredondamento.

\subsubsection{O ALGORITMO BST}

Considere uma sequência $h_{n}(n=0,1,2, \ldots)$ que converge a zero conforme $n \rightarrow \infty$. Em muitas aplicações, $h_{n}=1 / n$ onde $n$ é o tamanho de um sistema finito. $\hat{E}$ importante salientar que, ao contrário do algoritmo VBS, o algoritmo BST não necessita de sequências consecutivas, sendo até mesmo possivel que $n$ tenha valores não inteiros (Henkel e Schütz, 1988).

Seja $T(h)$ uma função com expansão

$$
T(h)=T_{c}+a_{1} h^{\omega}+a_{2} h^{2 \omega}+\cdots,
$$

onde $\omega$ é um expoente e $a_{1}$ e $a_{2}$ são constantes.

O limite $T_{c}$ desejado é obtido a partir de uma tabela de extrapolantes, como a seguinte, por exemplo: 


$$
\begin{aligned}
& T_{0}{ }^{(0)} \\
& T_{1}^{(0)} \\
& T_{0}^{(1)} T_{1}^{\left({ }^{(1)}\right.}{ }^{T_{2}^{(0)}} T_{3}^{\left({ }^{(0)}\right.} \\
& T_{0}^{(2)} T_{1}^{(2)} T_{2}^{(1)} \\
& T_{0}^{(3)}
\end{aligned}
$$

Os $T_{m}^{(n)}$ são calculados a partir de:

$$
\begin{aligned}
& T_{-1}^{(n)}=0 \\
& T_{0}^{(n)}=T\left(h_{n}\right), \\
& T_{m}^{(n)}=T_{m-1}^{(n+1)}+\left(T_{m-1}^{(n+1)}-T_{m-1}^{(n)}\right)\left[\left(\frac{h_{n}}{h_{n+m}}\right)^{\infty}\left(1-\frac{T_{m-1}^{(n+1)}-T_{m-1}^{(n)}}{T_{m-1}^{(n+1)}-T_{m-2}^{(n+1)}}\right)-1\right]^{-1} .
\end{aligned}
$$

O expoente $\omega$ é um parâmetro livre. A minimização do erro $\varepsilon_{m}^{(i)}=2\left(T_{m}^{(i+1)}-T_{m}^{(i)}\right)$ fornece um critério intrinseco para a escolha de $\omega$ (Henkel e Schūtz, 1988).

\subsubsection{DIAGRAMA DE FASES}

Com o objetivo de obter o diagrama de fases através de "finite size scaling", truncamos a expansão em série (4.1) mantendo termos até uma determinada ordem $x^{N^{\prime}}$ ( $N^{\prime}$ é a máxima potência fixa). A partir desta função de "grand-partição" truncada, correspondente a animais com tamanhos $N \leq N^{\prime}$, calculamos a densidade e a compressibilidade isotérmica (expressões (4.2) e (4.3)) associadas ao tamanho finito $N^{\prime}$.

Para qualquer valor arbitrário de fugacidade $x$, podemos determinar a temperatura $T$ que maximiza a compressibilidade isotérmica $K_{T}$. O gráfico de $x$ versus $T$ conduz à "fronteira de fase" correspondente ao valor finito $N^{\prime}$ (Figura 4.2). Concluimos que, para $x$ fixo e diferentes valores $N^{\prime}$, temos uma sequência $T^{\left(N^{\prime}\right)}$ de "temperaturas críticas". A temperatura extrapolada desta sequência 
determina um ponto do diagrama de fases de um sistema de tamanho infinito.

Assumimos que a sequência $T^{\left(N^{\prime}\right)}$ tem a seguinte forma assintótica $\left(N^{\prime} \rightarrow \infty\right)$,

$$
T^{\left(N^{\prime}\right)}=T_{c}+a_{1} N^{\prime^{-\omega}}+a_{2} N^{\prime^{-2 \omega}}+\cdots,
$$

com uma dependência de lei de potência próxima à temperatura crítica $T_{c}$. Esta é justamente a forma (4.4) com $T\left(h=1 / N^{\prime}\right)=T^{\left(N^{\prime}\right)}$.

Para cada fugacidade fixa $x$, consideramos as sequências de valores conhecidos $\left\{N^{\prime}\right\} \equiv\{7,10,13,16,19\}$ e $\left\{T^{\left(N^{\prime}\right)}\right\}$. Aplicamos o algoritmo BST para extrapolar a temperatura $T_{c}$. Empregamos as equações (4.5), para valores $\{n\} \equiv\{0,1,2,3,4\}$, identificando-se $\left\{h_{n}\right\} \equiv\left\{1 / N^{\prime}\right\} \equiv\{1 / 7, \cdots, 1 / 19\}$ e $\left\{T_{0}^{(n)}\right\} \equiv\left\{T\left(h_{n}\right)\right\} \equiv\left\{T^{\left(N^{\prime}\right)}\right\}$. O erro $\varepsilon$ na determinaçāo de $T_{c}$ é calculado pelo módulo da diferença entre as duas temperaturas extrapoladas no penúltimo estágio do algoritmo BST, isto é, $\varepsilon=\left|\varepsilon_{m=3}^{(0)}\right|=2\left|\left(T_{3}^{(1)}-T_{3}^{(0)}\right)\right|$. O expoente $\omega$ é um parâmetro livre, de forma que permitimos que este assuma diferentes valores para uma determinada sequência a ser extrapolada. A minimização do erro $\varepsilon$ conduz a um critério intrinseco para escolher $\omega$. Deveras, para cada fugacidade $x$, selecionamos $o$ expoente $\omega$ que minimiza este erro.

$\mathrm{Na}$ Figura 4.2, apresentamos as "fronteiras de fase" correspondentes a valores finitos $N^{\prime}=7,10,13,16$ e 19 (linhas azuis). Utilizando o método dos quadrados minimos, obtemos a melhor curva que se ajusta às temperaturas criticas extrapoladas através do algoritmo BST. Esta curva corresponde ao diagrama de fases de um sistema infinito e está representada na figura por linha vermelha. Ela separa a fase expandida da fase colapsada e está em boa concordância com o diagrama de fases obtido através de matrizes de transferência (Derrida e Herrmann, 1983). Entretanto, a posição exata do ponto tricritico sobre o diagrama de fases é muito dificil de obter. Contudo, para este propósito, aplicaremos a técnica dos aproximantes diferenciais parciais na próxima seção. 


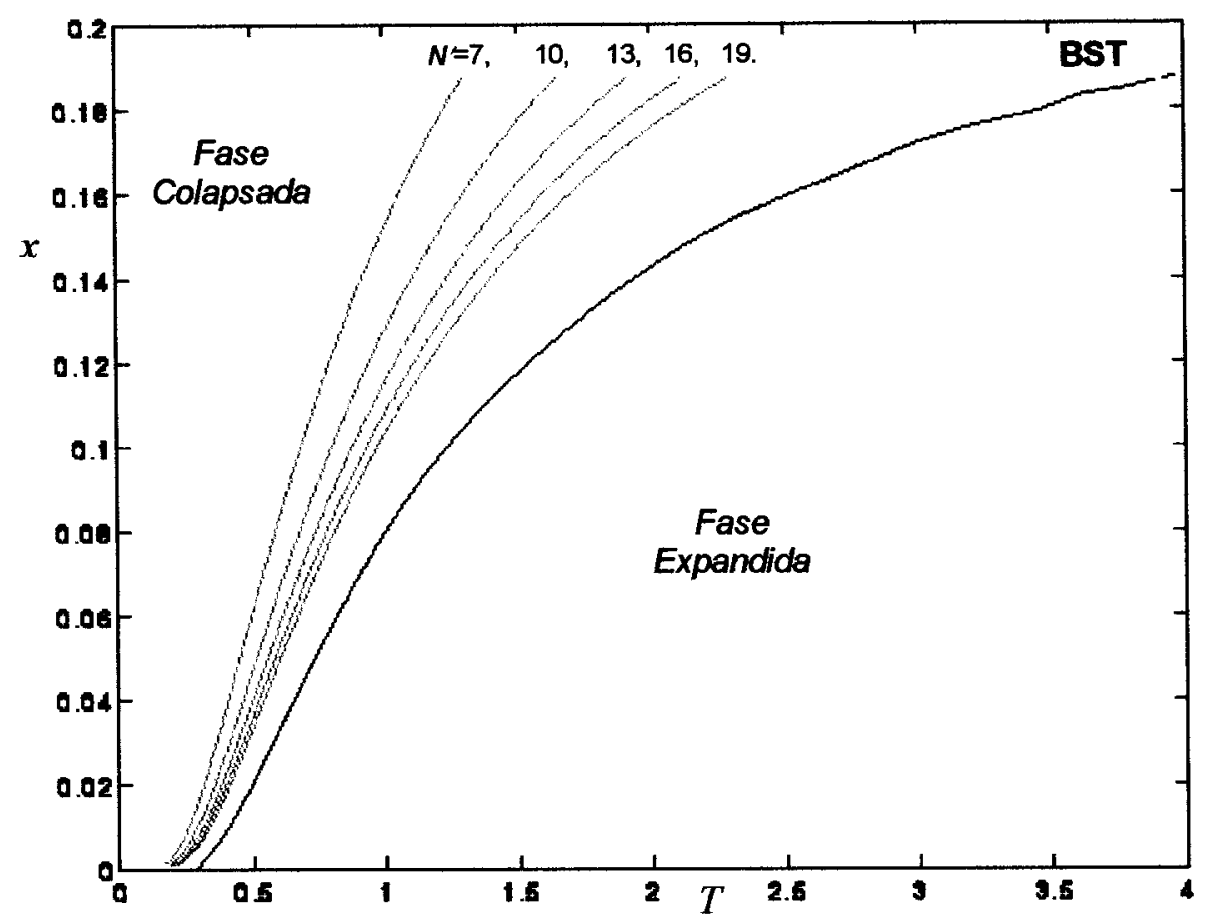

Figura 4.2: Diagrama de fases de um modelo de animais em colapso obtido através do algoritmo de extrapolação BST (curva em vermelho). Os diagramas de fase correspondentes a valores finitos $N=7,10,13,16$ e 19 estäo representados por linhas azuis.

$\mathrm{Na}$ Figura 4.3, apresentamos o gráfico do expoente $\omega_{\min }$ correspondente ao minimo erro versus a temperatura extrapolada $T_{c}$. Observemos que $\omega$ é somente um expoente efetivo desde que a equação (4.6) é somente vâlida no limite assintótico. Grandes flutuações acontecem na proximidade da temperatura tricrítica $T_{t} \sim 0.5$ e elas parecem tender assintoticamente a $\omega_{\min } \sim 0.95$ na região de altas temperaturas onde começa a ocorrer uma transição de fase de segunda ordem. Encontramos o valor médio $\left\langle\omega_{\min }\right\rangle=1.02$ no intervalo de temperatura $0 \leq T \leq 4$. O aumento de $\omega_{\min }$ próximo a $T_{t} \sim 0.5$ é certamente um indício da presença do ponto tricrítico. 


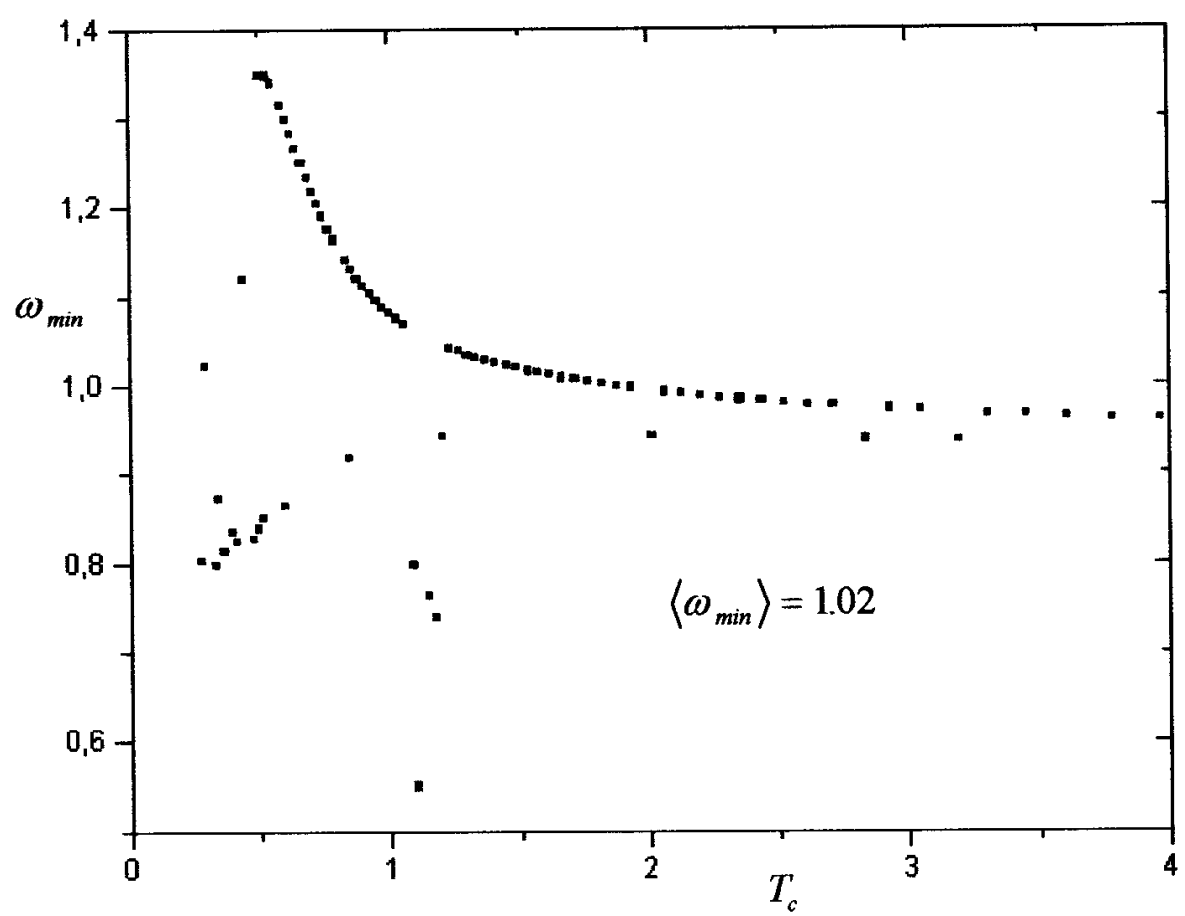

Figura 4.3: Expoente $\omega_{\min }$ (que minimiza o erro na extrapolação BST) como funçảo da temperatura extrapolada $T_{\mathrm{c}}$. 


\subsection{APLICAÇÃO DOS APROXIMANTES DIFERENCIAIS PARCIAIS}

Para analisar as propriedades multisingulares da compressibilidade isotérmica do sistema, aplicamos o método dos aproximantes diferenciais parciais (PDAs), que foi estudado no capitulo 2.

A partir do cálculo prévio das expressões (4.1), (4.2) e (4.3), em função das variáveis $x$ e $y$, podemos então expandir $K_{T}(x, y)$ em série (até ordem $x^{19} y^{18}$ ) e identificar

$$
f(x, y) \equiv x^{5} K_{T}(x, y) \equiv \sum_{\left(i, i^{\prime}\right) \in I} f_{i, i^{\prime}} x^{i} y^{i^{\prime}},
$$

onde os coeficientes $f_{i, i^{\prime}}$ são conhecidos para $\left(i, i^{\prime}\right)$ pertencentes ao conjunto de índices $I$ (veja equação (2.17)). Verificamos que a série, convenientemente definida com o fator $x^{5}$ através de (4.7), apresenta uma propriedade importante: $f(x, y)$ é triangular superior, ou seja, $f_{i, i^{\prime}} \equiv 0$ para $i<i^{\prime}$. Alêm desta propriedade, cuja importância logo veremos, a série $f(x, y)$ pode ser utilizada na análise do comportamento de $K_{T}(x, y)$ na vizinhança do ponto multicrítico, através de PDAs.

Conforme demonstrado no capitulo 2 (equação (2.41)), o comportamento de escala de $f(x, y)$ na proximidade de um ponto multicrítico $\left(x_{c}, y_{c}\right)$ é reproduzido pelo seu aproximante,

$$
F(x, y)=|\widetilde{x}|^{-\gamma} Z\left(\frac{\widetilde{y}}{|\widetilde{x}|^{\phi}}\right)+B_{0} \quad,
$$

onde lembramos que $\widetilde{x}$ e $\widetilde{y}$ são combinações lineares de $x-x_{c}$ e $y-y_{c}$ (equações (2.14)), $\gamma$ é o expoente de escala e $\phi$ é o expoente "crossover". Através do método dos PDAs, determinamos o ponto multicrítico e os expoentes $\gamma$ e $\phi$ associados a $f(x, y)$. 


\subsubsection{EQUAÇÕES GERATRIZES}

Apliquemos o método à série conhecida $f(x, y)$. Conforme vimos na seção 2.5.1, o aproximante desta função é a solução $F(x, y) \equiv F_{K: M N L J}$ da equaçāo (2.15). Primeiramente, selecionamos os conjuntos de rótulos $J, L, M, N$ (de acordo com critérios que veremos abaixo) e construímos os polinômios $U_{J}(x, y), P_{L}(x, y), Q_{M}(x, y)$ e $R_{N}(x, y)$. A fim de obtermos as equações geratrizes para os coeficientes polinomiais, substituí-mos $F(x, y)$ por $f(x, y)$ em (2.15) e igualamos os coeficientes de mesma potência em ambos os lados da equação, somente para as ordens $x^{k} y^{k^{\prime}}$ tais que $\left(k, k^{\prime}\right) \in K$, onde $K$ é o conjunto de rótulos das igualdades. Uma dada equação geratriz, especificada pelo elemento $\left(k, k^{\prime}\right) \in K$, é

$$
\begin{aligned}
u_{k, k^{\prime}} \delta^{J}{ }_{\left(k, k^{\prime}\right)}+\sum_{\left(l, l^{\prime}\right) \in L} f_{k-l, k^{\prime}-l^{\prime}} p_{l, l^{\prime}} & -\sum_{\left(m, n^{\prime}\right) \in M}(k-m+1) f_{k-m+1, k^{\prime}-m^{\prime}} q_{m, m^{\prime}} \\
& -\sum_{\left(n, n^{\prime}\right) \in N}\left(k^{\prime}-n^{\prime}+1\right) f_{k-n, k^{\prime}-n^{\prime}+1} r_{n, n^{\prime}}=0
\end{aligned},
$$

onde o símbolo delta é definido por: $\delta^{J}{ }_{\left(k, k^{\prime}\right)}=1$ se $\left(k, k^{\prime}\right) \in J$ ou, $\delta^{J}\left(k, k^{\prime}\right)=0$ se $\left(k, k^{\prime}\right) \notin J$. Como as equações geratrizes são homogêneas, um dos coeficientes polinomiais pode ser escolhido arbitrariamente: utilizamos a normalização padrão $p_{0,0}=1$. Para evitar que o conjunto de equações algébricas seja indeterminado, devemos escolher as cardinalidades dos conjuntos $K, J, L, M$ e $N$ de forma que o número de equações linearmente independentes seja igual ao número de coeficientes polinomiais (incógnitas). Utilizamos computação algébrica ("Maple”) para obter a solução do sistema de equaçōes geratrizes.

\subsubsection{FORMATOS DOS CONJUNTOS $M, N, L, J, K$}

A escolha dos elementos $\left(m, m^{\prime}\right) \in M,\left(n, n^{\prime}\right) \in N,\left(l, l^{\prime}\right) \in L,\left(j, j^{\prime}\right) \in J$ e $\left(k, k^{\prime}\right) \in K$ (ou seja, dos formatos dos conjuntos $M, N, L, J$ e $K$ ) é um 
exercício sutil. Na seção 2.5.4, vimos que existem critérios importantes para guiar tal escolha, os quais se baseiam em teoremas concernentes às propriedades de fidedignidade e de invariância dos PDAs (ver Fisher e Styer, 1982; Styer e Fisher,1983). São vários os teoremas, alguns dos quais especificamente desenvolvidos para aplicação na análise de séries triangulares superiores. Felizmente, este é o nosso caso. Isto justifica o fato de termos destacado a importância de que a série em estudo $f(x, y)$ é triangular superior. Na literatura, muitas das séries analisadas $g(x, y)$ que surgem em aplicações práticas são triangulares superiores (Chen et al., 1982; Barma e Fisher, 1985). Em certos casos, pode ocorrer que $x^{n} g(x, y)$ seja triangular superior para $n$ inteiro. Os teoremas que se aplicam a estas funções são: o Teorema 3.7 (Fisher e Styer, 1982), que estabelece formatos apropriados para os conjuntos de rótulos a fim de assegurar fidedignidade, desde que $p_{0,0}-h q_{1,0}-h^{\prime} r_{0,1} \neq 0$ (onde $h$ e $h^{\prime}$ são inteiros não negativos) e; o Teorema 6.3 (Styer e Fisher, 1983), que apresenta critérios, absolutamente compativeis com os do Teorema 3.7, para assegurar invariância de Euler.

Assim sendo, escolhemos os formatos dos conjuntos de rótulos $M, N, L, J$ e $K$ de acordo com estes dois teoremas. Contudo, para toda escolha possivel de $K$, obtemos um conjunto de equaçōes em que estão contidas relações obstantes que satisfazem $p_{0,0}-h q_{1,0}-h^{\prime} r_{0,1}=0$ e que, portanto, violam uma das condições para fidedignidade. Apesar disto, as condições que asseguram invariância de Euler são mantidas, fato este muito importante. Deveras, em muitos trabalhos onde o método dos PDAs é aplicado, os aproximantes selecionados são exclusivamente Eulerianos ou quase Eulerianos (Chen et al., 1982; Barma e Fisher, 1985).

Especificamente, o Teorema 6.3 (Styer e Fisher, 1983), para assegurar invariância de Euler, estabelece que os conjuntos de rótulos $M, N, L, J$ devem estar contidos num conjunto triangular superior de forma que $m \geq m^{\prime}+1, \quad n \geq n^{\prime}-1, \quad l \geq l^{\prime}$ e $j \geq j^{\prime}$. Também deve estar 
satisfeita a seguinte condição adicional: $\hat{m}-2=\hat{n}=\hat{l}=\hat{j}$, onde $\hat{m}, \hat{n}, \hat{l}$ e $\hat{j}$ são respectivamente as potências mais altas de $x$ nos polinômios $Q_{M}$, $R_{N}, P_{L}$ e $U_{J}$. Além disto, cada linha nos espaços cartesianos $\left(m, m^{\prime}\right)$, $\left(n, n^{\prime}\right),\left(l, l^{\prime}\right)$ e $\left(j, j^{\prime}\right)$ deve ser "flush right" (ter um fluxo para a direita), isto é, deve ser uma sequência, sem lacunas, de elementos que partem da respectiva máxima potência de $x$ em direção a um limite inferior. $O$ conjunto das igualdades $K$ deve ser triangular superior e "flush left" (ter um fluxo para a esquerda). A Figura 4.4 ilustra os formatos dos conjuntos $M, N, L, J$ e $K$ para a construção de aproximantes Eulerianos na análise de funções triangulares superiores.

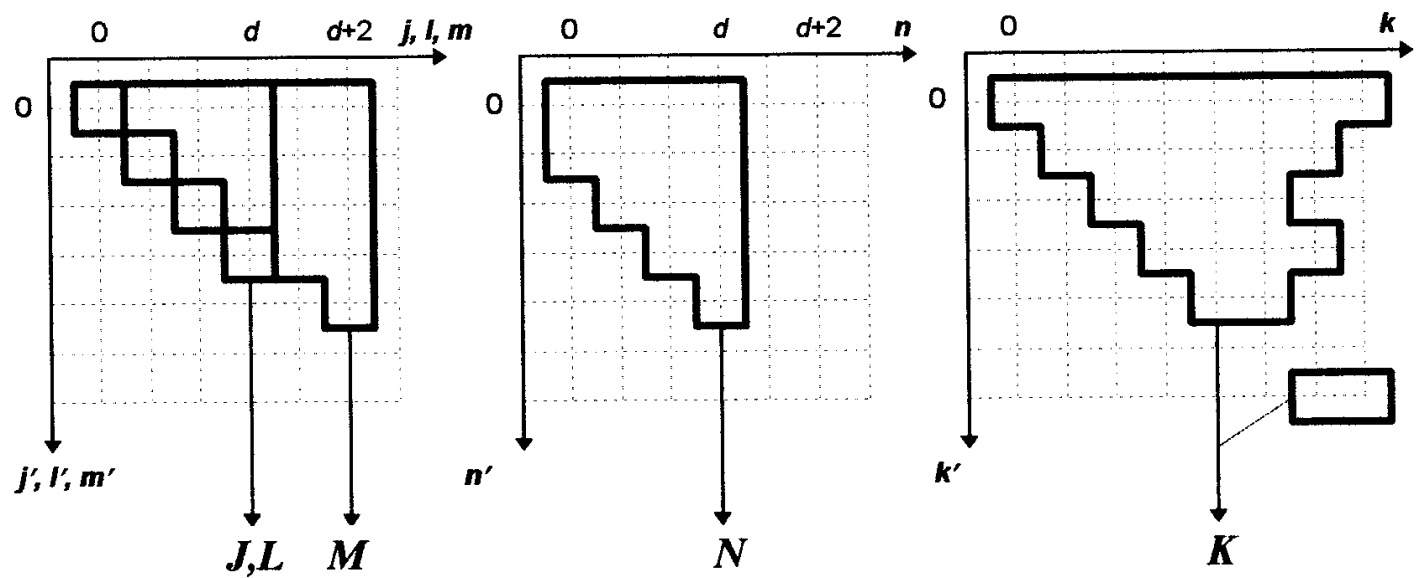

Figura 4.4: llustração dos formatos dos conjuntos de rótulos $J, L, M, N, K$ apropriados para construção de aproximantes Eulerianos, na análise de séries triangulares superiores (com $f_{i, i^{\prime}} \equiv 0$ para $\left.{ }^{\prime}<i^{\prime}\right)$. Cada ponto dos planos cartesianos $\left(j, f^{\prime}\right),(1, f),\left(m, m^{\prime}\right),\left(n, n^{\prime}\right),\left(k, k^{\prime}\right)$ que se encontre sobre uma das áreas acima delimitadas representa um elemento pertencente a um dos conjuntos $J, L, M, N, K$. A área delimitada por linhas vermelhas representa o conjunto de elementos pertencentes a $J$ ou $L$. As áreas delimitadas por linhas azuis representam, da esquerda para a direita, os conjuntos de elementos pertencentes a $M, N \in K$, respectivamente. $O$ máximo grau na potência de $x$ dos conjuntos $J, L$ e $N$ é $\alpha=3$ neste exemplo.

Deste modo, construímos os conjuntos triangulares superiores $M_{-}, N_{-} \quad \mathrm{e} \quad L$ correspondentes, respectivamente, aos polinômios $Q_{M}=x Q_{M_{-}}(x, y), \quad R_{N}=y R_{N_{-}}(x, y)$ e $P_{L}, \quad$ com $\hat{\boldsymbol{m}}-2=\hat{n}=\hat{l}=9$. Isto é compatível com as condições para assegurar invariância de Euler. Desde que para funções fortemente divergentes como $K_{T}$ o termo de "background" $U_{J}$ normalmente não é importante, fazemos $U_{J}=0$. A 
rigor, isto contraria o formato de $J$ estabelecido, porém um PDA homogêneo com $U_{J}=0$ pode ser invariante por transformação de Euler. Além disto, parece ser preferivel permitir que os conjuntos $M$ e $N$ tenham um maior número de elementos desde que estes determinam o padrão de fluxo das trajetórias características e portanto, o “locus” crítico (conforme será apresentado posteriormente).

\subsubsection{RESULTADOS NUMÉRICOS}

Uma vez selecionados os conjuntos $J=\varnothing$ e $M, N, L$ de acordo com os formatos acima mencionados, resolvemos numericamente $o$ sistema de equações geratrizes (4.9), para cada diferente escolha de $K$ compativel com o referido Teorema 6.3 (sobre invariância de Euler). Cada escolha fornece um conjunto solução $S_{K: M N L}=\left\{\left\{q_{m, m^{\prime}}\right\},\left\{r_{n, n^{\prime}}\right\},\left\{p_{l, l^{\prime}}\right\}\right\}$ a partir do qual podemos calcular numericamente $o$ aproximante $F_{K: N N L}(x, y)$ (equação $(2.42)$ ), bem como obter os parâmetros multicríticos. Vamos nos referir a cada solução como sendo um aproximante, muito embora estejamos somente interessados no cálculo dos parâmetros multicríticos e no traçado de algumas curvas características.

Para cada aproximante, determinamos os polinômios $Q_{M}, R_{N}, P_{L}$. e, através da teoria linear dos PDAs (seção 2.5.2), calculamos os parâmetros multicriticos. Como recapitulação, apresentamos abaixo as principais expressões envolvidas neste cálculo. $O$ ponto multicrítico $C \equiv\left(x_{c}, y_{c}\right)$ é determinado através da intersecção dos zeros de $Q_{M}$ e $R_{N}$ :

$$
Q_{M}\left(x_{c}, y_{c}\right)=R_{N}\left(x_{c}, y_{c}\right)=0 \text {. }
$$

Os coeficientes $Q_{1}, Q_{2}, R_{1}, R_{2}, P_{0}$ são então definidos através das equaçōes (2.22). As inclinações $e_{1}$ e $e_{2}$ dos eixos de escala podem ser estimadas atravês das soluções $e^{+}$e $e^{-}$da equação quadrática 


$$
Q_{2} e^{2}+\left(Q_{1}-R_{2}\right) e-R_{1}=0
$$

e os autovalores $\lambda_{1}$ e $\lambda_{2}$ são dados por

$$
\lambda_{1}=Q_{1}-\frac{R_{1}}{e_{2}} \quad, \quad \lambda_{2}=R_{2}-e_{1} Q_{2}
$$

Finalmente, calculamos o expoente "crossover"

$$
\phi=\frac{\lambda_{2}}{\lambda_{1}}
$$

e o expoente de escala

$$
\gamma=-\frac{P_{0}}{\lambda_{1}}
$$

Calculamos um total de 210 aproximantes homogêneos quase Eulerianos ${ }^{1}$. Utilizamos computação algébrica para efetuar os cálculos: programas em "Maple" foram desenvolvidos para obter a solução das equações geratrizes, determinar os polinômios, obter $o$ ponto multicritico e os expoentes $\gamma$ e $\phi . O$ tempo de CPU numa alphastation é de aproximadamente duas horas. Do total de 210 aproximantes, 109 exibem o ponto multicrítico nos intervalos $0.015<x<0.035$ e $y>1$. Lembremos que uma singularidade na região $y<1$ corresponde ao setor de interações repulsivas monômero-monômero. Destes pontos multicríticos: 90 (ou 82.6\%) sāo estáveis (com $\phi>0$ e $\lambda_{i}<0$ ); 13 (ou $11.9 \%$ ) são pontos de sela (com $\phi<0$ ) e; 6 (ou $5.5 \%$ ) são pontos espirais (com $\lambda_{i}$ complexo).

Em nossa análise, consideramos os pontos estáveis, que positivamente representam a maioria. Descartamos os pontos de sela (pois estes correspondem a um expoente $\phi<0$ que governa somente as

\footnotetext{
$1 \mathrm{Na}$ literatura, o uso de aproximantes que estão quase em conformidade com as exigências para invariância de Euler è considerado inteiramente satisfatório; ou seja, os aproximantes invariantes não apresentam uma convergência de resultados que seja obviamente melhor do que a apresentada pelos quase invariantes (Guttmann, 1989).
} 
correções de escala) e rejeitamos os pontos espirais (singularidades não fisicas).

Antes de calcularmos as médias e desvios estatísticos dos parâmetros criticos dos aproximantes, consideremos as trajetórias características de um típico aproximante com ponto multicrítico estável. Conforme vimos (equação (2.19)), uma trajetória característica rotulada por $z$, no plano $(x, y)$, satisfaz às equações

$$
\frac{\partial x}{\partial \tau}=Q_{M}(x, y) \quad \text { e } \quad \frac{\partial y}{\partial \tau}=R_{N}(x, y),
$$

onde $x=x(\tau, z)$ e $y=y(\tau, z)$. O conjunto de todas as trajetórias define um padrão de fluxo que é característico do aproximante em questāo. Determinamos algumas de suas curvas caracteristicas, através de integração numérica das equações diferenciais (4.15). A partir de um dado ponto inicial, a integração conduz a uma determinada curva caracteristica. Utilizamos um pacote computacional do "Maple" para solução numérica das equações diferenciais, o qual se baseia em um método de Runge-Kutta ("Fehlberg fourth-fifth order").

O padrão de fluxo das trajetórias características para este típico aproximante $(\phi>0)$, no plano $(T, x)$, é mostrado na Figura 4.5. Os “loci” $Q_{M}=0$ e $R_{N}=0$ estão representados por linhas verdes na mesma figura. Sua intersecção determina o ponto multicrítico $C$. As retas azuis descrevem as tangentes aos eixos de escala $\widetilde{x}$ e $\widetilde{y}$ no ponto $C$ no plano $(T, x)$. As trajetórias características são mostradas por linhas vermelhas enumeradas de 1 a 7 em sentido horário. As curvas 1 e 5 são tangentes ao eixo de escala $\tilde{y}$ no ponto multicrítico; elas correspondem à trajetória crítica. As setas indicam o sentido das trajetórias para $\tau$ crescente positivo. Note que as trajetórias não se encontram nem se cruzam exceto no ponto multisingular do aproximante. Desde que a inclinação $d x / d T$ de cada trajetória é proporcional a $Q_{M} / R_{N}$, a disposição das curvas de zeros determina a topologia do padrão de fluxo. Deveras, podemos observar na Figura 4.5 que a inclinação de 
uma trajetória passa por zero quando esta cruza o “locus” $Q_{M}=0$, enquanto a inclinação passa por infinito quando uma trajetória cruza o "locus" $R_{N}=0$.

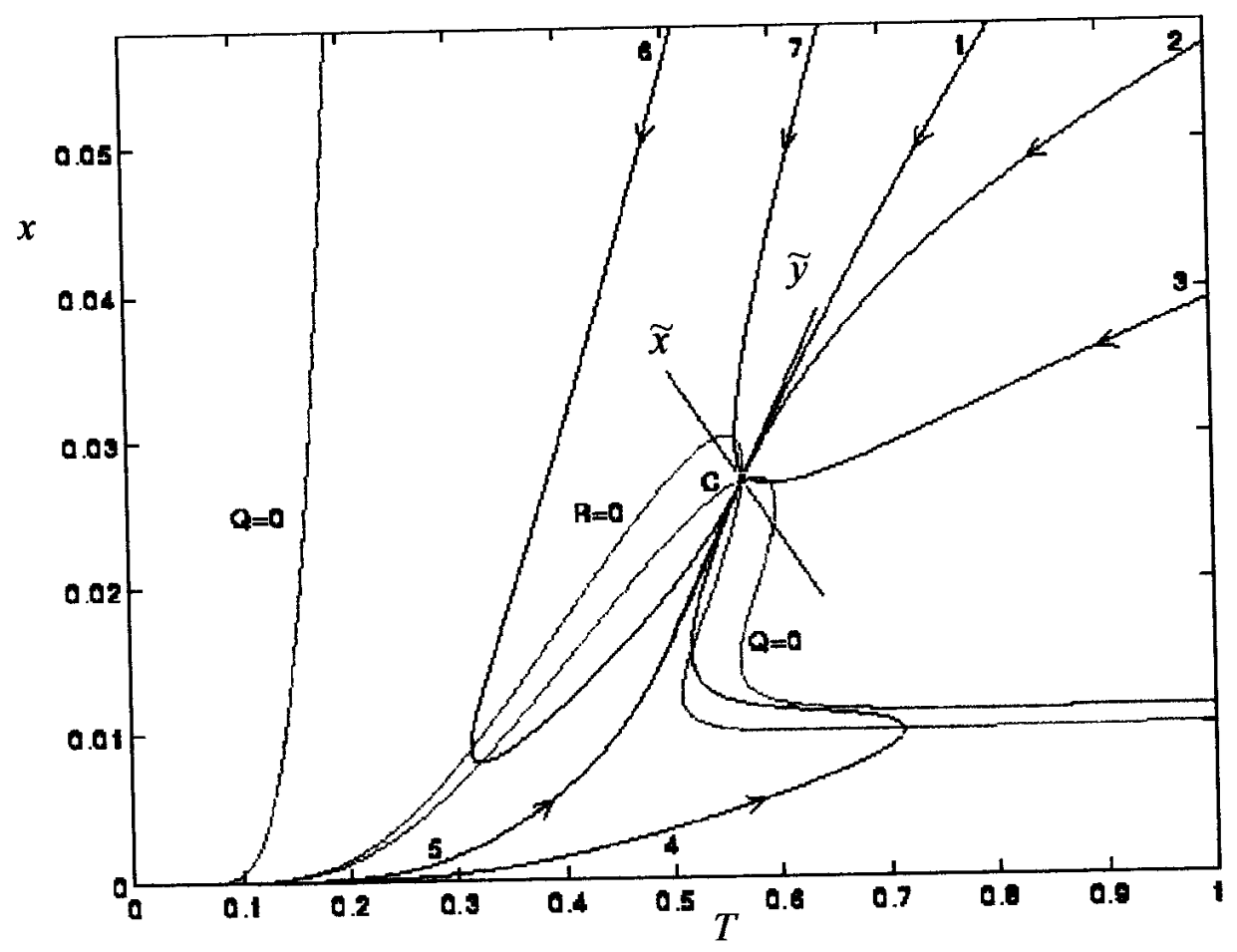

Figura 4.5: Padrảo de fluxo das trajetórias características de um típico aproximante com ponto multicrítico estável $(\phi>0)$. Algumas curvas caracteristicas (enumeradas de 1 a 7 ) ponto multicritico estavel ( $\phi$ inhas vermelhas. Os "loci" $Q=0$ e $R=0$ (linhas verdes) interceptam-se no ponto multicritico $C$. As retas representam as tangentes aos eixos de escala no ponto $C$, no plano $(T, x)$.

Na Figura 4.6, a trajetória crítica correspondente ao mesmo ponto estável é apresentada para intervalos maiores de temperatura e fugacidade. Os zeros $\mathrm{e}$ as tangentes aos eixos de escala no ponto multicritico $C$ também estão representados. Note que a linha crítica está em boa concordância com aquela extrapolada através do algoritmo BST (comparar com a Figura 4.2). 


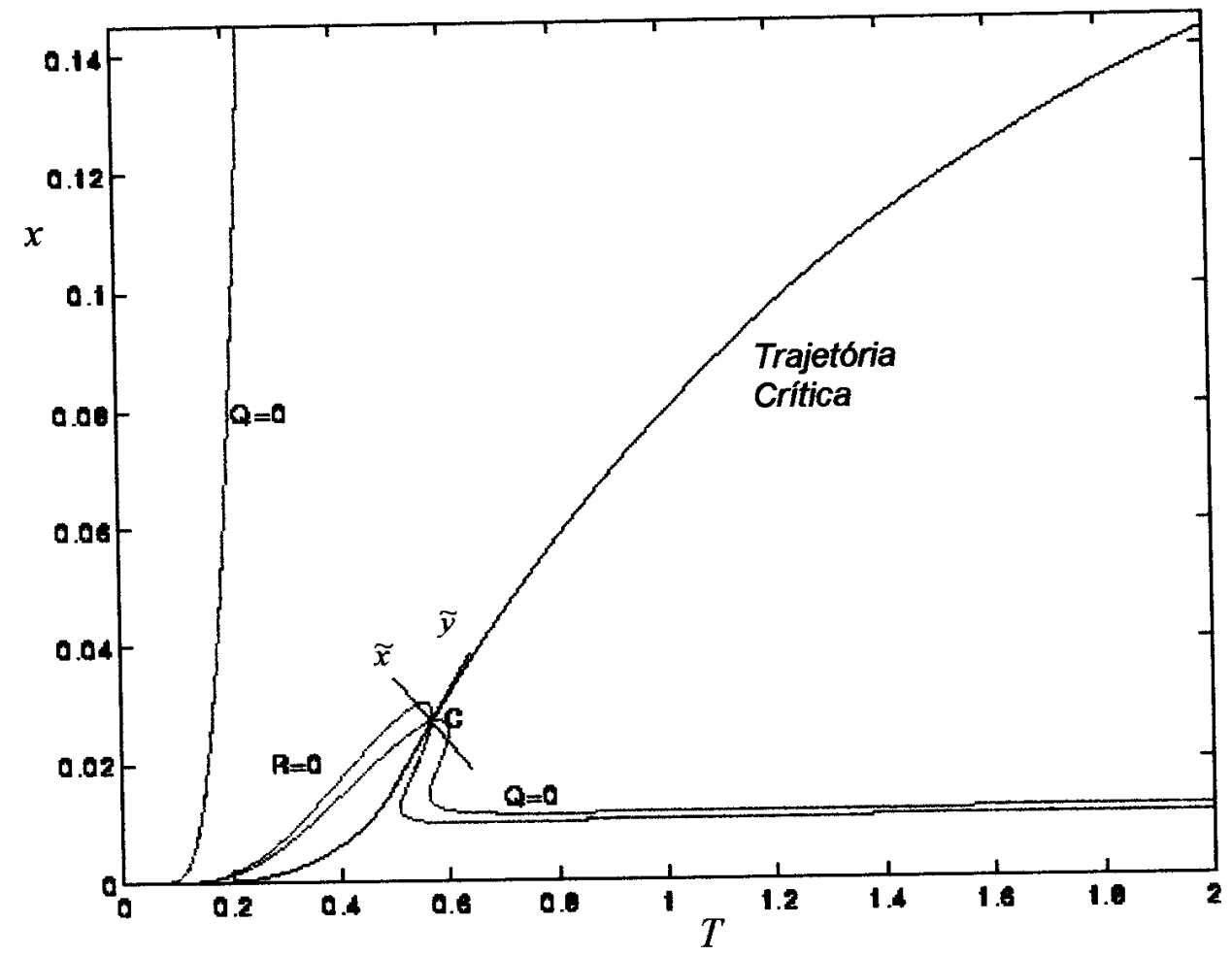

Figura 4.6: Trajetória crítica (em vermelho) correspondente ao mesmo aproximante com ponto multicrítico estável da Figura 4.4, em uma escala que abrange intervalos maiores de temperatura $T$ e fugacidade $x$. Os "loci" de zeros (em verde) e as tangentes aos eixos de escala (retas azuis) no ponto $C$ também são mostrados no gráfico.

Calculamos, agora, as médias e os desvios padrões da fugacidade tricrítica $\left(x_{t}=x_{c}\right)$ e da temperatura tricritica $\left(T_{t}=1 / \ln y_{c}\right)$, sobre 0 conjunto de singularidades relevantes (pontos estáveis):

$$
x_{t}=0.024 \pm 0.005 \quad \text { e } \quad T_{t}=0.54 \pm 0.04 \text {. }
$$

Estes resultados estão em muito boa concordância com os valores obtidos por Derrida e Herrmann (1983) utilizando-se matrizes de transferência em faixas bidimensionais: $x_{t}=0.0230 \pm 0.0004 \quad \mathrm{e}$ $T_{t}=0.535 \pm 0.005$ (ver Tabela 3.2).

Com relação a $\gamma$ e $\phi$, é importante salientar que os cálculos destes expoentes através de expressões que resultam da teoria linear dos PDAs (fórmulas (4.12), (4.13) e (4.14)) são completamente válidos somente para valores de $\phi$ no intervalo $1 / 2 \leq \phi \leq 2$, do contrário campos de escala não lineares devem ser considerados (seção 2.5.2). 
Observemos ainda que $\phi=\lambda_{2} / \lambda_{1} \rightarrow 1 / \phi$ se permutarmos os eixos $\widetilde{x}$ e $\widetilde{y}$ pois isto, de acordo com (2.24), equivale a uma permutação de $\lambda_{1}$ e $\lambda_{2}$. Como na teoria linear $1 / 2 \leq \phi \leq 2$, nosso critério para escolher as inclinaçōes dos eixos $\widetilde{x}$ e $\widetilde{y}$, ou seja, para escolher se $\left(e_{1}, e_{2}\right)$ é igual à solução $\left(e^{+}, e^{-}\right)$ou $\left(e^{-}, e^{+}\right)$de $(4.11)$, será aquele que conduz a um expoente $\phi$ no intervalo $1 / 2 \leq \phi \leq 1$. A outra possibilidade conduziria a um expoente $\varphi=1 / \phi$ no intervalo $1 \leq \varphi \leq 2$.

No cálculo dos valores médios dos expoentes, consideramos os aproximantes com $\phi \mathrm{em}$ seu referido intervalo restrito. $O$ expoente de escala e o expoente “crossover” obtidos são

$$
\gamma=1.4 \pm 0.2 \text { e } \phi=0.66 \pm 0.08 \text {. }
$$

O expoente $\phi$ está em muito boa concordância com o valor estimado pelo método de matriz de transferência $\phi=0.657 \pm 0.025$ (Derrida $\mathrm{e}$ Herrmann, 1983) e com o valor exato proposto $\phi=2 / 3$ (Vanderzande, 1993).

O expoente $\alpha$ do calor específico está relacionado ao expoente "crossover" $\phi$ através da relação de escala (3.20):

$$
\alpha=2-\phi^{-1} \approx 0.48
$$

\subsubsection{Escolhendo Conjuntos de Rótulos com Formatos Quadrados}

Adicionalmente, também exploramos a técnica dos PDAs escolhendo outros formatos para os conjuntos de rótulos. Especificamente, selecionamos formatos quadrados. Observemos que o critério em que se baseia esta escolha é ad hoc ${ }^{2}$. Entretanto, é válida a comparação dos resultados de ambas as estratégias. $\mathrm{Na}$ atual estratégia, os conjuntos $M, N, L$ não apresentam lacunas e seus

\footnotetext{
2 Relativo a um propósito particular; não geral.
} 
formatos são quadrados com graus $\hat{\boldsymbol{m}}=\hat{\boldsymbol{n}}=\hat{\boldsymbol{l}}=8$. O polinômio $U_{J}$ é nulo e $p_{0,0}=1$. Na equação diferencial parcial $(2.15), F(x, y)$ é substituído pela série $K_{T}(x, y)$ conhecida até ordem $x^{19} y^{18}$. Devido à presença de derivadas nesta equação, os elementos $\left(k, k^{\prime}\right)$ do conjunto $K$ são escolhidos nos intervalos $0 \leq k \leq 18$ e $0 \leq k^{\prime} \leq 17$. Equações que se originam de coeficientes com menor potência são fixas e outras equaçōes, oriundas de um conjunto maior que inclui coeficientes com potências mais altas, são adicionadas de modo combinatório.

Este procedimento fornece 451 aproximantes que exibem pontos tricríticos com o seguinte perfil: 15 pontos estáveis, 79 pontos instáveis e 357 pontos de sela (os pontos espirais, não físicos, são rejeitados). Além do esperado ponto tricrítico, a maioria dos aproximantes apresenta uma variedade de outros pontos multicríticos no plano $(T, x)$, alguns deles com natureza não fisica. Por exemplo, um típico aproximante com ponto de sela apresenta um ponto fixo extra $D$ sobre o eixo $x=0$, que pode ser considerado como uma singularidade espúria desde que sabemos que $K_{T}(x, y)$ é analítica nesta região. Além do mais, este ponto nāo pertence à trajetória crítica (que é tangente ao eixo $\widetilde{y}$ no ponto tricrítico principal $\left.C \equiv\left(T_{c}, x_{c}\right)\right)$. Há um outro ponto fixo $B$ sobre a trajetória crítica, na região $T<T_{c}$. Em princípio, este ponto poderia mudar o comportamento crítico ao longo do "locus" $C B$. Este tipo de ponto fixo adicional já foi encontrado na literatura (Barma e Fisher, 1985). Foi chamado de ponto de fronteira ("border point") e interpretado como uma representação prematura de um ponto tricrítico incipiente. Estudamos também a estatística de pontos fixos extras sobre o conjunto de aproximantes com pontos tricríticos estáveis ou instáveis. Aproximadamente $94 \%$ destes aproximantes contém singularidades espúrias (distribuídas em todos aproximantes com pontos estáveis e em 73 dos instáveis). Os pontos de fronteira aparecem em $14.9 \%$ destes aproximantes (especificamente, em 12 aproximantes com pontos estáveis e somente em 2 com pontos instáveis). Novamente, as médias das quantidades relevantes foram tomadas sobre este conjunto de 
aproximantes (pontos de sela foram descartados). As estimativas para a fugacidade $\mathrm{e}$ temperatura tricríticas são: $x_{t}=0.024 \pm 0.009 \mathrm{e}$ $T_{t}=0.55 \pm 0.08$. As médias dos expoentes de escala e "crossover" são realizadas sobre os aproximantes com $\phi$ no intervalo $1 / 2 \leq \phi \leq 2$ e os resultados são: $\gamma=1.9 \pm 0.5$ e $\phi=0.63 \pm 0.09$.

Podemos agora comparar estes resultados com aqueles obtidos a partir de aproximantes quase invariantes por transformação de Euler (ver equações (4.16) e (4.17)). As estimativas de ambas as estratégias estão em boa concordância, mas desvios padrōes menores são provenientes dos aproximantes quase Eulerianos. Além disto, conforme vimos, os casos não razoáveis (pontos de sela e singularidades espúrias) são muito mais frequentes nos aproximantes "não invariantes". Ao contrário, os pontos multicríticos estáveis constituem a maioria em nossos aproximantes quase Eulerianos. Uma vez mais, a importância dos aproximantes invariantes (que fornecem estimativas mais estáveis e confiáveis) foi verificada. Neste sentido, as estimativas nas equações (4.16) e (4.17) são os resultados preferiveis.

\subsubsection{SUMÁRIO}

Para estudar a transição de colapso em polímeros ramificados, consideramos um modelo com dois parâmetros, temperatura e fugacidade. O polimero é descrito por um animal fortemente embebido na rede quadrada (sem contatos), com interaçōes atrativas entre sítios primeiros vizinhos. Graças a uma enumeração exata destes animais, pudemos construir a função geratriz do sistema, calcular sua compressibilidade isotérmica e então verificar a existência de um ponto tricrítico separando uma região de transição de fase de primeira ordem de uma de segunda ordem. Um algoritmo de extrapolação simples (BST) nos permitiu determinar o diagrama de fases.

Para estudar mais profundamente o ponto tricritico, aplicamos os aproximantes diferenciais parciais para localizar a singularidade e 
estimar os expoentes de escala correspondentes. A importância do uso dos aproximantes invariantes foi verificada uma vez mais. Os valores que calculamos estão em muito boa concordância com aqueles obtidos por outras técnicas.

Esperamos que este trabalho possa encorajar outros pesquisadores a utilizar o método dos PDAs que é especialmente designado para tratar multisingularidades. 


\section{MODELO DE CRESCIMENTO CINÉTICO}

\subsection{INTRODUÇÃ̃}

Durante as últimas décadas, o fenômeno da polimerização tem sido estudado através do emprego de muitos modelos. Conforme vimos (capítulo 3), a idealização mais simples de uma cadeia polimérica é a caminhada aleatória. Se a configuração não puder se interceptar, temos a caminhada auto-exclusiva ("self-avoiding walk" - SAW), utilizada no modelo de polimeros lineares em soluções diluídas (Flory, 1969; de Gennes, 1979). As previsões numéricas do SAW diferem consideravelmente daquelas da caminhada aleatória de uma cadeia ideal (com livre permissão para se interceptar). Por outro lado, os animais na rede, ou aglomerados conectados de sítios ocupados, constituem-se num bom modelo para polimeros ramificados em solventes diluidos no limite de altas temperaturas.

No presente capitulo, consideramos um modelo alternativo no estudo da polimerização, o denominado modelo de crescimento cinético (Majid et al., 1984; Herrmann, 1984; Lyklema, 1986). Este é mais realista do que o SAW no sentido de que a extremidade de crescimento da cadeia é repelida pelos sítios ocupados. A extremidade da cadeia cresce, a cada unidade de tempo, em direção a um dos sítios primeiros vizinhos não visitados, interrompendo o crescimento se todos os sítios 
ao seu redor estiverem ocupados. Recentemente, L. S. Lucena, C. Tsallis e colaboradores generalizaram o modelo de crescimento cinético a fim de incorporar a possibilidade de ramificações e também a presença de impurezas (Lucena et al., 1994). Este novo modelo de crescimento de polimeros ramificados $^{1}$ exibe uma transição finita-infinita devido à competição entre ramificações e obstáculos. No espaço $(b, c)$, onde $b$ é a probabilidade de ramificação e $c$ é a concentração de impurezas, Lucena et al. (1994) encontraram um linha crítica que separa os regimes de crescimento finito e infinito. Em um trabalho muito recente, Andrade et al. (1996) incorporaram ao modelo uma regra dinâmica que permite ao sistema conduzir-se espontaneamente à probabilidade de ramificação crítica (criticalidade auto-organizada).

No capítulo 6 , investigamos os aspectos topológicos e dinâmicos deste modelo de crescimento cinético generalizado (Neves e Onody, 1995). Detectamos, neste estudo, uma transição de rugosidade na superficie do polimero.

No capítulo 7, estudamos este modelo de uma maneira ainda mais realista ao incluirmos forças atrativas de curto alcance entre os monômeros (Onody e Neves, 1996b). Através de um método de Monte Carlo, incorporamos ao modelo um outro parâmetro relevante, a temperatura reduzida $T$. Obtemos, no plano $(T, b)$, o diagrama de fases que separa os regimes de crescimento finito e infinito.

\subsection{MODELO DE CRESCIMENTO CINÉTICO}

\subsubsection{CAMINHADA DE CRESCIMENTO CINÉTICO}

Majid et al. (1984) propuseram um novo modelo para descrever o crescimento irreversivel de polimeros lineares: a caminhada de crescimento cinético ("kinetic growth walk" - KGW). Para explicarmos

\footnotetext{
I Este modelo de crescimento cinético generalizado para incorporar ramificações e impurezas é atualmente denominado modelo de crescimento de polimeros ramificados ( ${ }^{\star}$ branched polymer growth model" - BPGM).
} 
este modelo, considere a Figura 5.1. Numa caminhada auto-exclusiva (SAW), escolhe-se aleatoriamente o próximo passo em direção a um dos sitios primeiros vizinhos (excluindo o previamente ocupado); se a direção escolhida conduzir a um sítio que já tenha sido visitado, a caminhada termina. Ao contrário, na caminhada de crescimento cinético, escolhe-se aleatoriamente o próximo passo em direção a um dos sítios primeiros vizinhos não visitados; a caminhada somente termina quando não houver nenhum sítio disponível. Portanto, o KGW é muito menos sensivel ao atrito do que o SAW uma vez que a extremidade da cadeia sempre escapará quando houver um sítio adjacente ainda nāo visitado. Por outro lado, o KGW nāo está totalmente livre de armadilhas: a extremidade pára de crescer quando todos os sítios vizinhos ao seu redor já tiverem sido visitados. A justificativa para tal modelo baseia-se no fato de que o crescimento do polímero somente é possivel através do movimento de um único iniciador em direção a algum dos sítios primeiros vizinhos com monômeros bifuncionais não saturados.

SAW

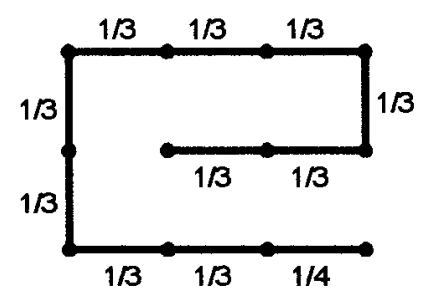

KGW

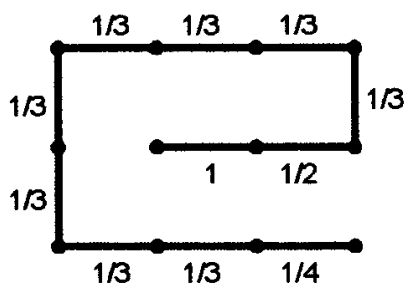

Figura 5.1: Duas configuraç̋̃es idênticas são mostradas, com pesos apropriados em cada passo, para um SAW e um KGW. O ponto inicial está representado em verde.

A distância média $R$ entre as extremidades da cadeia, após $N$ passos, escala conforme $R \sim N^{v}$. Argumentos cinéticos do tipo Flory (Majit et al., 1984) mostram que a dimensão fractal $d_{f}$ do KGW é dada por 


$$
d_{f}=v^{-1}=\frac{d+1}{2} \text {. }
$$

Acima de uma dimensão crítica $d_{c}=3$, o expoente $v$ assume o valor correspondente ao de uma caminhada aleatória ideal $(v=1 / 2)$. $O$ resultado de Flory para o SAW é $d_{f}=v^{-1}=(d+2) / 3$, com $d_{c}=4$.

Simulações de Monte Carlo do KGW em redes bidimensionais com $N \sim 10^{6}$ permitem estimar $d_{f}=1.48 \pm 0.02$; uma enumeração exata com todas possiveis caminhadas até 22 passos fornece $d_{f}=1.47 \pm 0.03$. Ambos os resultados são consistentes com a previsão $d_{f}=3 / 2 \mathrm{em} d=2$. Em três dimensões os dados numéricos suportam a previsão $d_{f}=2$ se um fator de correção logaritmica estiver presente, $\left\langle R^{2}>\sim N(\ln N)^{\alpha}\right.$, com $\alpha \approx 0.2$ (Majit et al., 1984).

\subsubsection{MODELO DE CRESCIMENTO DE POLÍMEROS RAMIFICADOS}

O modelo de crescimento cinético foi recentemente generalizado por Lucena et al. (1994) a fim de incorporar a possibilidade de ramificações e também a presença de impurezas. Atravês de simulações, Lucena et al. (1994) mostraram que a competição entre ramificação e obstáculos (devido às obstruçōes estéricas e impurezas) conduz a fenômenos interessantes associados com um novo tipo de transição de fase. Este tipo de fenômeno crítico deve ser relevante na discussão de polímeros ramificados reais; a inclusão de impurezas no modelo pode ser útil na discussão de uma variedade de substâncias (por exemplo, tintas poliméricas comerciais, em que a cor é obtida através da adição de pigmentos quimicamente inertes). Há também um interesse cientifico geral neste tipo de problema. Derrida (1991) enfatiza a importância de estudar polímeros ramificados em meios desordenados, especialmente devido às possiveis conexōes com outros problemas fundamentais como "spin glasses". 


\subsubsection{Descrição do Modelo}

Para descrever o modelo de crescimento de polimeros ramificados conforme proposto por Lucena et al. (1994), vamos nos referir à Figura 5.2. Considere uma rede quadrada $L \times L$ com uma concentração $c$ de impurezas. Cada sitio da rede pode estar vazio ou ocupado por um monômero ou uma impureza. Na figura, os sítios ocupados por monômeros estão representados em vermelho e os ocupados por impurezas estão representados em preto.

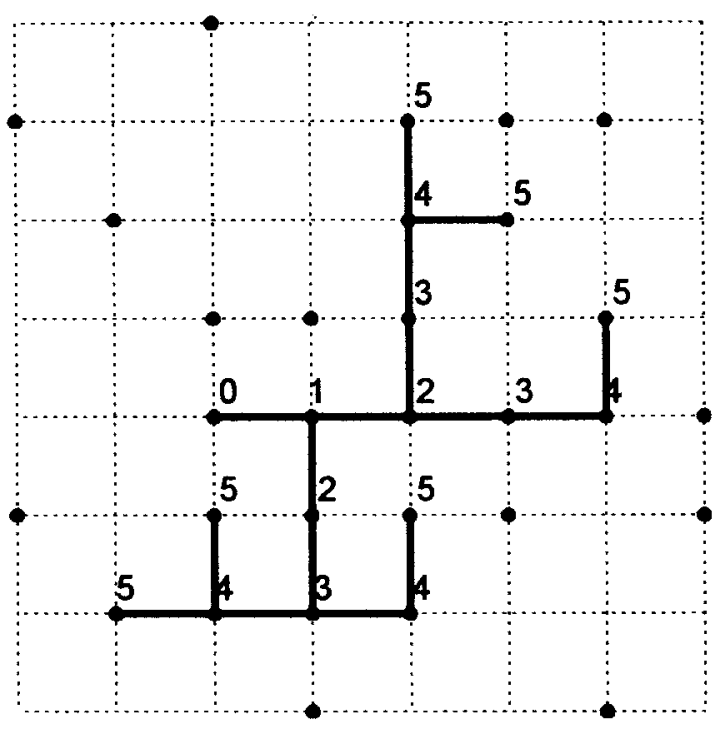

Figura 5.2: Exemplo de simulação do modelo de crescimento cinético (generalizado para polímeros ramificados) somente até instante $t=5$. Cada sítio da rede quadrada pode estar ocupado por uma impureza (representada em cor preta) ou por um monômero (em vermelho). Os números representam os instantes em que os sítios são ocupados por monômeros. Observe que uma das extremidades do polímero encontra-se num beco sem saida e, portanto, deverá interromper seu crescimento (tornando-se inativa). $O$ experimento somente terminará quando uma das extremidades do polimero tocar a fronteira da rede (polímero infinito) ou quando todas as extremidades tornarem-se inativas (polimero finito).

Inicialmente, o centro da rede (origem) é o único sitio que se encontra ocupado por um monômero (semente). No instante $t=0$, o polimero inicia seu crescimento a partir da origem em direção a um sitio adjacente vazio aleatoriamente escolhido. Em $t=1$, o sitio escolhido é preenchido por um monômero e torna-se a nova extremidade de 
crescimento. Esta extremidade pode então bifurcar e isto significa escolher duas direções que conduzam a sítios primeiros vizinhos vazios ou; pode manter seu crescimento linear, o que significa selecionar uma única direção que conduza a um sítio vazio. Os sítios assim escolhidos são ocupados, tornam-se as novas extremidades de crescimento e o processo continua recursivamente, sempre respeitando a auto-exclusão ("self-avoidance"). Em geral, a cada instante $t$, cada sitio ativo (ponta de crescimento) pode parar de crescer, bifurcar ou seguir linear, de acordo com as seguintes regras: (i) se a extremidade de crescimento estiver cercada somente por sítios ocupados, então seu crescimento é interrompido; (ii) se um único sítio adjacente à extremidade estiver vazio, o crescimento é necessariamente linear e em direção ao referido sítio e; (iii) se ao menos dois sítios adjacentes estiverem vazios, a extremidade pode bifurcar com probabilidade $b$ ou seguir linear com probabilidade $1-b$, em qualquer caso as direções são igualmente prováveis e aleatoriamente escolhidas dentre as disponiveis (aquelas que conduzem a sítios ainda vazios). $O$ intervalo de tempo unitário $t \leq t^{\prime}<t+1$, entre duas etapas consecutivas, define o tempo durante $o$ qual devem ser visitadas todas as extremidades de crescimento atuais (aquelas geradas pela ocupaçāo de sítios no instante $t$ ). Em cada intervalo, todas as extremidades ativas são seqũencialmente visitadas, em sentido horário, de acordo com a ordem de seus nascimentos.

Cada ponta ativa está conectada à origem por $t$ ligações. A extremidade sempre tenta evitar regiões preenchidas, porém, às vezes, pode cair em uma armadilha, isto é, num beco sem saida (“cul de sac"). Nesta situação, como vimos, a ponta torna-se inativa, interrompendo seu crescimento. Um experimento é finalizado quando: o aglomerado de sítios ocupados por monômeros (ou "cluster") tocar a fronteira da rede (caso em que o polímero é denominado "infinito") ou; quando todas as pontas tornarem-se extremidades inativas (polímero "finito").

Em cada experimento, o número de ligaçōes ocupadas (que conectam sítios vizinhos e correspondem às direções escolhidas no 
processo de crescimento) é denotado por $N$. As médias de quantidades relevantes são realizadas sobre um conjunto de muitos experimentos: o nümero total de ensaios é $N_{e} \sim 10^{6}$.

\subsubsection{LNHA CRÍTICA $b_{c}(c)$ E DIMENSÃO FRACTAL}

No estudo do modelo de crescimento cinético, Lucena et al. (1994) denotam por $P_{\infty}$ a fração dos polímeros que são infinitos e por $P_{N}(N)$ a lei de distribuição de $N$, correspondente a polimeros finitos. Ao término de um dado experimento, determinam o menor retângulo (com lados paralelos ao do quadrado $L \times L$ ) que contém um polímero finito e definem $s \equiv \sqrt{s_{x} s_{y}}$, onde $s_{x}$ e $s_{y}$ são os comprimentos dos dois lados do retângulo. Determinam, então, a lei de distribuição $P_{s}(s)$ associada a polímeros finitos e o tamanho médio $\xi \equiv\langle s\rangle$ que desempenha o papel do comprimento de correlação nas transições de fase. A dimensão fractal $d_{f}$ do polímero ramificado é definida através de $\langle N\rangle \propto \xi^{d_{f}}$.

Os experimentos são realizados sobre uma rede quadrada com uma concentração $c \in[0,1]$ de impurezas, cuja distribuição ("quenched") foi previamente congelada. Uma questão levantada e particularmente interessante consiste em analisar se as impurezas introduzem uma nova classe de universalidade no problema. Deveras, é importante observar que as obstruções estéricas ("steric hindrances") são devidas tanto à auto-exclusão ("self-avoidance") quanto às impurezas.

Os resultados apresentados por Lucena et al. (1994) foram obtidos com os valores $300 \leq L \leq 5000$ e $200 \leq N_{e} \leq 10^{6}$. Na Figura 5.3 são apresentadas algumas curvas de polidispersão $P_{N}(N)$. Foi verificado que, na maioria dos pontos no espaço $(b, c), P_{N}(N)$ decai exponencialmente com $N$ (Figura 5.3(a)). Há, contudo, uma linha (crítica) sobre a qual o decaimento torna-se uma lei de potência (Figura 5.3(b)). Para $c=0$, o valor crítico de $b$ é $b_{c}(0) \approx 0.055$. 

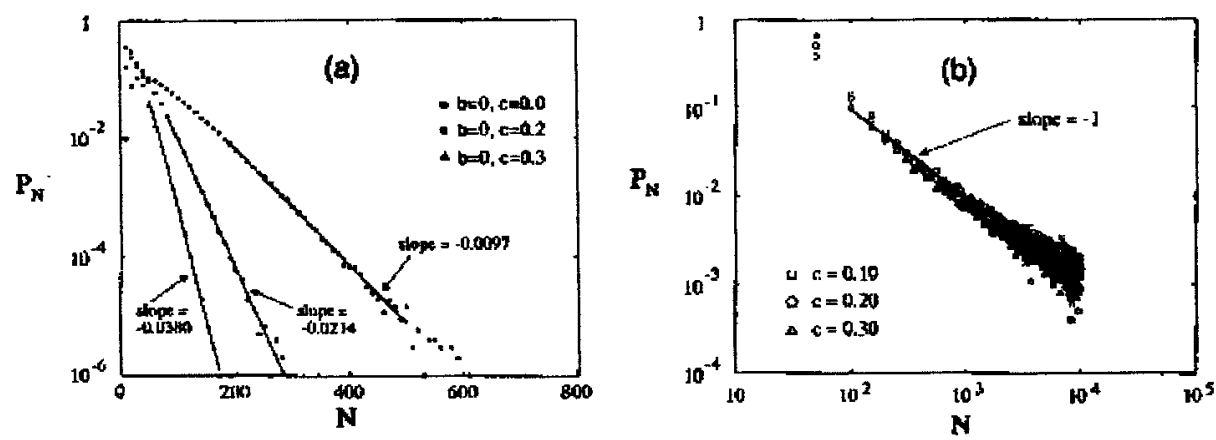

Figura 5.3: Lei de distribuição de polidispersăo : (a) fase de crescimento finito (representação semi-log, $L=1000$ e $N_{\theta}=10^{6}$ ); (b) sobre a linha crítica $\left(b_{c}(c), c\right)$ (representação $\log -\log , L=1000$ e $N_{e}=20000$ ). (Lucena et al., 1994).

O comportamento do comprimento de correlação de $\xi$ como função de $b$, para diferentes valores de $c$ e $L$, é apresentado na Figura 5.4.

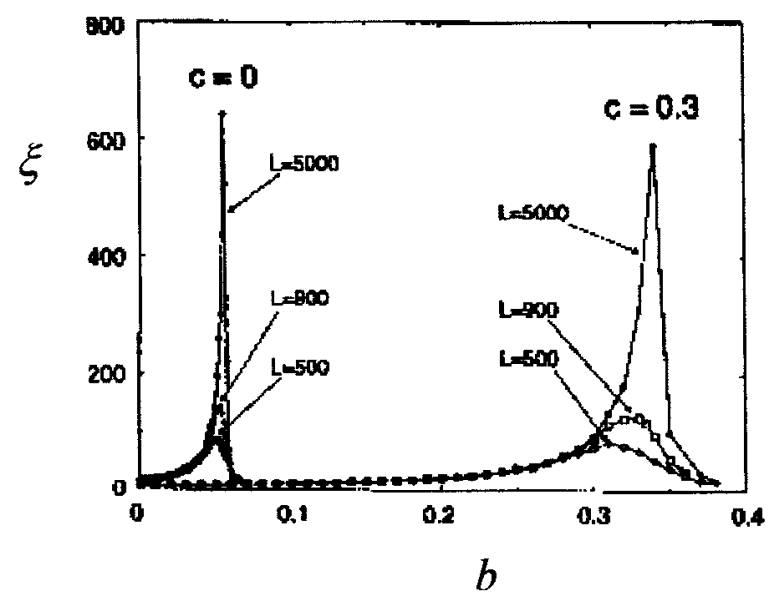

Figura 5.4: Resultados típicos que mostram o comportamento de $\xi$ em função de $b\left(1000 \leq N_{e} \leq 20000\right)$. (Lucena et al., 1994).

O parâmetro de ordem $P_{\infty}(b, c)$ e a linha crítica $\left(b_{c}(c), c\right)$ que separa os regimes de crescimento finito e infinito (diagrama de fases) são apresentados na Figura 5.5. 

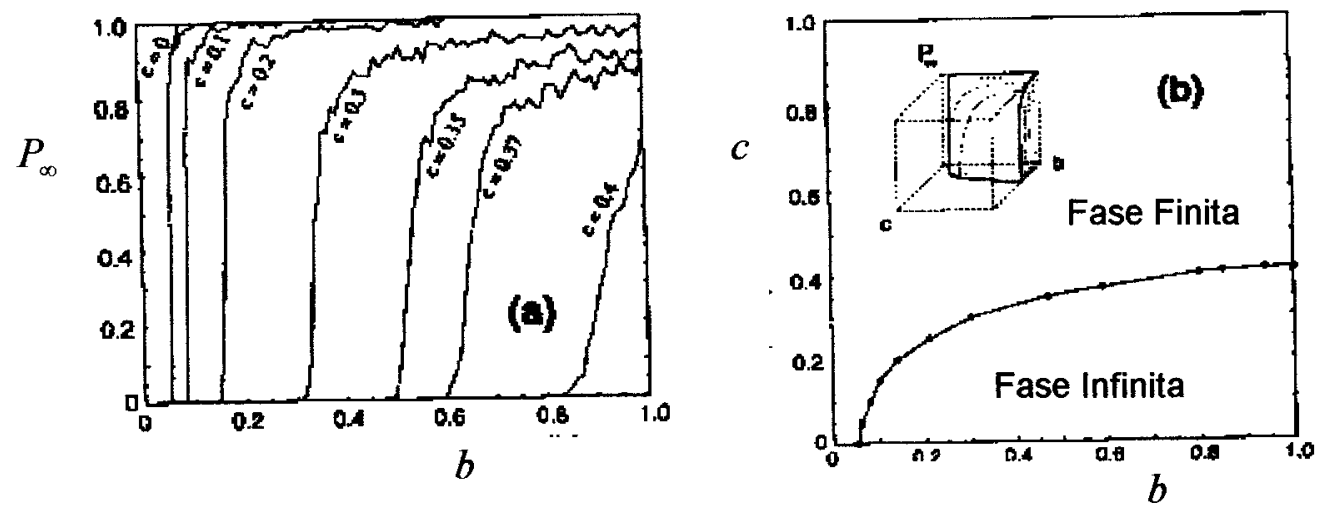

Figura 5.5: (a) Resultados típicos para o parâmetro de ordem $P_{\infty}$ como função de $b$ e $c(L=300)$; (b) Diagrama de fases $(300 \leq L \leq 5000)$; o "inset" representa $P_{\infty}(b, c)$. (Lucena et al., 1994).

A representação $\log M$ versus $\log R$, onde $M$ é a massa do polimero contida num quadrado de lado $R$, fornece a dimensão fractal $d_{f}$. A partir deste tipo de construção, Lucena et. al. (1994) extraíram $d_{f} \approx 2 \pm 0.004$ para os pontos dentro da região de crescimento infinito. Sobre a linha critica, obtiveram valores variando monotonicamente de $d_{f}=1.83$, em $(b, c)=(0.055,0)$, até $d_{f}=1.76$, em $(b, c)=(1,0.4072)$. Esta ligeira variação foi julgada consistente com uma única classe de universalidade, caracterizada por $d_{f} \approx 1.8$, ainda que a possibilidade de comportamento não universal não tenha sido definitivamente excluida.

O ponto $(b, c)=(1,0.4072)$ corresponde à percolação por sitio. Neste modelo de percolaçāo (Stauffer, 1985), cada sítio da rede é ocupado com probabilidade $p$ ou está vazio com probabilidade $q=1-p$. Em uma rede infinita, existe um ponto crítico $p_{c}$ que indica uma transição de fase tal que, somente para $p>p_{c}$, existe um "cluster" infinito (grupo de sítios vizinhos ocupados que se estende através da rede). $\mathrm{Na}$ percolação por sítio na rede quadrada, a probabilidade de ocupaçāo crítica é $p_{c} \approx 0.5928$. Portanto, no crescimento de polimeros ramificados, com $b=1$, a concentração crítica $c$ de impurezas que separa as fases finita e infinita é tal que $1-c=1-0.4072=0.5928 \approx p_{c}$. A interpretação deste fato baseia-se na observação de que o crescimento do polímero (e, portanto, a ocupação de sítios) somente pode ocorrer no subconjunto de pontos 
que não estão ocupados por impurezas. A Figura 5.6 mostra um crescimento tipico neste ponto: existem regiões pertencentes a um aglomerado ("infinito”) de sítios vazios que nunca serão ocupadas. Para tornar este ponto óbvio, Lucena et al. (1994) simularam o crescimento de polimeros com trifurcações (ao invês de bifurcações) e obtiveram preenchimento completo das regiões vagas. Neste caso, obtiveram consistentemente o valor $d_{f}=1.896$ que reproduz precisamente o valor $d_{f}$ associado à percolação por sítio (Stauffer, 1985). Desde que este valor é diferente de $d_{f} \approx 1.76$ correspondente às bifurcações, acredita-se que uma nova classe de universalidade está sendo exibida, claramente relacionada ao preenchimento incompleto dos aglomerados de sítios vazios.

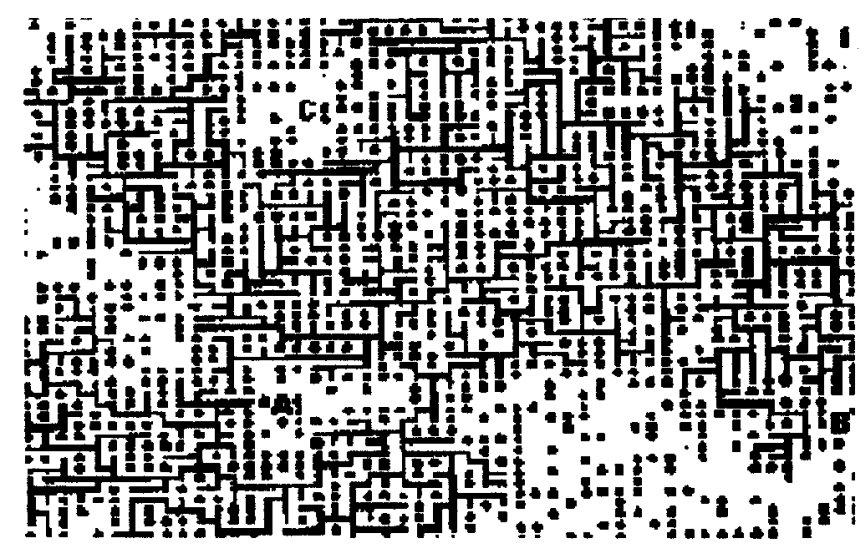

Figura 5.6: Fragmento típico de um "polimero" (cuja estrutura está representada por sítios conectados) gerado em uma rede $50 \times 50$ com uma distribuição aleatória de impurezas (sítios preenchidos năo conectados). A simulação corresponde ao ponto crítico $(b, c)=(1,0.4072)$. As regióes $A$ e $B$ pertencem ao aglomerado "infinito" de sítios vazios que não foram ocupados pelas bifurcaçбos; a regiāo $\mathrm{C}$ é um aglomerado finito de sítios vazios. (Lucena et al., 1994).

Aspectos topológicos, dinâmicos e efeitos de tamanho finito deste modelo de crescimento cinético (Neves e Onody, 1995) serão estudados no capitulo 6 . No capítulo 7 , incorporamos ao modelo o parâmetro temperatura $T$ e obtemos o diagrama de fases no plano $(T, b)$ (Onody e Neves, 1996b). 


\subsubsection{CRITICALIDADE AUTO-ORGANIZADA}

O conceito de criticalidade auto-organizada foi introduzido por Bak, Tang e Wiensenfeld (1987) como uma explicação plausivel para a tendência de sistemas grandes e complexos em ser conduzidos a estados críticos.

Em um trabalho muito recente, Andrade et al. (1996) mostraram que, no modelo de crescimento de polimeros ramificados, a autoorganização pode ser atingida, conduzindo e mantendo o sistema próximo à criticalidade. Eles incorporaram ao modelo a seguinte dinâmica global para governar a evolução da probabilidade de ramificaçāo $b(t)$ durante o crescimento do polímero,

$$
b(t+1)=b(t)+k\left[N_{T}-N_{A}(t)\right] \quad,
$$

onde $N_{A}(t)$ é o número de sítios ativos no instante $t, k$ é um coeficiente cinético e $N_{T}$ é um limite arbitrariamente especificado para $N_{A}(t)$. Por meio da equação acima, uma força restauradora é imposta ao sistema de forma que $b(t)$ flutua no tempo.

Em uma típica realização de crescimento do polímero sob estas condições, com probabilidade de ramificação inicial $b(0)=1$, coeficiente $k=10^{-3}$ e $N_{T}=80$, num sistema sem impurezas $(c=0)$, Andrade et al. (1996) constataram que o aglomerado inicialmente cresce como um objeto compacto e sua estrutura periférica muda gradualmente para a de um objeto fractal, como resultado da variação do parâmetro $b$. Esta evolução espontânea corresponde a uma trajetória no plano $(b, c)$ que tende à linha de transição finita-infinita. Após um período transiente e independentemente das condições iniciais, a evolução temporal de $b(t)$ atinge um estado auto-organizado caracterizado por um valor médio $<b>$ que recupera precisamente a probabilidade crítica $b_{c} \approx 0.056 \mathrm{em}$ $c=0$, separando os regimes de crescimento finito $\mathrm{e}$ infinito. Graficamente, $b(t)$ oscila em torno do estado crítico atingido após um 
breve transiente. No caso em que $c>0$, a fim de compensar a adicional limitação no crescimento, o sistema auto organizado é conduzido a um outro estado crítico com maior probabilidade de bifurcação (por exemplo, $b_{c} \approx 0.342$ em $c=0.3$ ). Como consequência, o método permite obter precisamente toda a linha critica no espaço de fase $(b, c)$. É importante enfatizar que neste novo método o sistema procura a criticalidade por si próprio enquanto que na proposta original (Lucena et al., 1994), a linha critica é localizada por procedimentos nos quais são utilizados parâmetros fixos.

Andrade et al. (1996) também observaram a evolução temporal do número de sítios ativos $N_{A}(t)$ para diferentes limites $N_{T}$ e diferentes valores de $k$ (os valores tipicos utilizados são: $N_{T}=100$ e $k=10^{-5}$; $N_{T}=200$ e $k=10^{-4} ; N_{T}=300$ e $k=10^{-3}$ ). Conforme esperado, o limite $N_{T}$ determina meramente o valor médio em torno do qual o número $N_{A}$ de sítios ativos flutua no tempo quando o sistema torna-se autoorganizado, ou seja, atinge um estado estacionário. A manutenção do número de sítios ativos próximo ao limiar $N_{T}$ é equivalente a assegurar a sobrevivência do polimero em crescimento próximo ao estado crítico. O comportamento de $N_{A}(t)$ e a influência do coeficiente $k$ podem ser compreendidos com uma análise de representação de campo médio, partindo-se da seguinte expressão:

$$
N_{A}(t+1)=[1-a(t)][1+b(t)] N_{A}(t) \quad .
$$

Nesta expressão, proposta por Andrade et al. (1996) para explicar o crescimento do polimero ramificado, $a(t)$ é a probabilidade de aniquilação (ou morte) de uma extremidade do polímero, causada pelos efeitos das obstruções estéricas $(0 \leq a(t) \leq 1)$. Deste modo, mecanismos de exclusão que conduzam à desativação ("self-avoidance" e impurezas) podem ser aproximadamente incorporados ao modelo. Considerando os limites nas equaçōes (5.2) e (5.3) (onde o tempo é contínuo), obtém-se

77

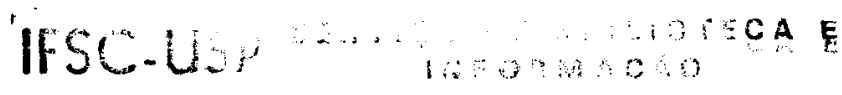




$$
\begin{gathered}
\frac{d b}{d t}=k\left[N_{T}-N_{A}\right], \\
\frac{d N_{A}}{d t}=[b(1-a)-a] N_{A}(t)
\end{gathered}
$$

Assumindo-se, por simplicidade, que a probabilidade $a$ é constante no estado estacionário do processo dinâmico, derivando-se a equação (5.5) e inserindo-se a equação (5.4) na expressão resultante, obtém-se

$$
\frac{d^{2} N_{A}}{d t^{2}}=k(1-a) N_{T} N_{A}-k(1-a) N_{A}^{2}+\frac{1}{N_{A}}\left[\frac{d N_{A}}{d t}\right]^{2}
$$

A presença do termo intermediário no lado direito da equação (5.6) fornece uma explicação convincente para a diversidade do comportamento oscilatório de $N_{A}(t)$, observado em diferentes valores de $k$. O parâmetro $k$ está portanto intrinsecamente relacionado ao comportamento oscilatório do sistema. Um grande valor de $k$ está diretamente associado à ocorrência de oscilações de altas freqüências na função $N_{A}(t)$. Os demais termos estão relacionados à tendência de crescimento do polímero na ausência de mecanismos de realimentação que conduzam o sistema de volta ao valor $N_{T}$. 


\section{TOPOLOGIA, DINÂMICA E EFEITOS DE TAMANHO FINITO DE UM MODELO DE CRESCIMENTO CINÉTICO}

\subsection{INTRODUÇÃO}

O modelo de crescimento cinético, generalizado para o estudo da polimerização ramificada na presença de impurezas (Lucena et al., 1994), foi abordado no capítulo anterior. No presente capítulo, nosso objetivo é estudar novos aspectos deste modelo, com ênfase em sua topologia e dinâmica (Neves e Onody, 1995). Todas as simulações são realizadas na rede quadrada.

Inicialmente, considerando que a configuração do polímero pode ser identificada com uma árvore na rede, realizamos uma estatistica do número de ligações e dos tipos de vértices. Esta análise nos permite determinar a transição finita-infinita bem como um tipo de transição de rugosidade na superficie do polímero. Obtemos as dimensões fractais dos aglomerados ("clusters") na transição finita-infinita (os resultados são diferentes daqueles obtidos por Lucena et al. (1994) e o motivo disto será explicado no texto). Também estudamos a evolução temporal dos aglomerados. Calculamos o tempo médio de vida dos aglomerados finitos, a função de autocorrelação temporal de suas massas e os 
expoentes críticos dinâmicos correspondentes. Uma seção é dedicada à análise dos efeitos de tamanho finito: para várias concentrações de impurezas, utilizamos uma técnica de cumulantes de quarta ordem (Binder, 1981, 1987, 1990; Kaski et al., 1984; Landau e Binder, 1985) para obter as probabilidades de ramificação críticas $b_{c}$ e para estimar os expoentes criticos $\beta$ e $v$ associados, respectivamente, ao parâmetro de ordem e ao comprimento de correlação do sistema. Finalmente, na ausência de impurezas, descrevemos a rugosidade da superficie do polimero em termos dos expoentes de Hurst.

\subsection{TOPOLOGIA E DIMENSÃO FRACTAL}

\subsubsection{O MODELO}

Simulamos um modelo de crescimento cinético (com probabilidade de bifurcação $b$ ) numa rede quadrada $L \times L$ com concentração $c$ de impurezas aleatoriamente distribuídas. Em cada experimento, a polimerização ramificada é simulada de acordo com as regras descritas na seçāo 5.2.2.1 e com a seguinte diferença: o processo de crescimento do polimero é mantido enquanto pelo menos uma das extremidades do aglomerado estiver ativa (internamente aos limites da rede). Na forma original proposta por Lucena et al. (1994), o processo deve ser interrompido no instante em que alguma das extremidades de crescimento tocar a fronteira da rede pela primeira vez. Assim, em nossas simulações, as configurações finais não possuem sítios ativos. Esta diferença é importante e será comentada posteriormente. Quando uma extremidade do polímero estiver sobre a fronteira da rede $\mathrm{e}$ escolher um sentido de crescimento direcionado para o exterior, então consideramos tal extremidade como sendo um sítio inativo. Se um aglomerado tocar a fronteira uma (ou mais) vezes, este será denominado polimero infinito. 


\subsubsection{ASPECTOS TOPOLÓGICOS}

Durante o crescimento do polímero, podemos identificar cada uma de suas configurações com uma árvore-ligação ("bond tree”), ou seja, com um animal fracamente embebido na rede e que não possui ciclos (ver classificação dos animais na rede na seção 3.3.2). A recíproca nem sempre é verdadeira: nem toda árvore-ligação corresponde a uma configuraçāo gerada pelo modelo de crescimento de polímeros ramificados. Por exemplo, o subgrafo conectado mostrado na Figura 6.1 é uma árvore-ligação cuja configuração não pode ser gerada (em nenhum instante $t$ ) pelas regras de crescimento descritas na seção 5.2.2.1 (para $c=0)$.

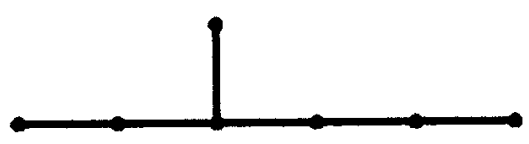

Figura 6.1: Um subgrafo conectado sem ciclos (árvore-ligaçăo), que nåo corresponde a nenhuma configuração possivel gerada pelo modelo de crescimento cinético com $b \neq 0$ e $c=0$.

As árvores na rede podem ser classificadas de acordo com o número $n$ de ligações e o número $n_{k}$ de vértices com $k$ ligações. Por exemplo, a árvore na Figura 6.1 possui $n=6, n_{1}=3$ (número de extremidades livres), $n_{2}=3, n_{3}=1$ e $n_{4}=0$. Desde que cada ligação conecta dois vértices, há dois vinculos relacionando os $n_{k}$ (Camacho et al., 1992):

$$
\sum_{k} n_{k}=n+1
$$

e

$$
\sum_{k} k n_{k}=2 n
$$


Adicionalmente a esta classificação, Camacho et al. (1992) também consideraram o número $n_{b}$ de dobras ("bends") nos seguimentos lineares de uma árvore; na rede quadrada, uma dobra é definida como sendo um sítio onde duas (e somente duas) ligações se unem em ângulo reto. Camacho et al. realizaram uma enumeraçāo exata das árvores em várias redes bidimensionais, como função do números $n, n_{b}, n_{1}$ e $n_{3}$. A enumeração está consistente com outros dados disponiveis na literatura, que foram previamente publicados por Gaunt et al. (1984) e Privman e Redner (1987).

Retornando ao modelo de crescimento de polímeros ramificados em estudo, denotamos por $N(t)$ o número de ligações ocupadas até o instante $t$ (na Figura 5.2, $N(0)=0, N(1)=1, N(2)=3, N(3)=6$, $N(4)=10 \ldots$. E E claro que $N(t)$ depende também da probabilidade de ramificação $b$. Obviamente, se o polímero for linear $(b=0)$ então $N(t)=t$.

No limite termodinâmico $(L \rightarrow \infty), \quad N(t)$ pode crescer indefinidamente com $t$ (regime de crescimento infinito) ou pode parar num determinado instante $t$ (regime de crescimento finito). Similarmente, definimos $N_{k}(t)$ como sendo o número de vértices com $k$ ligações. Uma vez que as trifurcações não podem ocorrer, temos $N_{4}(t)=0$.

Identificando a configuração polimérica (no instante $t$ ) com uma ărvore-ligação e empregando as equações (6.1) e (6.2), temos

$$
N_{1}(t)=N_{3}(t)+2
$$

e

$$
N_{2}(t)=N(t)-2 N_{3}(t)-1,
$$

onde escolhemos $N(t)$ e $N_{3}(t)$ como variáveis independentes.

Em nossas simulações, calculamos estas quantidades para todo instante $t$. Lembremos que a passagem de $t$ para $t+1$ ocorre somente 
depois que todos sítios ativos no estágio $t$ tenham sido consultados sobre sua probabilidade de bifurcar. Calculamos as médias $N(t)$ e $N_{3}(t)$ sobre um grande número de experimentos $N_{e}$. Para $c \neq 0$, escolhemos inicialmente uma distribuição aleatória de impurezas. Sobre esta configuração congelada, realizamos um número $N_{q}$ de experimentos ("quenched"). Então, uma nova configuraçāo de impurezas é selecionada e mais $N_{q}$ simulaçōes são feitas. Repetimos este processo $N_{a}$ vezes ("annealed"), de modo que o número total de experimentos $N_{e}$ é igual a $N_{a} \times N_{q}$. A forma "annealed" é simulada para evitar conclusões tendenciosas quando $c$ é alto. A dependência temporal de $N(t)$ e $N_{3}(t)$ será estudada na próxima seção.

Para investigar as propriedades estáticas (ao término do crescimento do aglomerado), calculamos o número $N$ de ligações e o número $N_{3}$ de vértices com 3 ligaçōes no instante final do processo de crescimento. Sobre o conjunto de todos os experimentos, obtemos seus valores médios $\langle N\rangle$ e $\left\langle N_{3}\right\rangle$.

Definimos o parâmetro de ordem do sistema como sendo a razão entre a massa média dos aglomerados e sua área acessível:

$$
\langle\rho\rangle=\frac{\langle N+1\rangle}{(1-c) L^{2}} .
$$

Originariamente, o parâmetro de ordem foi definido como sendo a fração $\left\langle\rho_{0}\right\rangle$ de polímeros infinitos no total de experimentos (Lucena et al., 1994). De acordo com esta definição, em um único experimento, o parâmetro de ordem é discreto, isto é, vale $\rho_{0}=1$, se o polímero for infinito, ou $\rho_{0}=0$, caso contrário. Há, portanto, uma grande flutuação deste parâmetro de ordem. No presente trabalho, pretendemos localizar o ponto crítico da transição finita-infinita através de um método de intersecção de cumulantes (ver seção 6.4). Para isto, devemos calcular o cumulante $U_{L}$ da distribuição de probabilidade do parâmetro de ordem (definido em (6.13)) e, assim, a definição dada na equação (6.5) é mais 
apropriada, uma vez que nosso parâmetro de ordem $\rho$ é contínuo e medido em uma situação estática de equilíbrio. Deveras, $\rho$ é calculado quando já não mais existem sítios ativos na rede. Na seção 6.2.3, também calculamos a dimensão fractal em uma situação estática de equilíbrio. Os resultados obtidos nesta situação estática final são mais estáveis.

No limite termodinâmico $(L \rightarrow \infty)$ e na fase finita, ambas as definições de parâmetro de ordem coincidem: $\langle\rho\rangle \rightarrow 0$ e $\left\langle\rho_{0}\right\rangle \rightarrow 0$. O "locus" onde o parâmetro de ordem se anula define uma linha crítica $b=b_{c}(c)$ no espaço $(b, c)$.

A Figura 6.2 mostra a variação do parâmetro de ordem $\langle\rho\rangle$ como função de $b$ para diferentes concentrações de impurezas. Podemos observar uma transição ("bulk") que separa os regimes de crescimento finito e infinito.

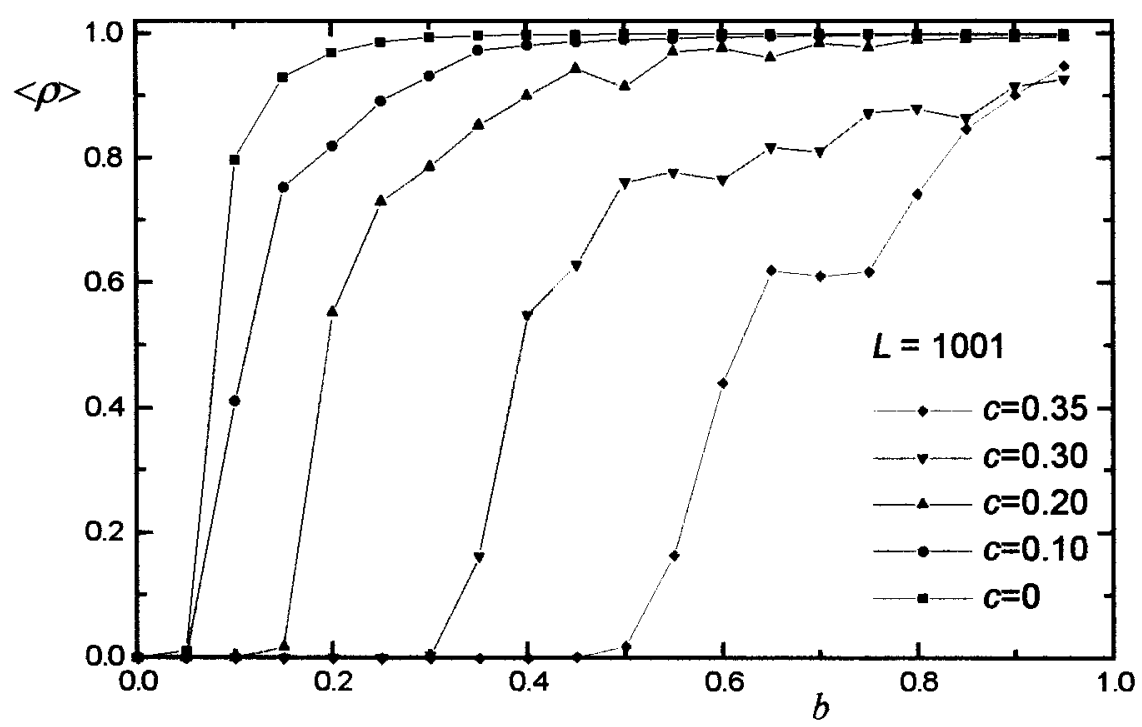

Figura 6.2: Parâmetro de ordem $<\rho>$ como função de $b$, para $c=0,0.10$, $0.20,0.30$ e 0.35 . As simulaçōes foram realizadas em uma rede quadrada de tamanho $L=1001$.

Enquanto $\langle N\rangle$ é uma função monotonicamente crescente de $b$ $\left(b>b_{c}\right),\left\langle N_{3}\right\rangle$ passa por um máximo em $b \approx 0.2$ para $c=0$, conforme 
podemos observar na Figura 6.3. À primeira vista, este fato parece ser contraditório uma vez que poderíamos esperar que $\left\langle N_{3}\right\rangle$ também fosse uma função monotonicamente crescente. Se visualizarmos a simulação do crescimento do aglomerado, notaremos que (em $b \approx 0.2$ ) ocorre um alisamento de sua superficie e que esta adquire o formato de um losango. O máximo é um indício de que uma transição de rugosidade está ocorrendo ${ }^{1}$. A origem da transição parece ser de natureza geométrica. Se $b \rightarrow 1$, então cada sítio ativo tenderia a bifurcar de um modo similar ao que ocorreria numa árvore de Cayley (com ramificação $r=2$ ). Mas esta árvore de Cayley não pode ser embebida na rede quadrada.

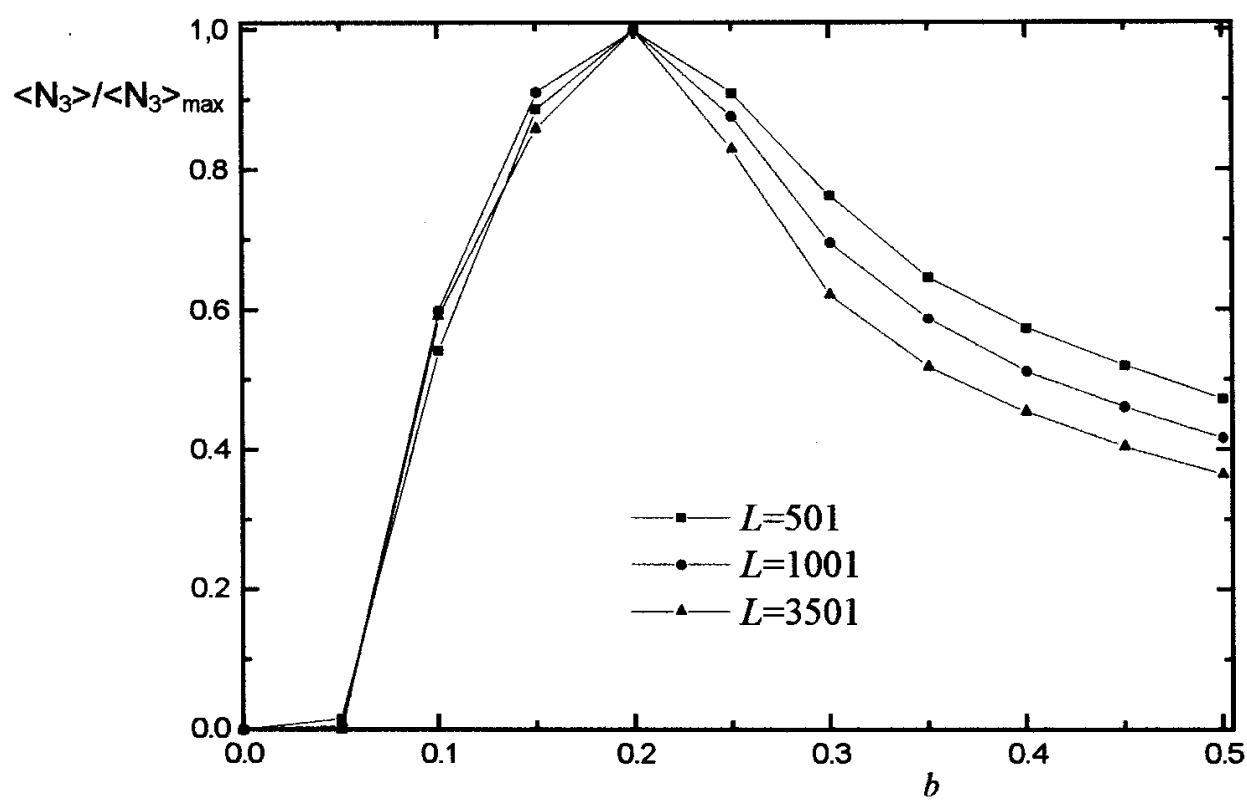

Figura 6.3: $\left\langle\mathrm{N}_{3}>\left\langle\mathrm{N}_{3}\right\rangle_{\max }\right.$ versus $b$ para $c=0$, onde $\left\langle\mathrm{N}_{3}\right\rangle_{\max }$ é o máximo valor de $\left\langle N_{3}>\right.$. Os resultados relativos a $L=3501$ foram gerados em um CRAY.

Para ilustrar o alisamento da superficie, numa pequena rede quadrada $(L=51)$ sem impurezas $(c=0)$, simulamos o modelo de crescimento cinético com probabilidade de bifurcação $b=0.5>0.2$. Na Figura 6.4, mostramos uma "fotografia do polimero" em crescimento, no instante em que este toca a fronteira. Deveras, podemos visualizar que

\footnotetext{
1 Agradecemos a L. S. Lucena e seu grupo por nos comunicar este fato.
} 
a superficie tende a adquirir o formato de um losango (fase "lisa"). Este efeito torna-se diluído na presença de impurezas e mais acentuado com o aumento do tamanho da rede.

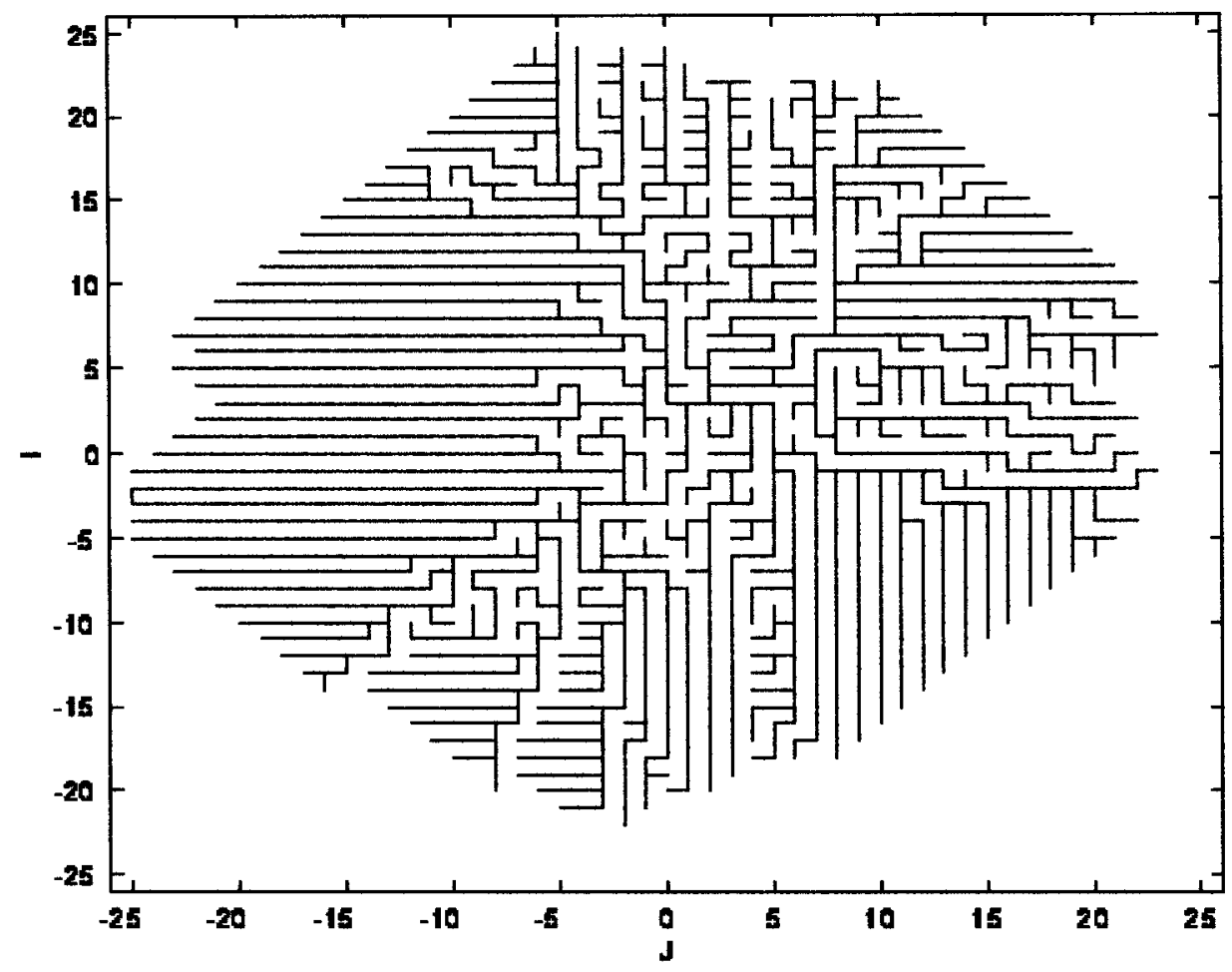

Figura 6.4: Configuração de um aglomerado de sítios conectados gerado em uma simulação do modelo de crescimento cinético com $b=0.5, c=0$ e $L=51$. A figura equivale a uma "fotografia do polimero" em crescimento, no instante em que este toca a fronteira. Para este valor de $b$ (maior que $b=0.2$ ) e conforme 0 aglomerado cresce, podemos visualizar que sua superficie tende a adquirir o formato de um losango (fase "lisa").

\subsubsection{DIMENSÃO FRACTAL}

De acordo com a definição de Mandelbrot, um fractal ê uma forma constituida de partes similares ao todo (Mandelbrot, 1986). Um objeto fractal com massa $M$ e comprimento caracteristico $l$ (por exemplo, seu raio de giração) obedece à equação $M \propto l^{D_{F}}$, onde o expoente $D_{F}$ é a dimensão fractal, que é usualmente diferente da dimensão Euclidiana $d$ da rede. Na caminhada aleatória simples (seção 3.2.1), a massa é proporcional ao número de passos e, portanto, varia com a distância quadrática média entre as extremidades da cadeia, significando que a 
dimensão fractal é 2 (em $d=2$ ou $d=3$ ). Na teoria de percolação (Stauffer, 1985), os "clusters", no limite de percolação, são fractais com dimensões fractais $1.896(d=2)$ e $2.5(d=3)$.

A dimensão fractal $D_{F}$ do polímero ramificado pode ser obtida através de

$$
\langle N\rangle \propto \xi^{D_{F}} \quad,
$$

onde $\xi$ é o comprimento de correlação medido da forma proposta por Lucena et al. (1994): ao término de um particular experimento, os tamanhos $l_{x}$ e $l_{y}$ do menor retângulo que contém um polímero finito é determinado e $\xi \equiv\left\langle\left(l_{x} l_{y}\right)^{1 / 2}\right\rangle$.

Próximo a $b_{c}$, temos

$$
\langle\rho\rangle \sim\left|b-b_{c}\right|^{\beta}
$$

$\mathrm{e}$

$$
\xi \sim\left|b-b_{c}\right|^{-v}
$$

onde $\beta$ e $v$ são expoentes críticos.

Das equações (6.5) e (6.6) obtemos $\langle\rho\rangle \propto \xi^{D_{F}-2}$. A substituição das leis de potência (6.7) e (6.8) na última relação resulta em $|b-b|^{\beta+\left(D_{F}-2\right) v} \propto$ constante. Isto resulta na famosa relação de escala

$$
D_{F}=2-\frac{\beta}{v},
$$

válida para $d=2$ (Stauffer, 1985).

Obtemos as dimensões fractais atravês das inclinações dos gráficos $\log -\log$ da massa $\langle N\rangle+1$ versus $L(L=161,181,201,221 \mathrm{e} 241) \mathrm{em}$ $b \approx b_{c}$ para muitas concentraçōes $c$ e $N_{e} \sim 10^{5}$. Os $b_{c}$ são estimados utilizando-se um método de cumulantes (ver seção 6.4). Uma técnica de regressão linear é utilizada para determinar $D_{F}$ e seu erro (ver 
Tabela 6.1). A Figura 6.5 mostra o gráfico logarítmico da massa versus $L$ para $c=0$.

\begin{tabular}{|c|c|}
\hline \multicolumn{1}{|c|}{ P } \\
\hline $\boldsymbol{c}$ & $\boldsymbol{D}_{\boldsymbol{r}}$ \\
\hline 0 & $1.963 \pm 0.006$ \\
\hline 0.1 & $1.946 \pm 0.002$ \\
\hline 0.2 & $1.928 \pm 0.007$ \\
\hline 0.3 & $1.87 \pm 0.05$ \\
\hline
\end{tabular}

Tabela 6.1: Dimensões Fractais

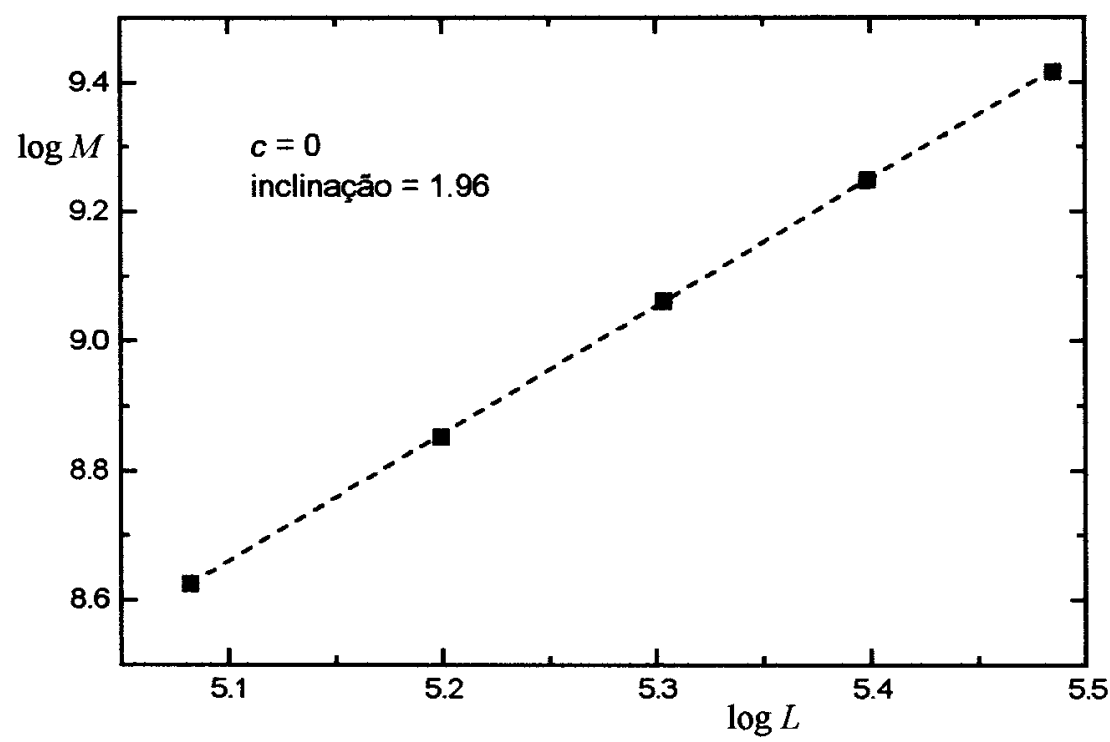

Figura 6.5: Gráfico logarítmico de $M=<N>+1$ versus $L$. A inclinaçăo é a dimensão fractal para $c=0$.

A Tabela 6.1 deve ser comparada com os resultados obtidos por Lucena et al. (1994), os quais apontam para uma dimensão fractal que varia monotonicamente de $1.83(\mathrm{em}(b, c)=(0.055,0))$ para 1.76 (em $(b, c)=(1,0.4072))$, ainda que a possibilidade de uma única classe de universalidade não esteja descartada. A discrepância entre estes valores e os nossos é devida às diferentes medidas de massa que foram realizadas para o cálculo da dimensão fractal. Em nossa determinação da dimensão fractal, esperamos até que toda a rede se torne uma zona 
morta. Nos modelos de crescimento, geralmente são definidas as zonas ativa e morta e isto permite determinar uma interface precisa. Muitos modelos têm zonas ativa e morta determinadas de uma maneira aproximada (por exemplo, DLA - Witten e Sander, 1981). Lucena et al. (1994) analisaram os parâmetros fisicos e expoentes críticos enquanto o sistema estava ainda ativo. Por outro lado, nossa análise é baseada em uma situação estática final, quando então não há mais sítios ativos na rede quadrada.

\subsection{DINÂMICA}

\subsubsection{DEPENDÊNCIA TEMPORAL DA MASSA}

Investigamos a evolução temporal das massas dos aglomerados como funções de $b$ e $c$. Em todos os casos, observamos que a massa média $(M=\langle N\rangle+1)$ do polímero evolui obedecendo à lei de potência assintótica

$$
\langle N(t)\rangle \sim t^{\theta},
$$

conforme é mostrado na Figura 6.6(a). Neste gráfico, o limite máximo no eixo $\log (t)$ corresponde a um tempo $t$ médio que o aglomerado necessita para atingir a fronteira. Também apresentamos a variação de $\theta$ em função de $b$ na Figura 6.6(b), para um sistema finito de tamanho $L=1001$. O expoente parte de $\theta=1$ em $b=0$, aumenta até um valor máximo e então converge para $\theta=2$ conforme $b$ tende a 1 . O pico ocorre logo acima do ponto crítico $b_{c}$ estimado (para $c=0, b_{c} \approx 0.059$ ), indicando que a massa aumenta mais rapidamente. Este comportamento é também verificado em outras concentraçōes de impurezas. Ao longo de pontos sobre a linha crítica $\left(b_{c}(c), c\right)$ (ver Tabela 6.3), o expoente $\theta$ decai sensivelmente de $\theta=1.87$, em $\left(b_{c}, c\right)=(0.0585,0)$, até $\theta=1.82$, em $\left(b_{c}, c\right)=(0.361,0.3)$. 


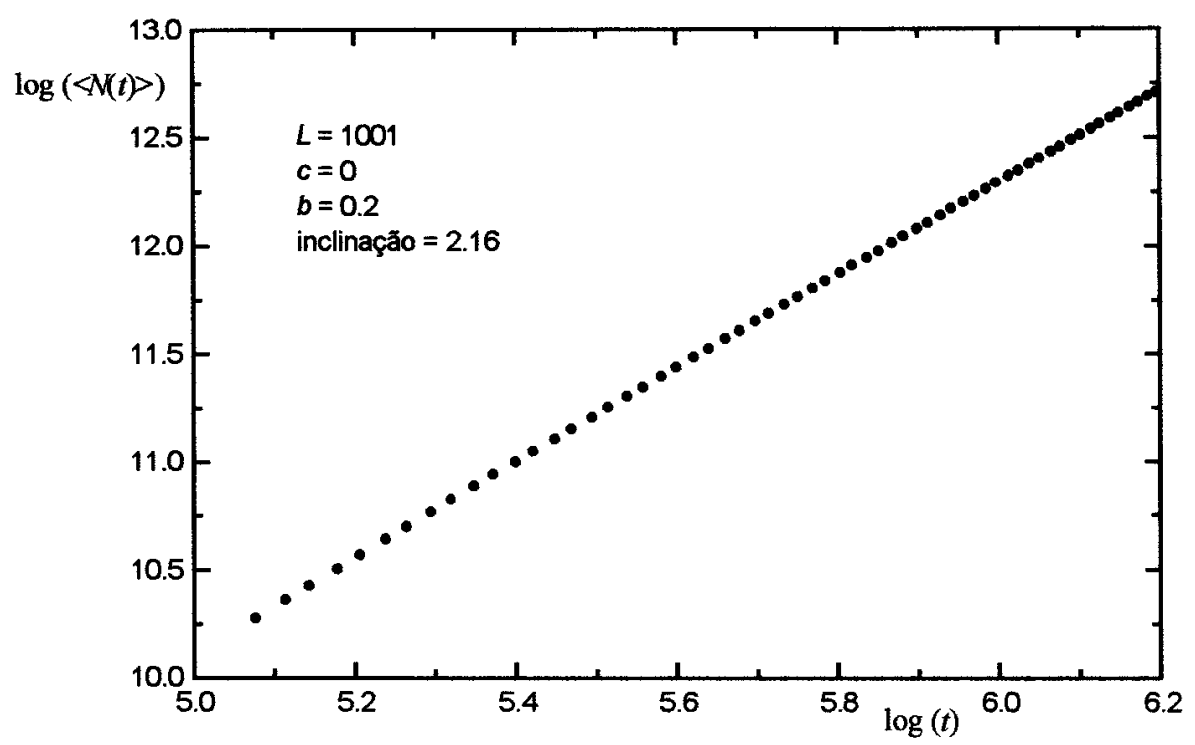

Figura 6.6(a): Típico gráfico $\log (<N(f)>)$ versus $\log (f)$.

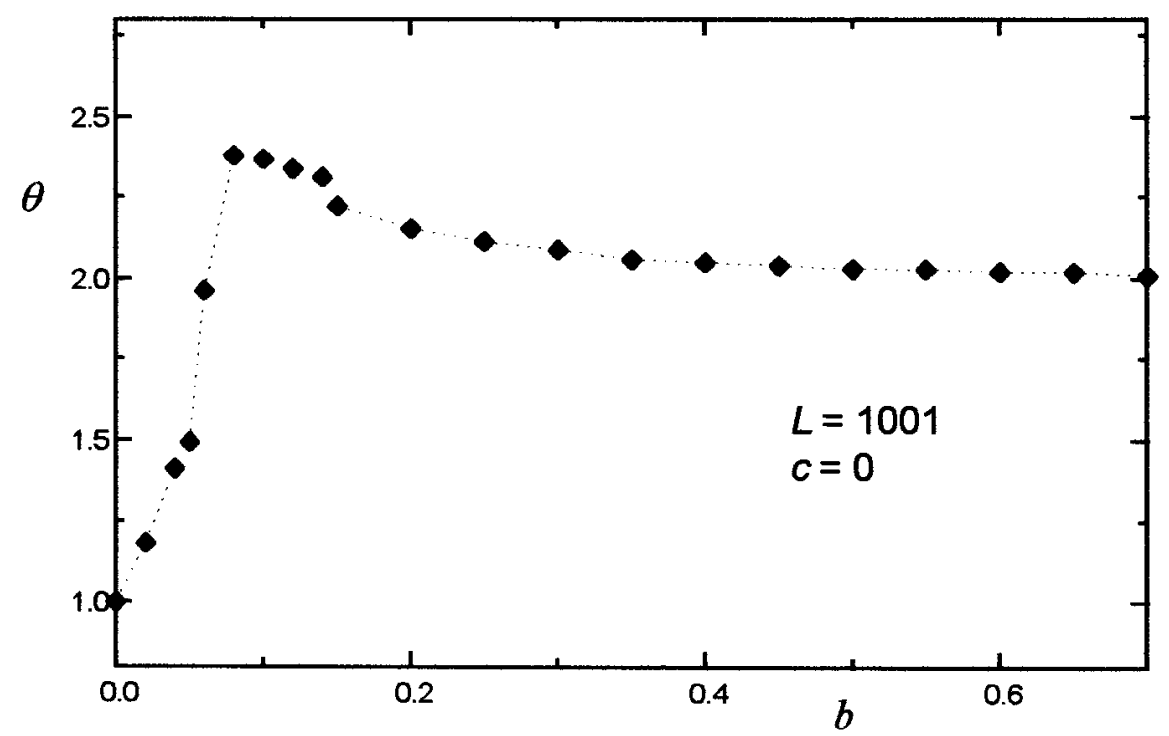

Figura 6.6(b): Variaçāo de $\theta$ versus b.

Exceto no caso em que $b=0$ (onde $\left\langle N_{3}(t)\right\rangle=0$ ), o número de vértices com 3 ligações também segue uma lei de potência assintótica, $\left\langle N_{3}(t)\right\rangle \sim t^{\theta_{3}}$, com $\theta_{3}(b)$ apresentando um comportamento similar ao de $\theta(b)$.

Seria interessante analisar o comportamento de $\theta(b)$ no limite termodinâmico. A partir de medidas de $\theta(b)$ realizadas em redes com tamanhos finitos $L$ cada vez maiores, os resultados então poderiam ser extrapolados no limite $L \rightarrow \infty$. 


\subsubsection{TEMPO MÉDIO DE VIDA}

Podemos identificar no sistema dois tempos caracteristicos, $T_{i} \mathrm{e}$ $T_{f}$. $T_{i}$ é o tempo médio para os aglomerados infinitos tocarem a fronteira. $T_{f}$ corresponde ao tempo médio de vida dos aglomerados finitos.

$\mathrm{Na}$ Figura 6.7, apresentamos $T_{f}$ versus $b$, onde podemos claramente observar um pico estreito sobre o ponto crítico estimado $b_{c}$ $(c=0.2)$. Para $b<b_{c}$, há uma predominância de aglomerados finitos com um pequeno número de bifurcações. Conseqüentemente, as extremidades de crescimento são escassas e os efeitos de obstrução estéricas podem ser fatais. Logo, o tempo médio de vida é curto. Para $b>b_{c}$, a maioria dos aglomerados são infinitos desde que as bifurcações são eventos freqūentes. Portanto, para que um aglomerado permaneça finito, deverá morrer o quanto antes, caso contrário nunca o fará. Novamente, o tempo médio de vida é curto.

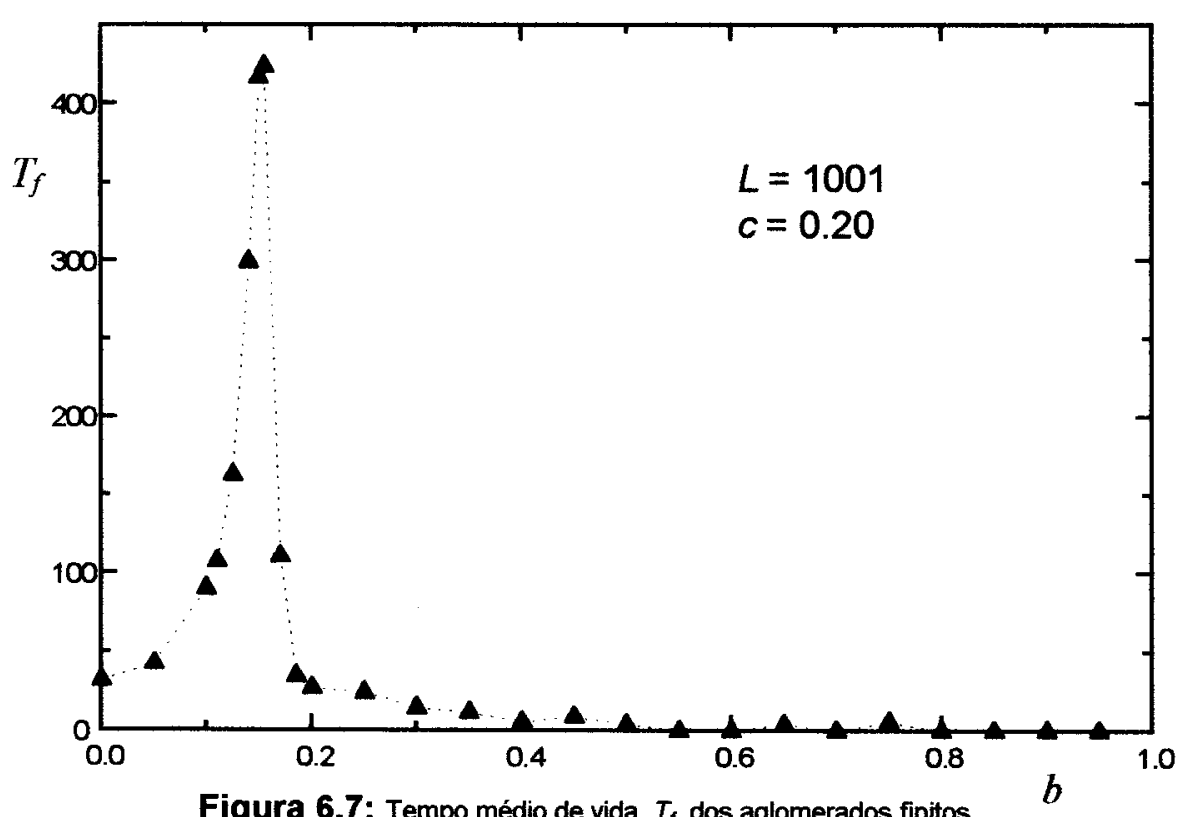

Figura 6.7: Tempo médio de vida $T_{f}$ dos aglomerados finitos. 


\subsubsection{ESTATÍSTICA DE AGLOMERADOS}

Podemos também estudar como o conjunto de aglomerados evolui no tempo. Para cada instante $t$, em um total de 100 experimentos, contamos o número de aglomerados finitos que tenham permanecido ativos até então, mais o número de aglomerados infinitos que ainda não tenham tocado a fronteira. Os resultados são apresentados na Figura 6.8 para $L=1001$ e $c=0.2$.

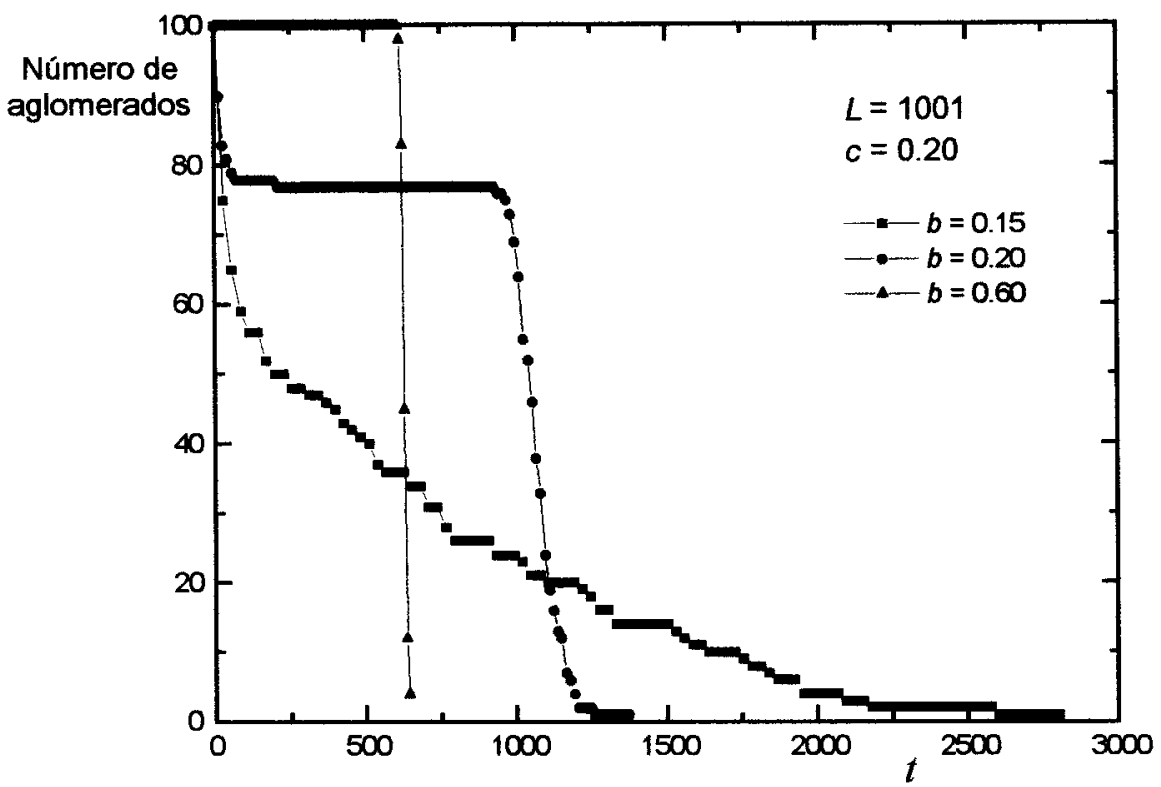

Figura 6.8: Número de aglomerados (= número de aglomerados finitos ativos + número de aglomerados infinitos que ainda não tocaram a fronteira) no instante $t$.

Uma vez que há uma mudança notória do decaimento suave em $b=0.15$ para o aparecimento de um platô em $b=0.20$, esperamos encontrar uma transição de fase neste intervalo. Deveras, antecipamos (da seção 6.4) nossa estimativa do ponto critico: $b_{c}=0.168$.

Analisemos o que se passa de uma maneira mais profunda. Primeiramente, para $b<b_{c}$ (fase finita) há poucos aglomerados infinitos enquanto que os finitos não são todos necessariamente efêmeros, desde 
que a probabilidade de ramificação, embora pequena, é não nula. Isto é, os tempos médios de vida dos aglomerados finitos estão amplamente distribuídos conforme pode ser visto na curva $b=0.15$ na Figura 6.8. Por outro lado, para $b>b_{c}$, os aglomerados finitos são efêmeros $\mathrm{e}$ responsáveis pela primeira queda da curva $b=0.20 \mathrm{em} t \sim T_{f}=30$. Há 22 aglomerados finitos. Os restantes são infinitos e tocarão a fronteira em $t \sim T_{i}=1100$. Deste modo, a largura do platô pode ser interpretada como a diferença $T_{i}-T_{f}$. Claramente, o mesmo raciocínio pode ser facilmente aplicado ao caso $b=0.60$.

\subsubsection{FUNĢÃO DE AUTOCORRELAÇÃO TEMPORAL}

Um outro problema importante consiste em encontrar o tempo de descorrelação $\tau_{d}$ do sistema. Para este propósito, calculamos a função de autocorrelação temporal da massa. Em um experimento particular, esta função é definida como

$$
C(\tau)=\frac{\langle M(t) M(t+\tau)\rangle-\langle M(t)\rangle^{2}}{\left\langle[M(t)]^{2}\right\rangle-\langle M(t)\rangle^{2}},
$$

onde $M(t)=N(t)+1$ é a massa do polimero e as médias são realizadas sobre o tempo. A função está normalizada de modo que $C(0)=1$.

O comportamento da função de autocorrelação temporal da massa, $\langle C(\tau)\rangle$ (aqui \langle\rangle significa uma média sobre todos os experimentos), versus $\tau$ é apresentado na Figura 6.9. Em $\tau=0$ as massas estão completamente correlacionadas. $\langle C(\tau)\rangle$ decai a zero se $\tau$ for suficientemente grande. O tempo de descorrelação é determinado através de $C\left(\tau_{d}\right)=0$. Observando as três curvas, está claro que conforme aproximamos o ponto critico estimado $\left(b_{c} \approx 0.058\right)$ o tempo característico $\tau_{d}$ aumenta cada vez mais, o que é uma manifestação do fenômeno "critical slowing down" (Binney et al., 1992). 


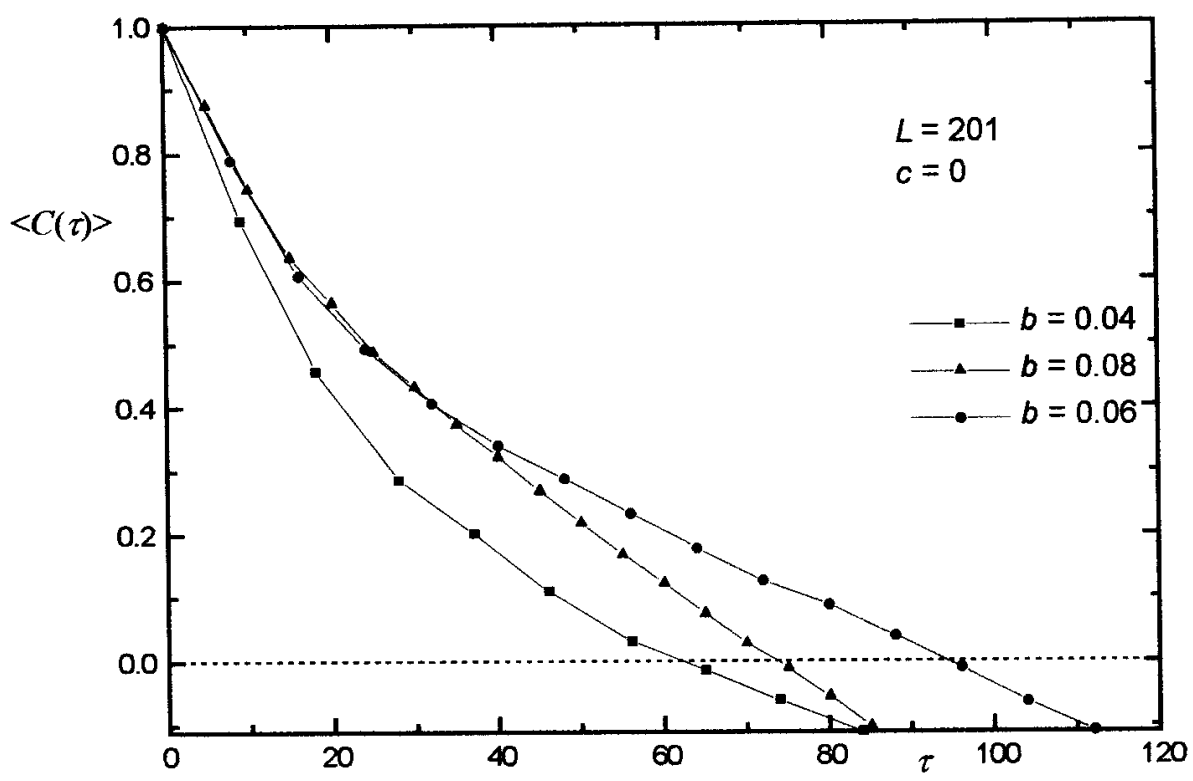

Figura 6.9: Função de autcorrelaçăo temporal da massa $\langle\mathrm{C}(\tau)>$.

\subsubsection{EXPOENTE CRÍTICO DINÂMICO}

Conforme a transição se aproxima, o comprimento de correlação $(\xi \propto L)$ também aumenta. Empiricamente, encontra-se que o tempo de descorrelação $\tau_{d}$ está relacionado ao comprimento de correlação por uma relação da forma

$$
\tau_{d}=\xi^{z},
$$

onde $z$ é conhecido como expoente crítico dinâmico.

Verificamos esta relação em $b \approx b_{c}$ e estimamos $z$ para muitas concentrações e tamanhos de rede. A Figura 6.10 ilustra o gráfico $\log -\log$ para $c=0$ enquanto a Tabela 6.2 apresenta os expoentes críticos dinâmicos estimados. Conforme $c$ aumenta e dentro dos erros estimados, podemos observar que $z$ tem uma tendência a decair. 


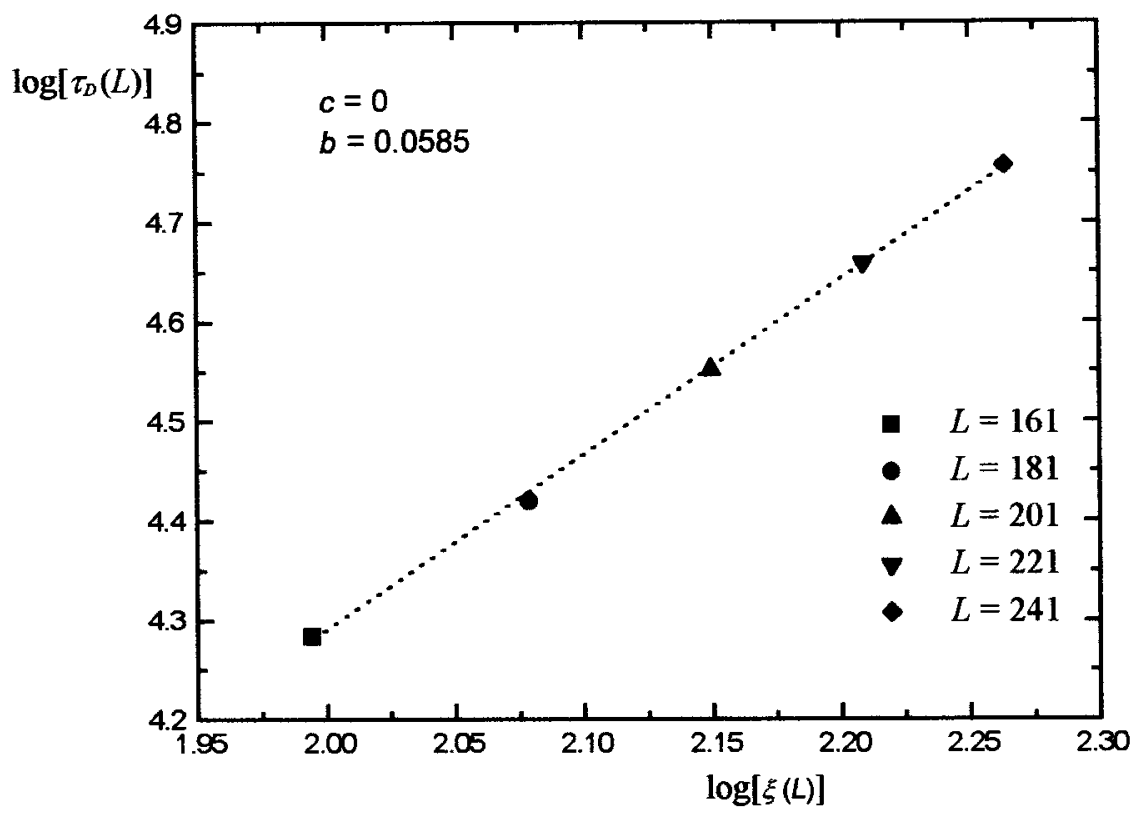

Figura 6.10: Gráfico $\log -\log$ do tempo de descorrelação $\tau_{D}(L)$ versus comprimento de correlação $\xi(L)$.

\begin{tabular}{|c|c|}
\hline c & $z$ \\
\hline 0 & $1.75 \pm 0.03$ \\
\hline 0.1 & $1.76 \pm 0.05$ \\
\hline 0.2 & $1.68 \pm 0.12$ \\
\hline 0.3 & $1.53 \pm 0.16$ \\
\hline
\end{tabular}

Tabela 6.2: Expoentes Críticos Dinámicos. 


\subsection{EFEITOS DE TAMANHO FINITO}

Utilizamos agora a teoria fenomenológica de "finite size scaling" para estimar $b_{c}$ e os expoentes críticos (Binder, 1990). O método empregado é baseado em uma análise da função de distribuição de probabilidade do parâmetro de ordem (Binder, 1981, 1987) que apresenta uma mudança substancial no ponto crítico. Uma medida conveniente desta mudança é fornecida pelo cumulante de quarta ordem $U_{L}$ da distribuição. No Anexo, estudamos amplamente o método de intersecção de cumulantes para localização do ponto crítico de um sistema.

Em nosso estudo, o cumulante de quarta ordem normalizado pode ser escrito como

$$
U_{L}=1-\frac{\left\langle\rho^{4}\right\rangle_{L}}{3\left\langle\rho^{2}\right\rangle_{L}^{2}}
$$

para um sistema de tamanho $L$.

Na fase ordenada do sistema $\left(b>b_{c}\right)$ e para $b \rightarrow 1$, esperamos que a função de distribuição de probabilidade do parâmetro de ordem apresente um máximo em $\langle\rho\rangle \approx 1 \mathrm{e}$, neste caso, um raciocínio análogo ao demonstrado no Anexo, permite concluir que $U_{L} \rightarrow$ constante positiva. Por outro lado, quando $b \rightarrow 0$, na fase desordenada, o máximo tende a $\langle\rho\rangle=0$ e o cumulante $U_{L} \rightarrow 0$ (decrescendo com o aumento de $L)$. Além disso, para $b \approx b_{c}$, uma hipótese de escala que conduza a $U_{L}=\widetilde{U}(L / \xi)$ (tal como no caso de sistemas magnéticos - ver Anexo) implica no fato de que, exatamente sobre a criticalidade, $U_{L}$ tende a um valor fixo $U^{*}$. Como resultado, os gráficos de $U_{L}$ para diferentes tamanhos de $L$ devem interceptar o mesmo $U^{*}$, fornecendo uma estimativa do ponto crítico. 
Um gráfico logarítmico dos cumulantes de quarta ordem $U_{L}$ versus $b$ para vários tamanhos de rede $(\mathrm{e} c=0)$ é mostrado na Figura 6.11. As curvas interceptam-se entre si em um ponto que estimamos como $b_{c}$.

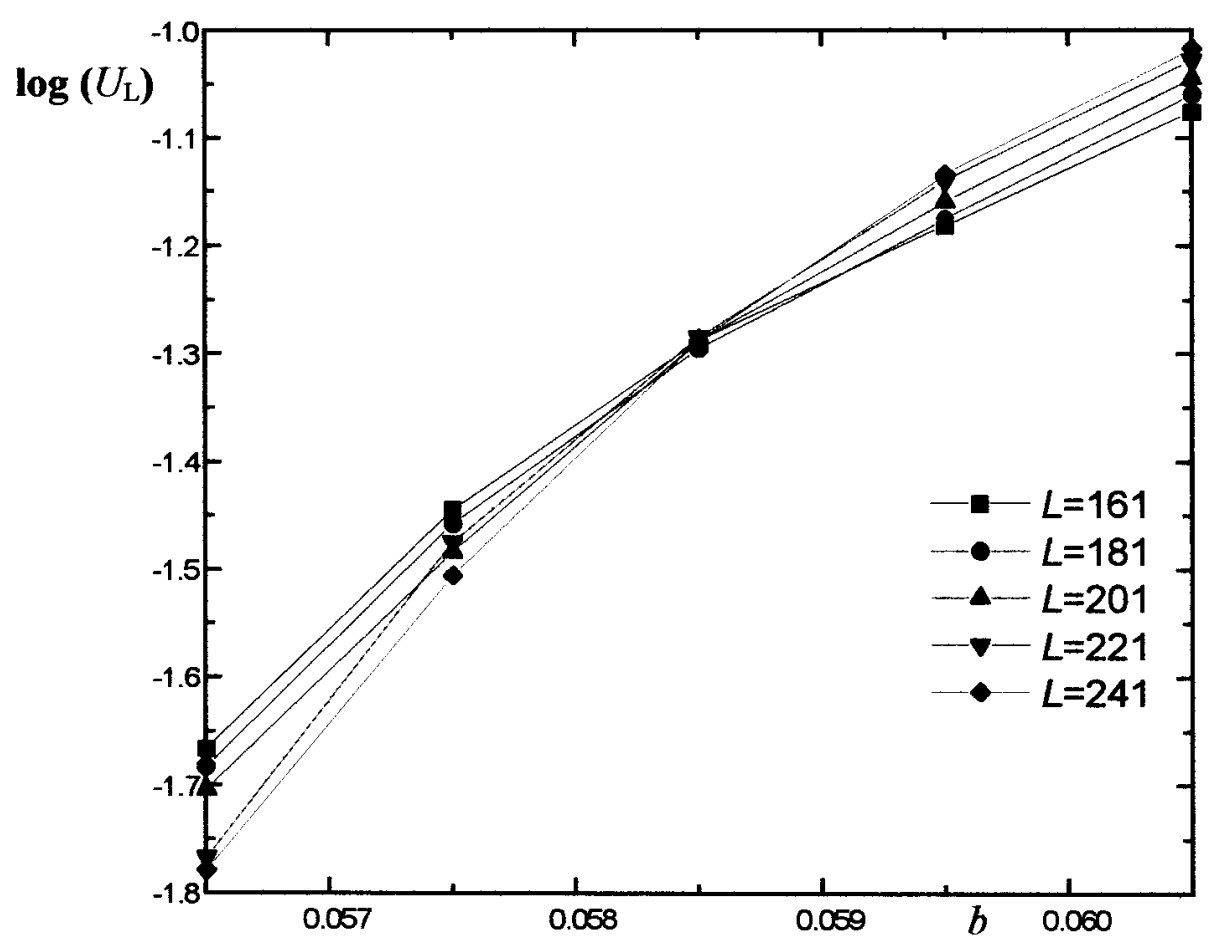

Figura 6.11: Cumulante de quarta ordem $U_{L}$ versus $b$, para $c=0$ e tamanhos $L=161,181,201,221$ e 241. A intersecção das curvas nos permite estimar $b_{c}=0.0585 \pm 0.0002$.

A escolha particular do conjunto $L=161, \ldots, 241$ resulta de um compromisso entre o máximo tamanho $L$ que na prática pode ser simulado (com um erro estatístico aceitável) e o valor mínimo de $L$ onde as formas assintóticas assumidas acima são confiâveis.

Como um aumento da concentração de impurezas também é acompanhado por um aumento de seu erro estatístico, simulamos números diferentes de experimentos: $N_{e} \sim 10^{5}, 2 \times 10^{5}, 3 \times 10^{5}, 3 \times 10^{5}$ respectivamente em $c=0,0.1,0.2,0.3$.

A Tabela 6.3 mostra os valores estimados de $b_{c}$ para algumas concentraçōes. Os valores centrais foram obtidos através da média de 
todos pontos de intersecção. Os erros são os desvios padrōes. Observase um aumento consistente da probabilidade de ramificação crítica a fim de compensar a limitação de crescimento imposta pela presença de impurezas. Nossas estimativas de $b_{c}$ são ligeiramente maiores do que aquelas previamente obtidas por Lucena et al. (1994) (por exemplo, $b_{c}=0.055$ para $c=0$ ).

\begin{tabular}{|c|c|c|}
\hline & \multicolumn{3}{|c|}{ b } \\
\hline $\boldsymbol{c}$ & $\boldsymbol{b}_{\boldsymbol{c}}$ & $\boldsymbol{v}$ \\
\hline 0 & $0.0585 \pm 0.0002$ & $1.63 \pm 0.12$ \\
\hline 0.1 & $0.0915 \pm 0.0006$ & $1.42 \pm 0.37$ \\
\hline 0.2 & $0.168 \pm 0.002$ & $1.54 \pm 0.49$ \\
\hline 0.3 & $0.361 \pm 0.007$ & $1.32 \pm 0.47$ \\
\hline
\end{tabular}

Tabela 6.3: Estimativas de $b_{c}$ e expoentes criticos $v$.

Para estimar $v$ (ver Anexo; Binder, 1987, 1990) podemos expandir

$$
\begin{aligned}
& U_{L}=\widetilde{U}(L / \xi)=\widetilde{U}\left[L^{1 / v}\left(b-b_{c}\right)\right] \\
& \approx U^{*}+U_{1}^{*} L^{1 / v}\left(b-b_{c}\right)+U_{2}^{*} L^{2 / v}\left(b-b_{c}\right)^{2}+\cdots
\end{aligned}
$$

de onde podemos obter a inclinação da curva $U_{a L}$ ( $a$ é algum fator de escala) versus $U_{L}$ em $U^{*}$

$$
\left.\frac{\partial U_{a L}}{\partial U_{L}}\right|_{U^{*}}=a^{1 / v}
$$

Para $L$ e $a L$ fixos, podemos traçar o gráfico $U_{a L}(b)$ versus $U_{L}(b)$ (para valores de $b$ próximos a $b_{c}$ ) e estimar o coeficiente angular $\left[\partial U_{a L} / \partial U_{L}\right]_{U^{*}}$ da tangente à curva sobre o ponto crítico. Para vários pares $(L, a L)$ e de acordo com (6.15), podemos estimar o expoente $v \mathrm{e}$ sua barra de erro através da regressão linear do gráfico $\log \left[\partial U_{a L} / \partial U_{L}\right]_{U^{*}}$ versus $\log a$. Os expoentes $v$ estimados são 
apresentados na Tabela 6.3 e o gráfico de $v$ versus $c$ é apresentado na Figura 6.12. Conforme a concentração $c$ aumenta, o expoente $v$ parece decair com as barras de erro aumentando. A tendência deste decaimento é consistente com o valor $v=4 / 3$ da percolação usual em $d=2$ dimensões (Stauffer, 1985).

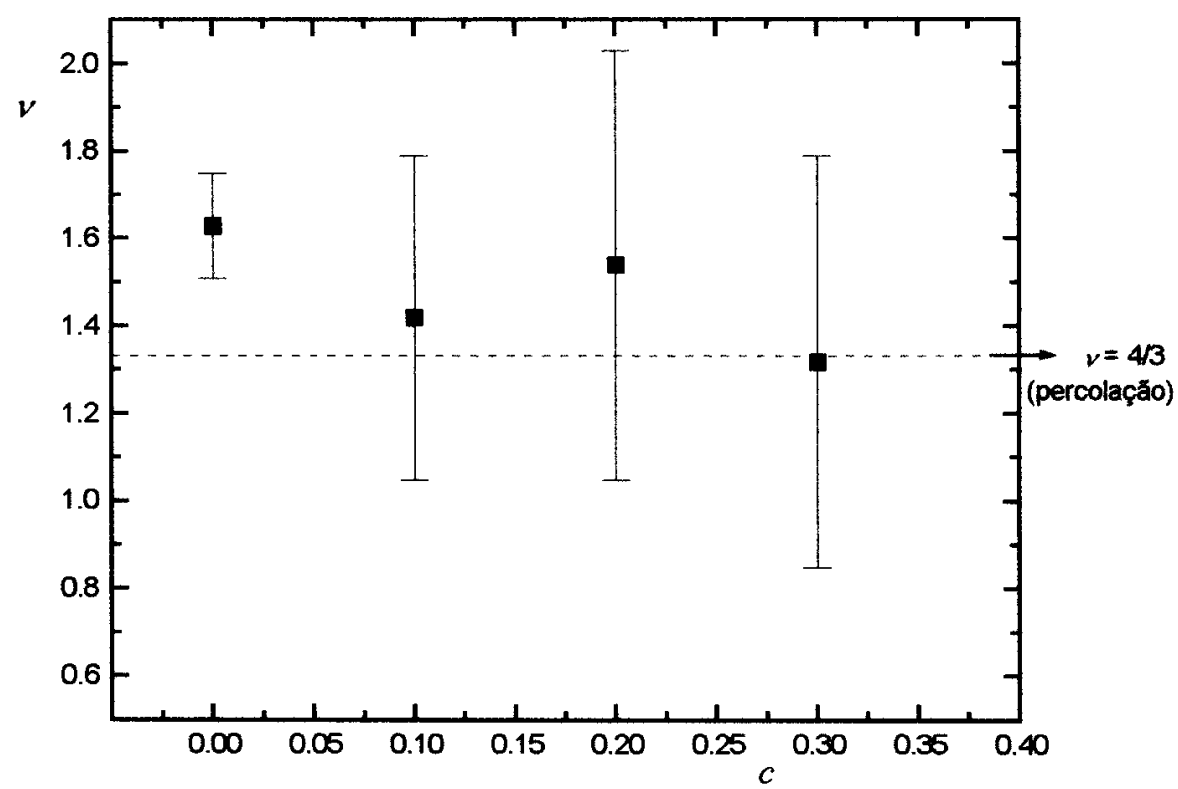

Figura 6.12: Expoente $v$ (com barra de erro) em funçăo da concentração de impurezas $c$.

Lembremos (da seção 5.2.4) que para estabelecer uma conexão entre este modelo de crescimento de polimeros ramificados $\mathrm{e}$ a percolação, devemos considerar o problema da percolação na rede quadrada com uma fração $p_{c}=0.5928$ de sítios ocupados. Se todos sítios nāo ocupados fossem associados a impurezas, então a concentração das mesmas seria $c=1-p_{c}=0.4072$. Entretanto, alguns sítios não ocupados podem nāo corresponder às impurezas mas sim a regiōes vazias, de forma que a conexão não é perfeita (Lucena et al., 1994).

O comportamento de $v$ (Tabela 6.3) juntamente com as dimensões fractais (Tabela 6.1) suportam fortemente a conjectura de uma linha crítica não universal. 
O expoente $\beta / v$ pode ser obtido a partir da razão dos segundos momentos $\left\langle\rho^{2}\right\rangle_{L, b_{c}}$ em $b_{c}$,

$$
W_{\beta}\left(b=b_{c}\right) \equiv-\frac{\ln \left[\left\langle\rho^{2}\right\rangle_{a L, b_{c}} /\left\langle\rho^{2}\right\rangle_{L, b_{c}}\right]}{\ln a} .
$$

Levando em consideração as correçōes devidas a "finite size scaling" (ver Anexo; Binder, 1981, 1987; Kaski, 1984; Landau e Binder, 1985) podemos escrever a seguinte equação:

$$
W_{\beta}\left(b=b_{c}\right) \approx \frac{2 \beta}{v}+\chi_{c} L^{-x_{c}} \frac{\left(1-a^{-x_{c}}\right)}{\ln a} .
$$

A avaliação de $W_{\beta}$ versus $(\ln a)^{-1}(a>1)$ para muitos pares $(L, a L)$, tratando-se o numerador do segundo termo como um parâmetro, deve resultar em estimativas de $2 \beta / v$ na extrapolação da intersecção $(\ln a)^{-1}=0$. Obtivemos a estimativa $\beta / v \approx 0.02 \pm 0.01$, para $c=0$. A substituição de $D_{F}$ (Tabela 6.1) na relação de escala (6.9) também permite avaliarmos $\beta / v=2-D_{F} \approx 0.04 \pm 0.01$. Este resultado tangencia $o$ anterior em 0.03. Devido a grandes erros numéricos, a estimativa de $\beta / v$ torna-se impraticável em concentraçōes de impurezas maiores.

\subsection{RUGOSIDADE DA SUPERFícIE}

Os processos de crescimento podem ser freqüentemente descritos em termos da propagação de uma frente de crescimento ou "zona ativa”. Após a passagem da frente de crescimento, a estrutura deixada para trás não se altera (Meakin, 1993). Isto de fato ocorre no presente modelo. Definimos a superficie do aglomerado como sendo composta por todas as extremidades de crescimento atuais. 
Um dos caminhos mais importantes em direção à caracterização de superficies rugosas é através das funçōes de correlação de diferença de altura (Feder, 1988; Meakin, 1993)

$$
C_{q}(\Delta r) \equiv\left\langle h(r+\Delta r)-\left.h(r)\right|^{q}\right\rangle^{1 / q},
$$

onde $h$ é a altura acima de uma superfície de referência lisa e $\Delta r$ é uma distância “horizontal" medida ao longo da mesma.

Em muitos casos, verifica-se que estas correlações têm a forma

$$
C_{q}(\Delta r) \sim(\Delta r)^{H_{q}} \quad .
$$

Quando, para todo $q, H_{q}=H$ ( $H$ é o expoente de Hurst), então tem-se um fractal auto-similar ("self-affine"). Do contrário, tem-se um multifractal. A lei de escala acima é válida em um intervalo

$$
\xi^{-}<\Delta r<\xi^{+},
$$

limitado por comprimentos de correlação horizontais superior $\xi^{+} \mathrm{e}$ inferior $\xi^{-}$(Meakin, 1993). Fisicamente, o cálculo de $C_{2}(\Delta r)$ para $\Delta r$ pequeno não distinguiria uma superficie que é globalmente e localmente lisa de uma superficie que é localmente lisa, porém globalmente rugosa. Isto explica o limite inferior $\xi^{-}$. Por outro lado, para $\Delta r$ grande, além do limite superior $\xi^{+}$, há uma região onde a estatística é pobre e os efeitos de borda tornam-se pronunciados.

A dimensão fractal $D$ da interface relaciona-se com o expoente de Hurst $H$ através de

$$
D=d-H \quad,
$$

onde $d$ é a dimensão Euclidiana da superficie de referência (no caso, $d=1$ ).

$\mathrm{Na}$ seção 6.2.2, interpretamos o máximo de $\left\langle N_{3}\right\rangle$ como um indicador da transição de rugosidade na superficie do polímero. Simulaçōes visuais mostram que a superficie do polímero torna-se mais 
lisa conforme $b$ aumenta (ver, por exemplo, ilustração na Figura 6.4). O polimero cresce como uma estrutura compacta cuja forma tende à de um losango. Consistentemente, escolhemos, como nossa superficie de referência, os lados de um quadrado inscrito na rede e que formam ângulos de $45^{\circ}$ com os eixos cartesianos, conforme indica a Figura 6.13. As alturas são medidas sobre esta referência quando o aglomerado toca a fronteira pela primeira vez.

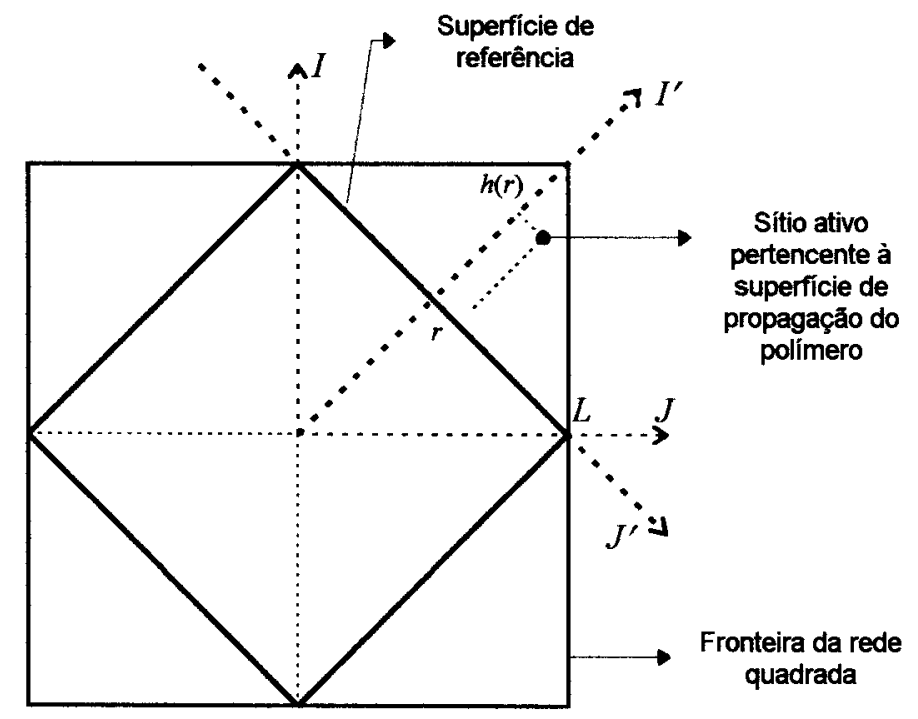

Figura 6.13: Superficie de referência (linhas contínuas em vermelho) para a medida das funçōes de correlação de diferença de altura $C_{q}(A r)$. A fronteira da rede quadrada $L X L$ corresponde ao perimetro em azul. O ponto indicado representa uma extremidade de crescimento da superfície do aglomerado. Como este ponto se encontra no primeiro quadrante da rede, suas coordenadas $(r, h(\eta))$ são medidas com rrelação ao sistema de eixos $J^{\prime} l '$ indicado.

Na Figura 6.14, apresentamos o gráfico de $\log \left(\left\langle C_{2}(\Delta r)\right\rangle\right)$ versus $\log \Delta r$ (note que todas probabilidades de ramificação escolhidas são maiores que o valor crítico $b_{c}$ da transição finita-infinita). Para $b>0.2$, claramente vemos o intervalo previsto na equação (6.20), onde a lei de escala (6.19) é válida. 


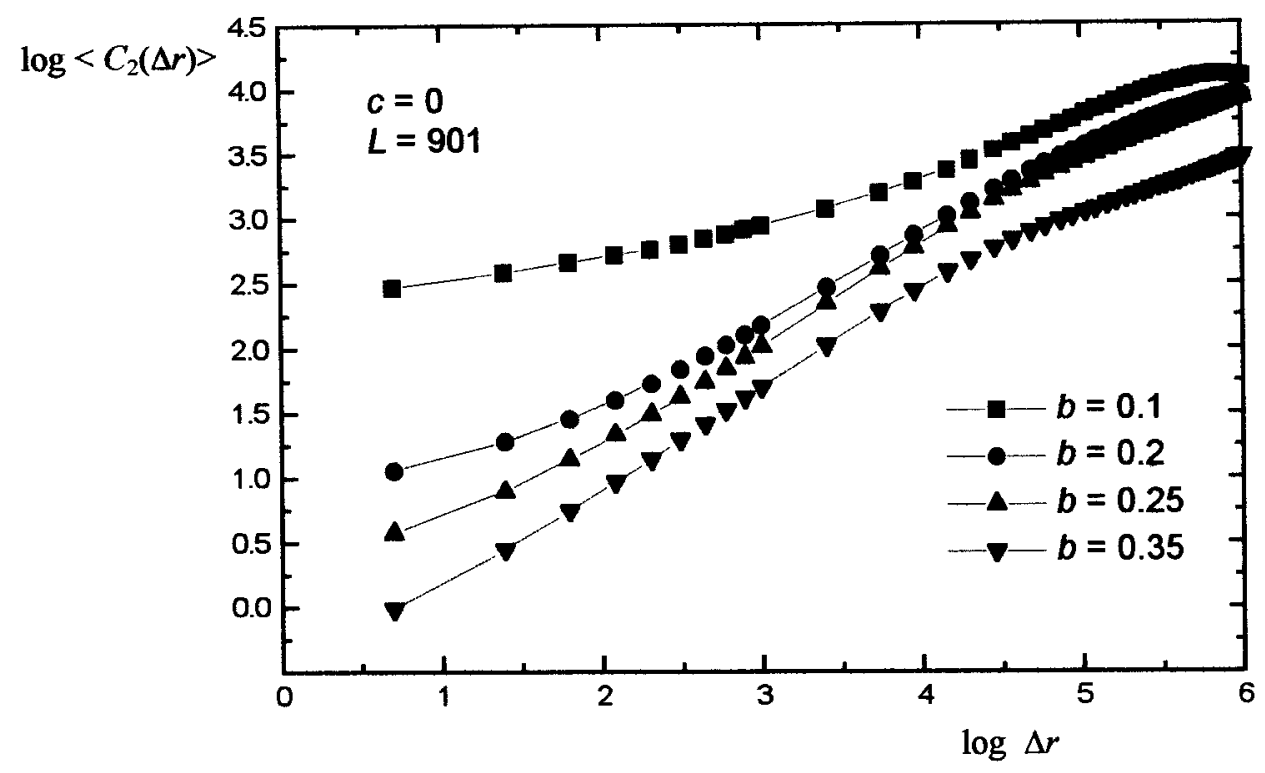

Figura 6.14: Gráfico logarítmico da função de correlação $\left\langle C_{2}(\Delta r)\right\rangle$ versus $\Delta r$.

A Tabela 6.4 apresenta os expoentes de Hurst avaliados de acordo com o procedimento acima para $c=0$ e $b \geq 0.25$ (regime de superfície lisa). Os expoentes de Hurst decrescem conforme a superficie torna-se mais lisa $(b \rightarrow 1)$. Isto é consistente com a equação (6.19) desde que, para uma distância fixa $\Delta r,\left\langle C_{2}(\Delta r)\right\rangle$ deve diminuir com o alisamento da superficie, o que implica $H \rightarrow 0$.

Os resultados também são consistentes com a equação (6.21), uma vez que no limite $H \rightarrow 0$ a dimensão fractal da interface $D \rightarrow 1$, portanto indicando uma superficie lisa.

\begin{tabular}{|c|c|}
\hline & \\
\hline $\boldsymbol{b}$ & $\boldsymbol{H}$ \\
\hline 0.25 & 0.48 \\
\hline 0.35 & 0.43 \\
\hline 0.50 & 0.23 \\
\hline 0.65 & 0.14 \\
\hline 0.80 & 0.10 \\
\hline
\end{tabular}

Tabela 6.4: Expoentes de Hurst $H$. 


\subsection{CONCLUSÕES}

Sumariamente, estudamos a polimerização ramificada em meios com impurezas através de simulações computacionais de um modelo de crescimento cinético. Os programas foram desenvolvidos em linguagem FORTRAN. O tempo de CPU médio dispendido em $N_{e}=10^{5}$ simulações na rede quadrada de tamanho $L=241$, com probabilidade de ramificação $b \approx 0.06$ e na ausência de impurezas, é igual a aproximadamente 11 horas numa Sunstation.

Exploramos diversos aspectos fisicos além daqueles previamente estudados por Lucena et al. (1994). Primeiramente, identificamos cada uma das configurações poliméricas com uma árvore na rede. Se esta correspondência fosse biunivoca, poderiamos utilizar dados de enumeração de animais recentes a fim de promover uma análise de séries. Apresentamos uma classificação topológica de uma árvoreligação com relação aos tipos de vértices e investigamos seu comportamento estático e dinâmico. Em particular, $\langle N\rangle$ é proporcional ao parâmetro de ordem e o comportamento de $\left\langle N_{3}\right\rangle$ fornece um indício para a detecção da transição de rugosidade. Observamos que a massa média do polímero cresce com $t$ de acordo com a lei de potência $\langle N(t)\rangle \sim t^{\theta}$.

As dimensões fractais foram calculadas na ausência de sítios ativos no interior da rede, isto é, no regime estático. Também estudamos a estatística e o tempo médio de vida dos aglomerados. A determinação da função de autocorrelação temporal da massa permitiu avaliarmos os expoentes críticos dinâmicos.

Através da teoria fenomenológica de "finite size scaling" estimamos $b_{c}$ e o expoente crítico $v$, para várias concentrações. Os cálculos são baseados numa técnica de cumulantes de quarta ordem. Ainda que a aplicação deste método tenha requerido um grande tempo 
computacional, conseguimos obter valores consistentes de $b_{c}$ e $v$. Nossos resultados sugerem que a linha crítica é não universal.

Finalmente, uma análise interessante do crescimento da superficie do polímero através da função de correlação de diferença de altura conduziu a estimativas dos expoentes de Hurst para uma concentração de impurezas nula.

Para estudarmos este modelo de crescimento de polímeros ramificados de uma maneira ainda mais realista, incluiremos forças atrativas de curto alcance entre os monômeros. Os resultados deste estudo serão apresentados no capítulo seguinte. 


\section{SIMUlaÇões de UM MOdELO dE CRESCIMENTO CINÉTICO COM INTERAÇÕES ATRATIVAS ENTRE SÍtIOS PRIMEIROS VIZINHOS}

\subsection{INTRODUÇÃ̃o}

No presente capitulo, estudamos o modelo de crescimento de polímeros ramificados de uma maneira ainda mais realista. Com este propósito, incluímos, no modelo de crescimento cinético, forças atrativas de curto alcance entre os monômeros (Onody e Neves, 1996b). A cada unidade de tempo (fixa) do crescimento do polimero, empregamos um método de Monte Carlo para obter uma amostra representativa do espaço de configurações. Assim, o sistema evolui quase-estaticamente e está sempre em equilíbrio com o banho térmico. Ao lado da temperatura reduzida $T$, o outro parâmetro relevante é a probabilidade de ramificação $b$ (somente estudamos o caso no qual a concentraçāo de impurezas $c$ é zero). Obtemos, no plano $(T, b)$, o

diagrama de fases que separa os regimes de crescimento finito e infinito. A baixas temperaturas, devido à presença de forças atrativas, a estrutura do aglomerado torna-se mais compacta, havendo um decréscimo na ocorrência das obstruções estéricas ("steric hindrances"), conforme será explicado adiante. Detectamos também uma transição 
secundária que se manifesta em todas as temperaturas e que se relaciona à rugosidade da superficie do polimero.

\subsection{MODELO DE CRESCIMENTO CINÉTICO}

Apresentamos agora uma breve revisão do modelo de crescimento cinético e, em seguida, desenvolvemos um método de Monte Carlo para ser aplicado ao mesmo. Cada sítio de uma rede quadrada $L \times L$ pode estar vazio ou ocupado por um monômero. Inicialmente, somente o centro está ocupado. No instante $t=0$, o polímero inicia seu crescimento a partir da origem em direção a um sítio adjacente aleatoriamente escolhido. Em $t=1$, este sitio é preenchido e torna-se a nova extremidade de crescimento que agora pode bifurcar com probabilidade $b$ ou manter seu crescimento linear com probabilidade $1-b$. Aplica-se este processo recursivamente sobre cada nova ponta de crescimento, de modo que esta sempre evite interceptar o polimero ("self-avoidance"). Todas direções de crescimento disponiveis são igualmente prováveis. A cada instante $t$, todas extremidades de crescimento atuais são seqüencialmente visitadas no sentido horário seguindo a ordem dos nascimentos. Todas as pontas estão conectadas à origem por $t$ ligações. Cada ponta sempre tenta evitar regiões preenchidas, porém, às vezes, pode encontrar-se em um beco sem saída ("cul de sac"). Nesta situação, o crescimento da ponta termina. O experimento é finalizado quando o aglomerado tocar a fronteira da rede (polimero infinito) ou quando todas as pontas tornarem-se extremidades mortas (polimero finito).

\subsection{UM MÉTOdO DE MONTE CARLO}

Consideramos o modelo de crescimento cinético descrito acima, conforme tratado por Lucena et al. (1994), mas agora modificado a fim de incluir uma energia atrativa $\varepsilon(\varepsilon<0)$ para cada par de monômeros 
primeiros vizinhos. A temperatura reduzida $T$ é definida por $T=1 / \beta|\varepsilon|$. Desenvolvemos agora um método de Monte Carlo. Considere todo par de sítios formado por uma ponta de crescimento no instante $t$ e um sitio adjacente ocupado previamente. Seja $N_{t}$ o número total de tais pares. Utilizando o mecanismo de crescimento explicado acima, existem, a cada instante $t$, diferentes configurações para as quais o sistema pode evoluir. Seja $C_{1}$ a primeira configuração no instante $t+1$, gerada pela aplicação das regras de crescimento no instante $t$. Esta adiciona uma energia $E_{1}=\varepsilon N_{t+1}\left(C_{1}\right)$ à energia total. Uma segunda configuração $C_{2}$ será sempre aceita se $E_{2}<E_{1}$; caso contrário, um número aleatório $r \quad(0 \leq r<1)$ é sorteado e a nova configuração é somente aceita se $r<e^{-\beta\left(E_{2}-E_{1}\right)}$. Este processo é repetido $N_{M}$ vezes, onde $N_{M}$ é o número de passos de Monte Carlo fixado. Observe que tal prescrição assemelha-se aos algoritmos de Swendsen e Wang (1987) ou Wolff (1989), no sentido de que todo o perimetro é "flipado" ao passar da configuração $C_{k}$ para $C_{k+1}$. Em geral, este tipo de dinâmica reduz efeitos indesejáveis como o "critical slowing down". Finalmente, devemos salientar que, num tempo fixo, o número de bifurcações que ocorrem na primeira configuração é mantido constante ao longo de todos os $N_{M}$ passos de Monte Carlo. Se assim não fosse, certamente a transiçāo de uma configuraçāo para outra favoreceria sistematicamente aquelas com mais sítios bifurcados (pois estas têm energias menores). Este cuidado evita uma simulação tendenciosa que possa corromper o significado de $b$ como um parâmetro externo. Obviamente, o número de bifurcaçōes evolui no decorrer do tempo. A Figura 7.1 ilustra a geração de duas hipotéticas configurações $C_{1}$ e $C_{2}$ em um único passo de Monte Carlo. 
$C_{1}$

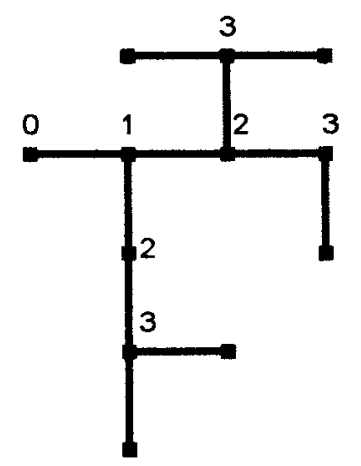

$C_{2}$

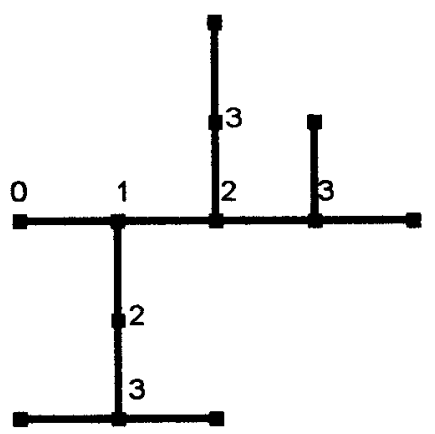

Figura 7.1: Um possivel aglomerado no instante $t=3$ (em azul) e duas hipotéticas configuraçōes $C_{1}$ e $C_{2}$ no instante $t+1$ (em vermelho), geradas pela aplicação das regras de crescimento no instante $t$. As configuraçōes $C_{1}$ e $C_{2}$ são geradas no primeiro passo de Monte Carlo. Se, ao término do processo de Monte Carlo, a configuraçăo $C_{1}$ fosse incorporada ao aglomerado, adicionaria a este uma energia $E_{1}=-7 \mid \delta_{1}$, enquanto que $C_{2}$ contribuiria com $E_{2}=-6 \mid s$. Neste passo de Monte Carlo exemplificado $\left(\Delta E=E_{2}-E_{1}=|s|>0\right)$, - critério adotado estabelece que a nova configuração $C_{2}$ poderá ser aceita com probabilidade $p=\exp [-\beta \Delta E]=\exp [-\beta|\delta|]$. Observe que o número de bifurcações que ocorrem em $C_{1}$ é mantido em $C_{2}$.

\subsection{PARÂMETRO DE ORDEM E COMPRIMENTO DE CORRELAÇÃo}

Neste estudo, adotaremos o parâmetro de ordem conforme definido originariamente por Lucena et al. (1994). Através desta definição, o parâmetro de ordem representa a fração dos polímeros que são infinitos. $O$ "locus" onde o parâmetro de ordem é nulo define uma linha crítica no espaço $(T, b)$. Novamente, lembramos que o comprimento de correlação $\xi$ do sistema pode ser medido através de: $\xi \equiv\left\langle\left(l_{x} l_{y}\right)^{1 / 2}\right\rangle$, onde $l_{x}$ e $l_{y}$ são os tamanhos do menor retângulo que contém um polímero finito, ao têrmino de um particular experimento. $\hat{\mathrm{E}}$ importante observar que, com esta definição, o comprimento de correlação também apresenta um pico com relaçāo à variaçāo de temperatura. A altas temperaturas, há um grande número de 
obstáculos dificultando o crescimento do polímero e, portanto, $\xi$ é pequeno. A baixas temperaturas, o número de obstáculos diminui devido à presença de forças atrativas. Isto significa que a maioria dos polímeros são infinitos, assim, para que um aglomerado permaneça finito é necessário que ele morra o quanto antes, pois do contrário ele cresceria indefinidamente. A morte súbita dos polimeros finitos implica em $\xi$ pequeno novamente. O máximo de $\xi$ localiza a transição de fase principal que separa os regimes de crescimento finito e infinito. No ponto de máximo, $\xi$ cresce com o tamanho da rede $L$. Naturalmente, no limite $T \rightarrow \infty$, a energia de ligação entre os monômeros é irrelevante e devemos reproduzir os resultados previamente obtidos por Lucena et al. (1994) e Neves e Onody (1995).

\subsection{CONFIGURAÇõeS GEOMÉtricas dOS AGLOMERAdOS}

Mostrar algumas configurações gráficas típicas dos aglomerados é tão instrutivo quanto ilustrativo. Para que estas configurações sejam visualizadas mais facilmente, realizamos algumas simulações em uma rede quadrada de tamanho $L=51$.

A primeira configuração (Figura 7.2) é uma cadeia linear $(b=0)$ que é infinita em $T=0$. Este resultado é completamente diferente daquele do modelo de crescimento cinético original (sem interações atrativas) onde, para $b=0$, o sistema está na fase finital $\mathrm{O}$ aglomerado é compacto e apresenta um paralelismo de ligações. A razão é a seguinte: quando a única extremidade de crescimento se curvar, o critério de mínima energia obriga-a a voltar-se novamente, seguindo um caminho paralelo à sua própria estrutura. Este comportamento impede o aparecimento de espaços vagos, torna o sistema compacto e mantém a ponta da cadeia crescendo indefinidamente. Devemos também mencionar que, a $T=0$, a fase é infinita para todo $b \geq 0$. Na Figura 7.3, mostramos um aglomerado simulado com parâmetros $T=0$ e $b=0.5$. A superficie adquire o formato de um losango tornando-se lisa e, portanto, 
indicando a ocorrência de uma transição de rugosidade. Deveras, para uma determinada temperatura, podemos observar que conforme $b$ aumenta, o número médio de sítios com três ligações $\left\langle N_{3}\right\rangle$ passa por um máximo que é um indício da transição de rugosidade (ver seção 6.22). Este fenômeno ocorre em todas as temperaturas. O pico de $\left\langle N_{3}\right\rangle$ ocorre em $b \approx 0.20$ a baixas temperaturas $(T<0.5)$ e tende a $b \approx 0.15$ a altas temperaturas.

Dois aglomerados foram simulados com $T=0.5$. Um destes aglomerados, gerado com $b=0.01$, encontra-se na fase finita (Figura 7.4), enquanto o outro, gerado com $b=0.03$, encontra-se na fase infinita (Figura 7.5).

Uma possivel configuração da caminhada de crescimento cinético (Majid et al., 1984) é reproduzida simulando-se o crescimento do aglomerado com $T \rightarrow \infty$ e $b=0$ (Figura 7.6). Deveras, neste ponto o sistema está na fase finita. Na Figura 7.7, mostramos um aglomerado obtido em uma simulação com parâmetros $T \rightarrow \infty$ e $b=0.05$ (neste caso, a probabilidade de bifurcação foi escolhida propositadamente próxima ao seu valor crítico). 


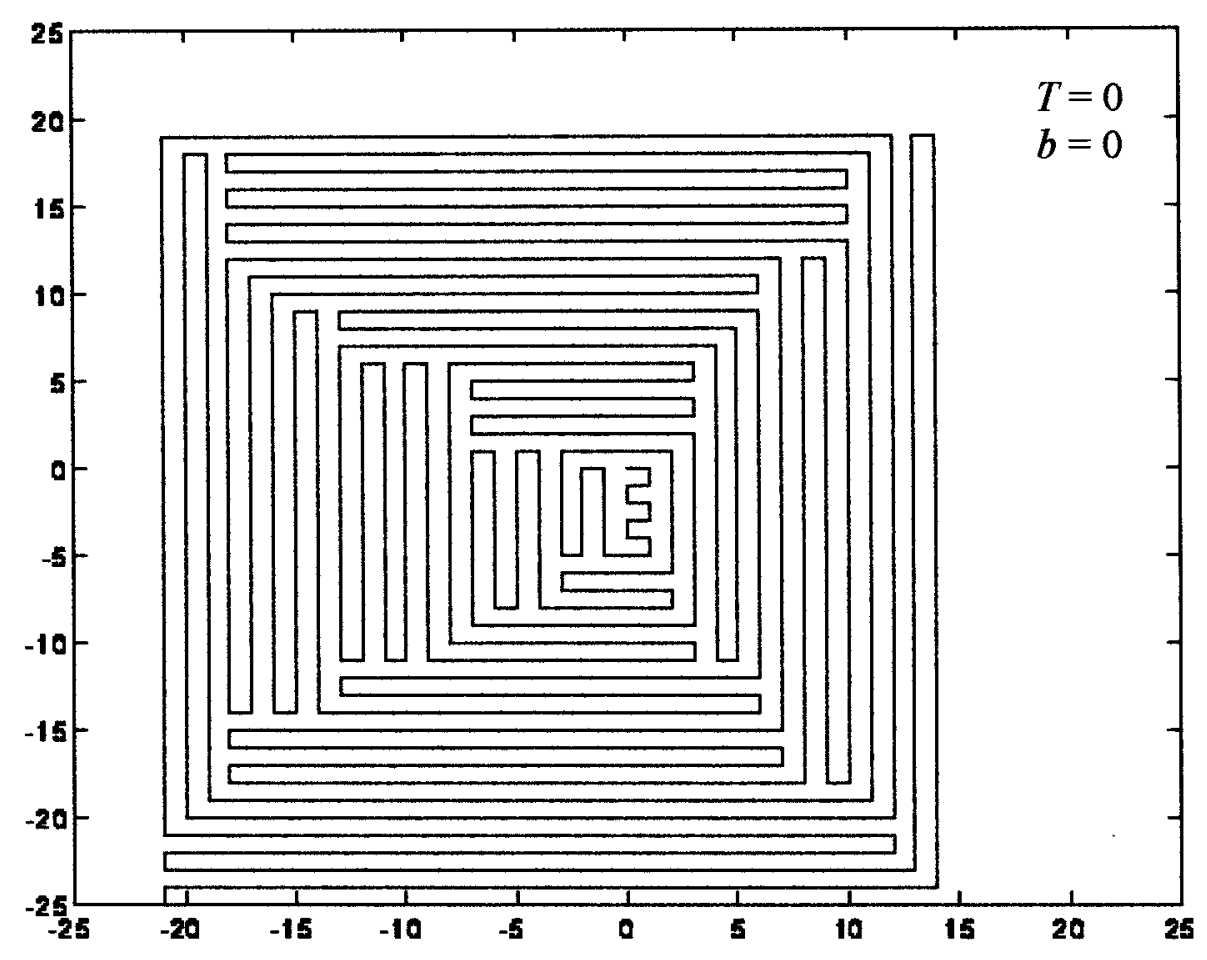

Figura 7.2: Configuração de uma cadeia linear $(b=0)$ que é infinita em $T=0$. Simulação realizada em uma rede quadrada de tamanho $L=51$, $\operatorname{com} N_{M}=400$.

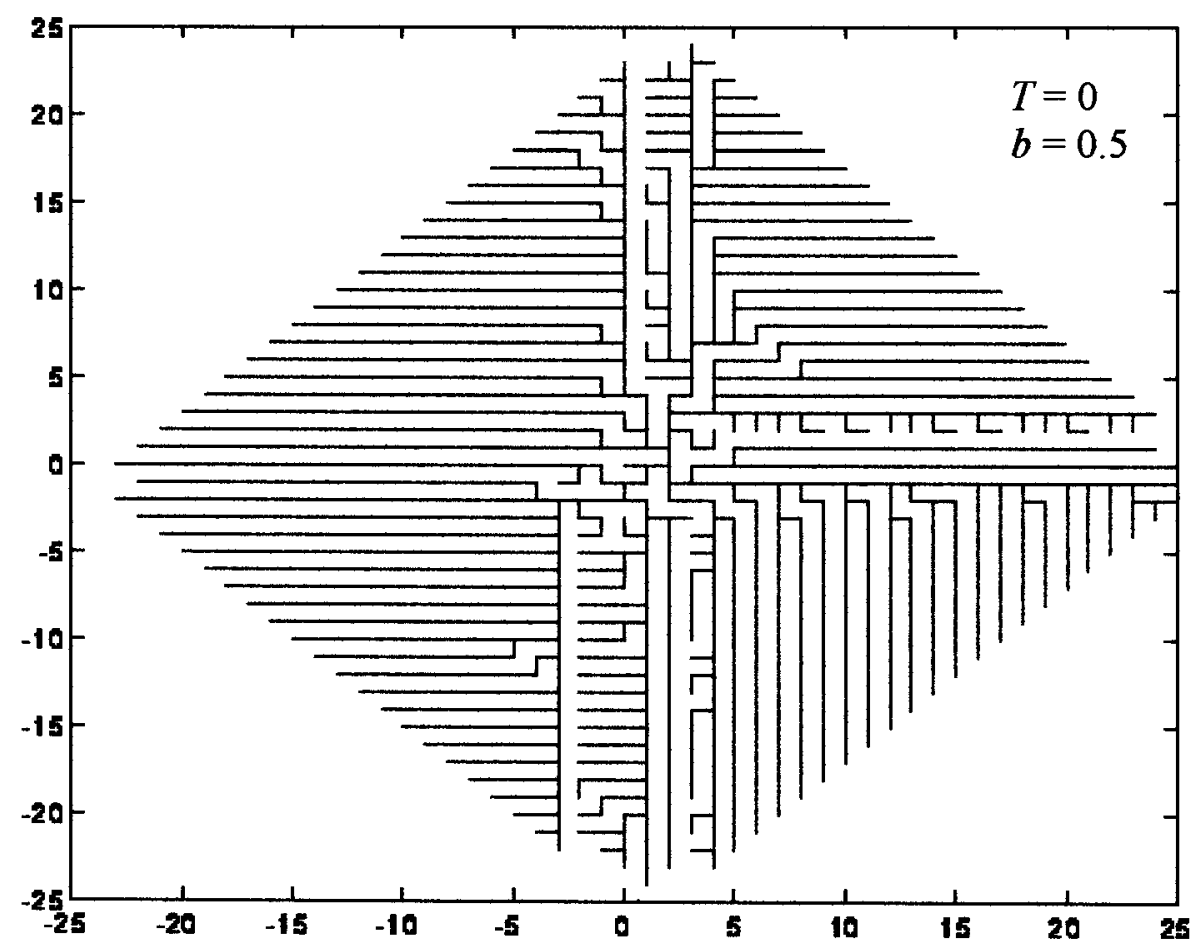

Figura 7.3: Configuração de um aglomerado simulado, com parâmetros $T=0$ e $b=0.5$, numa rede quadrada de tamanho $L=51$ e com $N_{M}=400$. Observe que a superfície adquire o formato de um losango, indicando a existência de uma fase "lisa". 


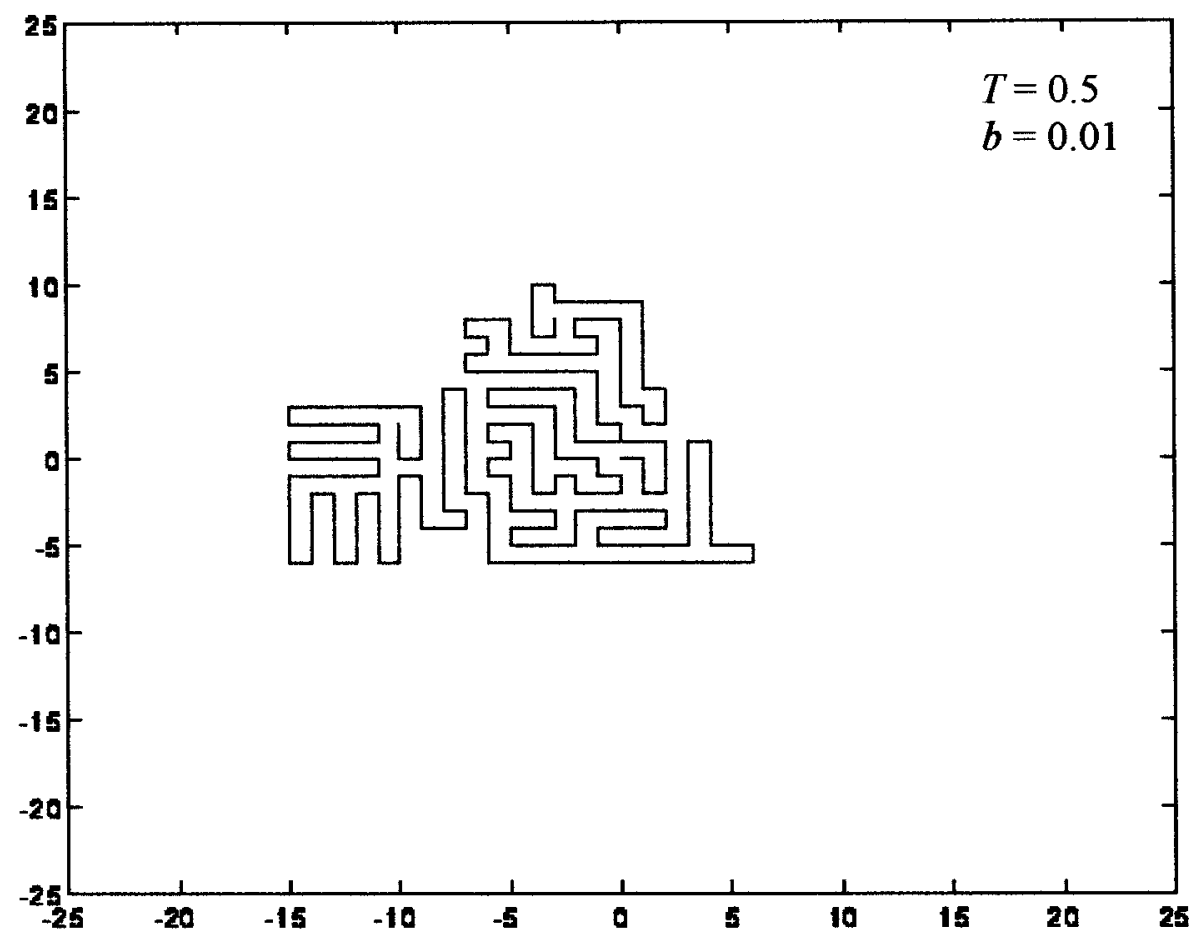

Figura 7.4: Configuração típica de um aglomerado simulado com parâmetros $T=0.5$ e $b=0.01$. Neste ponto, o aglomerado encontra-se na fase finita. Simulação realizada numa rede de tamanho $L=51, \mathrm{com} N_{M}=400$.

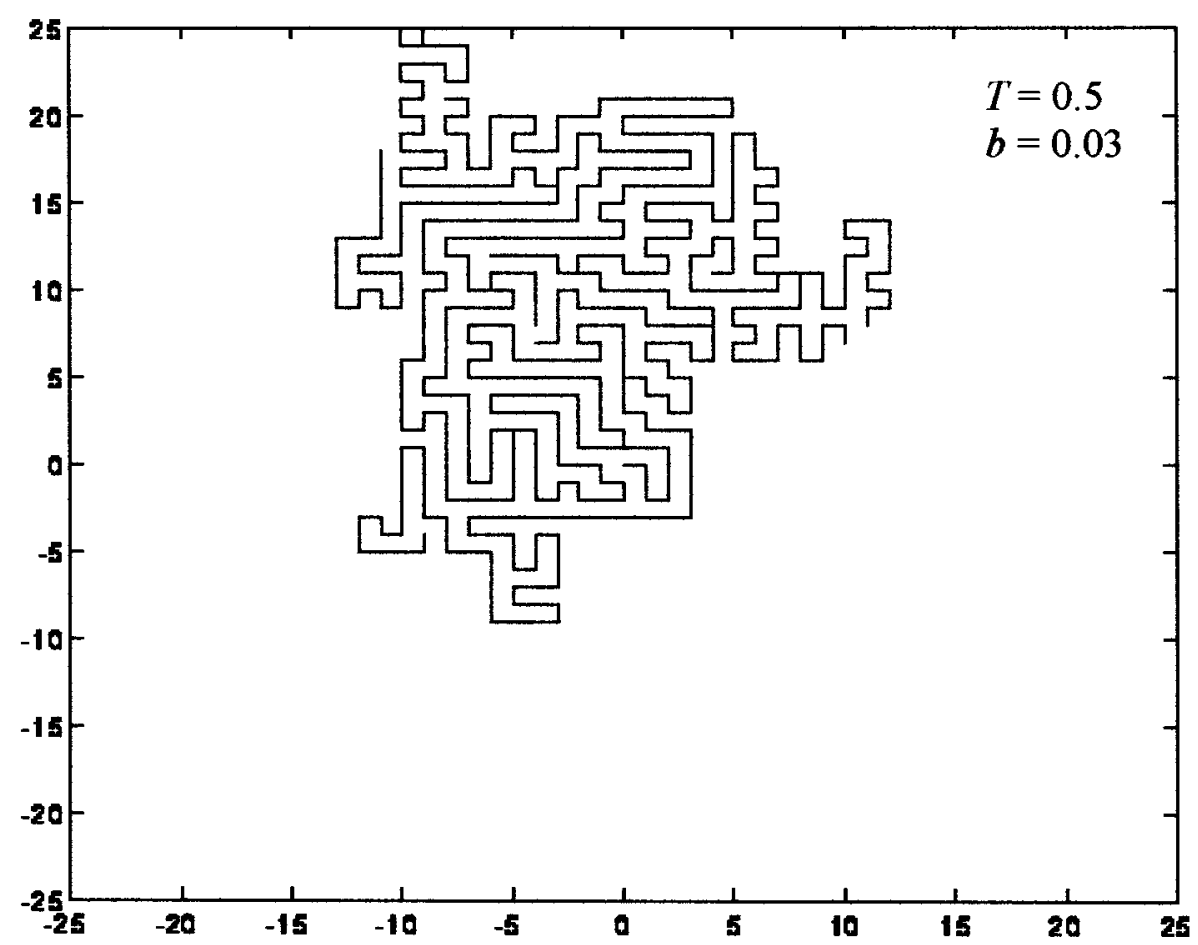

Figura 7.5: Configuração típica de um aglomerado simulado com parâmetros $T=0.5$ e $b=0.03$. Neste ponto, 0 aglomerado encontra-se na fase infinita. Simulaçāo realizada numa rede de tamanho $L=51$, com $N_{M}=400$. 


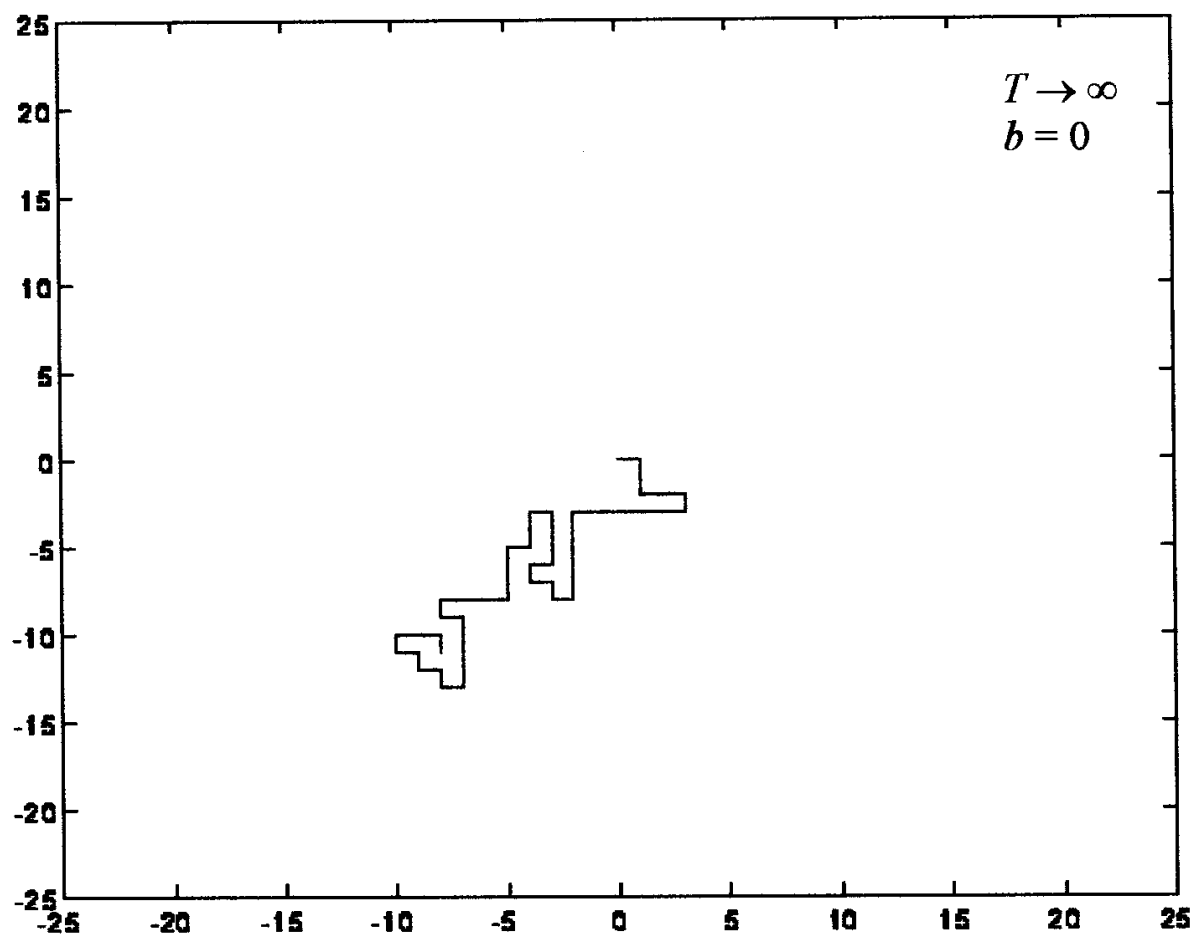

Figura 7.6: Possivel configuração da caminhada de crescimento cinético, reproduzida através do crescimento do aglomerado com $T \rightarrow \infty$ e $b=0$. Neste ponto, o sistema está na fase finita. Simulaçăo realizada em uma rede de tamanho $L=51$, com $N_{M}=400$.

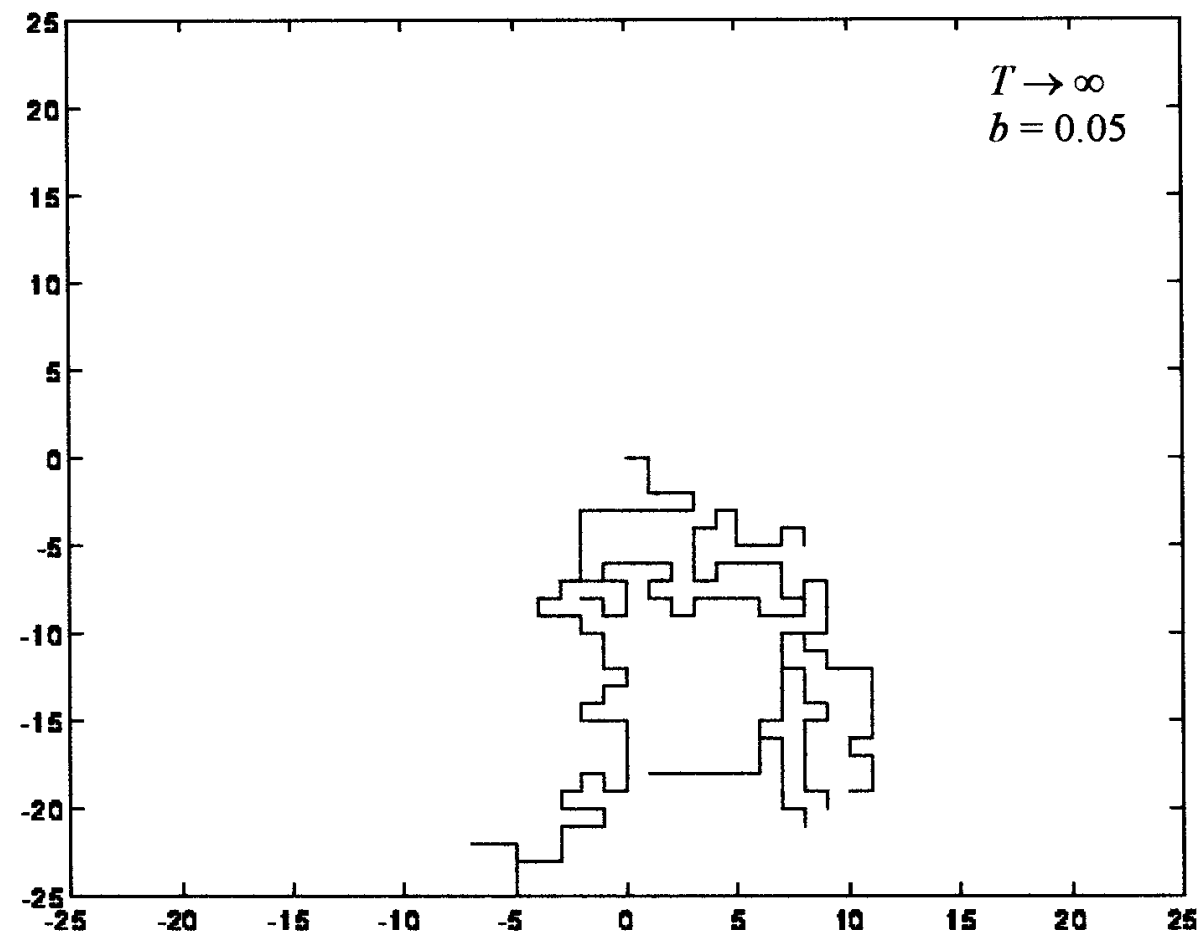

Figura 7.7: Configuraçāo de um aglomerado obtido através de uma simulaçāo realizada com parâmetros $T \rightarrow \infty$ e $b=0.05$ (numa rede quadrada de tamanho $L=51$, com $N_{M}=400$ ). A probabilidade de bifurcação $b$ foi escolhida propositadamente próxima ao seu valor critico. 


\subsection{DIAgRAMA DE FASES}

Apresentamos agora o diagrama de fases do sistema no plano $(T, b)$ (Figura 7.8).

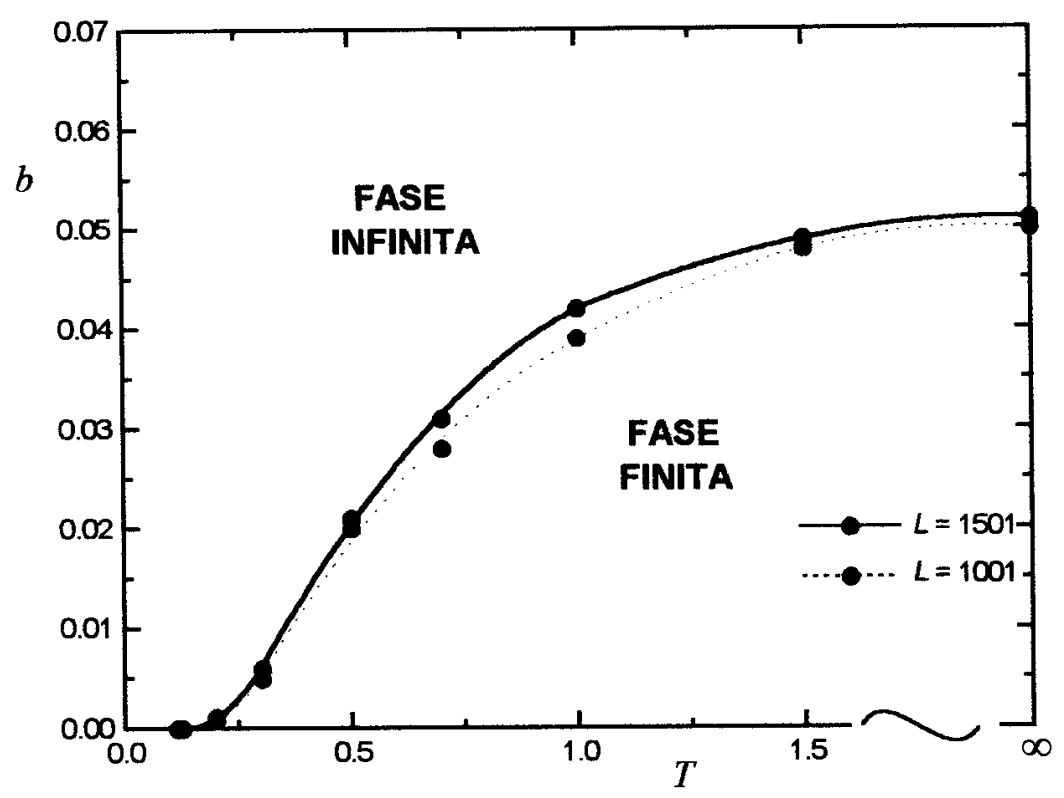

Figura 7.8: Linha crítica no plano $(T, b)$ separando as fases de crescimento finito e infinito.

A linha critica no diagrama de fases (Figura 7.8) é o "locus” onde o comprimento de correlação diverge. Uma transição de fase de segunda ordem separa os regimes de crescimento finito e infinito. Esta linha atinge o eixo $T$ em $T=0.115 \pm 0.005$ (particularmente este ponto foi obtido procurando-se o pico de $\xi$ a $b=0$ constante). Todos os outros pontos foram determinados fixando-se as temperaturas. Eles contém uma incerteza da ordem de $\Delta b \sim 10^{-3}$. Como guia para os olhos, traçamos uma curva passando por tais pontos. Em nossas simulações, o equilíbrio térmico (medido pela estabilização da energia do sistema) é atingido por volta de 400 passos de Monte Carlo para cada intervalo de tempo $[t, t+1]$. Simulamos sistemas de tamanho $L=1001$ e $L=1501$, realizando uma média sobre 100 experimentos. Os resultados são apresentados na Figura 7.8. Ainda que o limite termodinâmico $(L \rightarrow \infty)$ não tenha sido 
extrapolado, acreditamos que os nossos resultados para $L=1501$ (linha contínua vermelha) estão muito próximos do diagrama de fases real, uma vez que as simulações realizadas para $L=1001$ (pontos em azul) diferem menos de $3 \%$ com relação às realizadas para $L=1501$.

Agora podemos discutir o diagrama de fases. No limite $T \rightarrow \infty$, nossa estimativa $b_{c} \approx 0.051$ está em muito boa concordância com resultados prévios (Lucena et al., 1994; Neves e Onody ,1995). Neste regime de alta temperatura, a transição de fase resulta da competição entre obstáculos e ramificação. A energia atrativa entre os monômeros não desempenha nenhum papel. Por outro lado, a baixas temperaturas, o efeito dos obstáculos é tão reduzido (devido à presença de forças atrativas) que até mesmo a fase finita desaparece!

Sobre o eixo $b=0$, determinamos as temperaturas críticas $T^{*}(L)$ para sistemas de tamanhos $L=501,1001$ e 1501 e extrapolamos o valor $T^{*}=0.102 \pm 0.005$ utilizando o algoritmo BST (ver seção 4.3.1; Bulirsch e Stoer, 1964; Henkel e Schütz, 1988). Em cada sistema finito de tamanho $L$, todas as simulações realizadas abaixo da temperatura critica $T^{*}(L)$ conduziram ao crescimento de polimeros na fase infinita! Isto nos leva a descartar a hipótese de que a curva crítica apresente um comportamento do tipo função de Cauchy: $b \propto e^{-T_{0} / T}$. No ponto $T^{*}(L), o$ parâmetro de ordem parece aproximar-se de uma função degrau indicando que uma transição de fase de primeira ordem talvez esteja aí ocorrendo. Não descartamos a possibilidade de que $T^{*}$ possa corresponder a uma temperatura tricrítica onde a linha de segunda ordem termina. Seria interessante estudar este ponto mais profundamente e também obter algumas propriedades termodinâmicas do sistema, como, por exemplo, o calor específico. Então a questão da universalidade ao longo da linha crítica poderia ser abordada. 


\subsection{CONCLUSÕES}

Incluímos, no modelo de crescimento cinético, interações atrativas de curto alcance entre os monômeros. A partir do emprego de um método de Monte Carlo, obtivemos, no plano $(T, b)$, o diagrama de fases que separa os regimes de crescimento finito e infinito. Também constatamos uma transição de rugosidade na superficie do polímero, a qual deve manifestar-se em todas as temperaturas.

Os programas computacionais foram desenvolvidos em linguagem FORTRAN. O tempo de CPU dispendido em 100 simulações realizadas na rede quadrada de tamanho $L=1501$, com $N_{M}=400$ passos de Monte Carlo e parâmetros $T=1$ e $\quad b=0.042 \approx b_{c}(T=1)$, é igual a aproximadamente 12 horas numa Sunstation. Particularmente sobre este ponto do plano $(T, b)$, o parâmetro de ordem do sistema (fração de polimeros infinitos) é igual a 0.24. Maior tempo computacional deverá ser dispendido em simulações sobre pontos na fase infinita (onde o parâmetro de ordem tende a 1).

Em continuidade a este estudo, propomos, no capitulo seguinte, o cálculo das funções termodinâmicas do sistema no "ensemble grand canônico”, com a introduçāo da fugacidade, ao lado da temperatura. 


\section{CONCLUSões e PERSPECTIVAS}

\subsection{TRANSição de ColaPSO E SÉRIES}

Iniciamos este trabalho estudando métodos de análise de expansōes em séries de potências, com especial interesse na técnica dos aproximantes diferenciais parciais (capitulo 2).

Em seguida, abordamos o problema da transição de colapso em polimeros ramificados (capitulo 3). Conforme vimos, os animais na rede (subgrafos conectados) têm sido empregados como modelos teóricos para os polímeros ramificados em solução diluída.

No capítulo 4, analisamos a transição de colapso em um modelo de animais-sítio na rede quadrada (modelo de pares) e, para isto, empregamos o método dos aproximantes diferenciais parciais (PDAs) no estudo do comportamento multicrítico da expansão em série da compressibilidade isotérmica do sistema. Através dos PDAs, estimamos o ponto tricrítico e os expoentes da transição de colapso, obtendo ainda o padrão de fluxo das trajetórias características. O método, pela primeira vez aplicado no estudo de tal sistema, conduziu-nos a resultados que estão em muito boa concordância com os valores obtidos por outras técnicas. 
Propomos estender este estudo a modelos de animais-ligação bidimensionais (com contatos) e a modelos de animais tridimensionais (com e sem contatos). A enumeração de tais animais encontra-se disponivel na literatura (Madras et al., 1990). Os modelos de ciclos (equivalentes aos de pares) e os de contatos estão provavelmente em classes de universalidade diferentes, mas as evidências ainda não são conclusivas.

Uma outra proposta de pesquisa consiste em estabelecer uma nova classificação dos animais na rede, adaptada a um modelo para heteropolimeros. Até então, utilizamos modelos de animais que representam configurações poliméricas com um único tipo de monômero, onde cada vértice corresponde a um determinado monômero. Considere, agora, heteropolímeros com dois tipos de monômeros: $A$ e $B$. Representemos uma configuração geométrica do heteropolimero por um animal cujos vértices se apresentam, cada qual, com o rótulo $A$ ou $B$. Cada vértice rotulado por $A$ (ou $B$ ) representa um monômero do tipo $A$ (ou $B$ ) que ocupe, no heteropolimero, uma posição correspondente à do vértice, no animal. Para exemplificar o modelo, consideremos animais sem contatos (certamente, a análise seguinte estende-se a modelos com contatos). Num modelo onde não há contatos, o número de ligações presentes no animal é justamente igual ao número de pares de sítios primeiros vizinhos. Podemos escrever a funçāo de partição de um animal com $N$ sitios (e com interações entre primeiros vizinhos) como

$$
Z_{N}=\sum_{p_{\mathcal{A}}, p_{A B}, p_{B B}} \sum_{N_{A}=0}^{N} A\left(N, N_{A}, p_{A A}, p_{A B}, p_{B B}\right) e^{-\left(p_{A A} \varepsilon_{A B}+p_{A B} \varepsilon_{A B}+p_{B B} \varepsilon_{B B}\right) / T},
$$

onde $T=k_{B} T_{K}=1 / \beta$ e $A\left(N, N_{A}, p_{A A}, p_{A B}, p_{B B}\right)$ é o número de animais com $N$ vértices, $N_{A}$ vértices rotulados por $A$ (e portanto, com $N_{B}=N-N_{A}$ vértices rotulados por $B), p_{A A}$ pares de vértices $A-A$ primeiros vizinhos, $p_{A B}$ pares de vértices $A-B$ primeiros vizinhos e $p_{B B}$ pares de vértices $B-B$ primeiros vizinhos. As energias de interação de pares de sítios $A-A, A-B \mathrm{e}$ 
$B-B$ são denotadas, respectivamente, por $\varepsilon_{A A}, \varepsilon_{A B}$ e $\varepsilon_{B B}$. Estas energias devem ser escolhidas convenientemente. Neste sentido, a energia de todo o aglomerado é uma função dos inteiros $p_{A A}, p_{A B}$ e $p_{B B}$ :

$$
E_{N}=E_{N}\left(p_{A A}, p_{A B}, p_{B B}\right)=p_{A A} \varepsilon_{A A}+p_{A B} \varepsilon_{A B}+p_{B B} \varepsilon_{B B}
$$

Esta abordagem conduz a um interessante problema de análise combinatória: o da determinação dos números inteiros $A\left(N, N_{A}, p_{A A}, p_{A B}, p_{B B}\right)$. A presente proposta tem por objetivo a classificação das diferentes configurações de possiveis aglomerados em função de $N, N_{A}, p_{A A}, p_{A B}$ e $p_{B B}$ e em sua enumeração, através da determinação dos coeficientes $A\left(N, N_{A}, p_{A A}, p_{A B}, p_{B B}\right)$. Esta enumeração é mais geral do que a atualmente disponivel (Madras et al., 1990). Os métodos combinatoriais inventados por Sykes (1986) e o pacote computacional desenvolvido por Martin (1990) deverão ser generalizados a fim de que possam ser utilizados nesta enumeração.

Uma vez determinados tais coeficientes, para animais com um número de sítios $N \leq \widetilde{N}$, poderemos construir a função de "grand partição"

$$
\begin{aligned}
& G(x, y)=1+\sum_{N=1}^{\tilde{N}} Z_{N} x^{N}= \\
& 1+\sum_{N=1}^{\tilde{N}}\left[\sum_{p_{A A}, p_{A B}, p_{B B}} \sum_{N_{A}=0}^{N} A\left(N, N_{A}, p_{A A}, p_{A B}, p_{B B}\right) x^{N} y^{-E_{N}\left(p_{A A}, p_{A B}, p_{B B}\right)}\right],
\end{aligned}
$$

onde $x=e^{\mu / T}$ é a fugacidade e $y=e^{1 / T}$.

Tal como verificamos no estudo de um modelo de animais para polímeros ramificados (capítulo 4), esperamos também encontrar uma transição de colapso nos heteropolímeros. Analogamente àquele estudo, podemos, através de (8.3), calcular $G(x, y)$ (em um modelo de animais para heteropolímeros), obtendo então a densidade $\rho$ e compressibilidade $K_{T}$. Os PDAs podem ser aplicados no estudo do 
comportamento multicrítico das expansōes em séries das funções termodinâmicas do sistema.

\subsection{MODELO DE CRESCIMENTO CINÉTICO}

Uma proposta alternativa para o estudo do fenômeno da polimerização foi abordada no capítulo 5: o modelo de crescimento cinético. Exploramos diversos aspectos físicos deste modelo no capítulo 6. Apresentamos uma classificação topológica dos aglomerados com relação aos tipos de vértices e investigamos seu comportamento estático e dinâmico. Uma transição de rugosidade na superficie do aglomerado foi detectada e a superficie deste foi analisada. Através de "finite size scaling" (método de cumulantes de quarta ordem), estimamos também os parâmetros criticos da transição finita-infinita.

No capitulo 7, estudamos este modelo de uma maneira ainda mais realista ao considerarmos forças atrativas de curto alcance entre os monômeros. Empregamos um método de Monte Carlo durante a evolução do sistema, incluindo assim o parâmetro $T$ (temperatura reduzida). No plano $(T, b)$, obtivemos o diagrama de fases que separa as fases finita e infinita. Constatamos que a transição de rugosidade na superficie do aglomerado deve manifestar-se em todas as temperaturas.

Em continuidade a este estudo, propomos o cálculo das propriedades termodinâmicas do sistema.

Considere uma simulação de crescimento do aglomerado baseada neste modelo de crescimento cinético, com energia atrativa $\varepsilon<0$ entre monômeros vizinhos (seções 7.2 e 7.3). Conforme o aglomerado cresce, podemos identificar sua configuração (em cada instante) com uma árvore-ligação (animal com contatos e sem ciclos). Cada sítio ocupado representa um monômero, enquanto que a ligação indica uma determinada direção de crescimento do polimero. Seja $M$ (massa) igual ao número de monômeros ao término de um dado experimento. 
Obviamente, flutuações da massa ocorrerão nas simulações. Portanto, para calcular as funçōes termodinâmicas, devemos considerar o "ensemble grand canônico", no qual o sistema pode ter qualquer número de partículas. Além da temperatura reduzida $T$, devemos agora introduzir uma nova variável, a fugacidade $x$ do sistema, definida por $x=e^{\mu / T}$ onde $\mu$ é o potencial químico. O volume $V_{0}$ do sistema é constante (no caso, a rede considerada é a quadrada e $V_{0}=L^{2}$ ). A cada instante $t$, podemos aplicar um método de Monte Carlo para obter uma amostra representativa do espaço de configuraçôes do sistema, selecionando uma delas. Neste processo, um número aleatório $r$ $(0 \leq r<1)$ é gerado e uma nova configuração é aceita se $r<e^{-\left(\Delta E_{t}-\mu \Delta M_{t}\right) / T}$, onde $\Delta E_{t}$ e $\Delta M_{t}$ são as variações, respectivamente, da energia total de interação entre monômeros e do número de monômeros, relativamente a duas configurações sucessivas. O processo é repetido $N_{M}$ vezes $\left(N_{M}\right.$ é o número de passos de Monte Carlo), a cada instante $t$, em cada experimento. As médias estatísticas da energia de interação entre monômeros $(\bar{E})$ e do número de monômeros $(\bar{M})$ devem ser calculadas sobre um número de experimentos $N_{e} \gg 1$.

As funções termodinâmicas podem ser calculadas no "ensemble grand-canônico". A compressibilidade isotérmica é proporcional à flutuação $\overline{\delta M^{2}}=\overline{M^{2}}-\bar{M}^{2}$ do número de partículas

$$
K_{T} \sim \overline{\delta M^{2}}
$$

A flutuação de energia no "ensemble grand-canônico", $\overline{\delta E^{2}}=\overline{E^{2}}-\bar{E}^{2}$, é a soma de dois termos (Davidson, 1962): o primeiro é a flutuação de energia no "ensemble canônico" (onde o número de partículas está fixo), e portanto, é proporcional ao calor especifico $C_{V}$ a volume $V$ constante; o segundo é a flutuação de energia associada com a flutuação do número de partículas. De acordo com esta relação, o calor especifico é expresso como 


$$
T^{2} \frac{C_{V}}{k_{B}}=\overline{\delta E^{2}}-\left(\left.\frac{\partial \bar{E}}{\partial \bar{M}}\right|_{T, V}\right)^{2} \overline{\delta M^{2}}
$$

Podemos calcular $C_{V}$ a partir da equação (8.5). Fixando-se os parâmetros $T=T_{0}$ e $x=x_{0}$, podemos medir, após um grande número de experimentos, as flutuações da energia e do número de partículas. Variando-se ligeiramente a fugacidade em torno de $x=x_{0}\left(\operatorname{com} T=T_{0}\right.$ mantido constante), podemos entāo obter a energia interna como função de $x, \bar{E}=\bar{E}\left(x\left(\bar{M}, T_{0}, V_{0}\right), T_{0}, V_{0}\right)$, e calcular numericamente a derivada $(\partial \bar{E} / \partial \bar{M})_{T_{0}, V_{0}}$.

Finalmente, todo este estudo pode ser estendido a sistemas tridimensionais. 


\section{ANEXO: APLICAÇÃO DA TEORIA DE "FINITE SIZE SCALING" AO ESTUDO DE FENÔMENOS CRÍTICOS: MÉTODO DE CUMULANTES}

\subsection{INTRODUÇÃo}

Neste anexo, consideramos alguns avanços recentes concernentes à compreensão dos efeitos de tamanho finito ("finite size effects") em transições de fase de segunda ordem (Binder, 1981, 1987, 1990). Conforme vimos, os parâmetros críticos do sistema estudado no capitulo 6 foram determinados através de uma técnica de cumulantes. Esta técnica baseia-se no fato de que, no ponto crítico, a função de distribuição do parâmetro de ordem apresenta uma mudança substancial (Binder, 1981, 1987). O objetivo deste anexo é abordar a teoria fenomenológica de "finite size scaling" e mostrar, a partir do cálculo do cumulante da distribuição, como localizar o ponto crítico de um sistema e estimar os expoentes criticos. O estudo será realizado no contexto de sistemas magnéticos podendo, de modo análogo, ser estendido a outros sistemas.

Através da mecânica estatística, sabemos que o comportamento singular da energia livre, uma transição de fase, somente pode ocorrer 
no limite termodinâmico, $N \rightarrow \infty$. Num sistema finito, a energia livre é regular e não há transição de fase.

A teoria de "finite size scaling" descreve como as transições de fase ocorrem depois que o limite $N \rightarrow \infty$ é tomado, ainda que não ocorram para $N$ finito, mesmo se $N$ for muito grande. Num sistema finito, existe uma transição arredondada e deslocada sobre alguma região: a largura desta região tende a zero conforme $N \rightarrow \infty$.

Consideremos um sistema definido em uma rede hipercúbica $d$-dimensional com dimensões lineares iguais $L$. Suponha que uma transição de fase ocorra em função da temperatura $T$, à temperatura critica $T_{c}(\infty)$ no sistema infinito $(L \rightarrow \infty)$.

A largura da curva de transição (arredondada) estende-se sobre um intervalo de temperatura $\Delta T_{a r}$ (Figura 9.1):

$$
\Delta T_{a r} \sim L^{-\theta} \quad .
$$

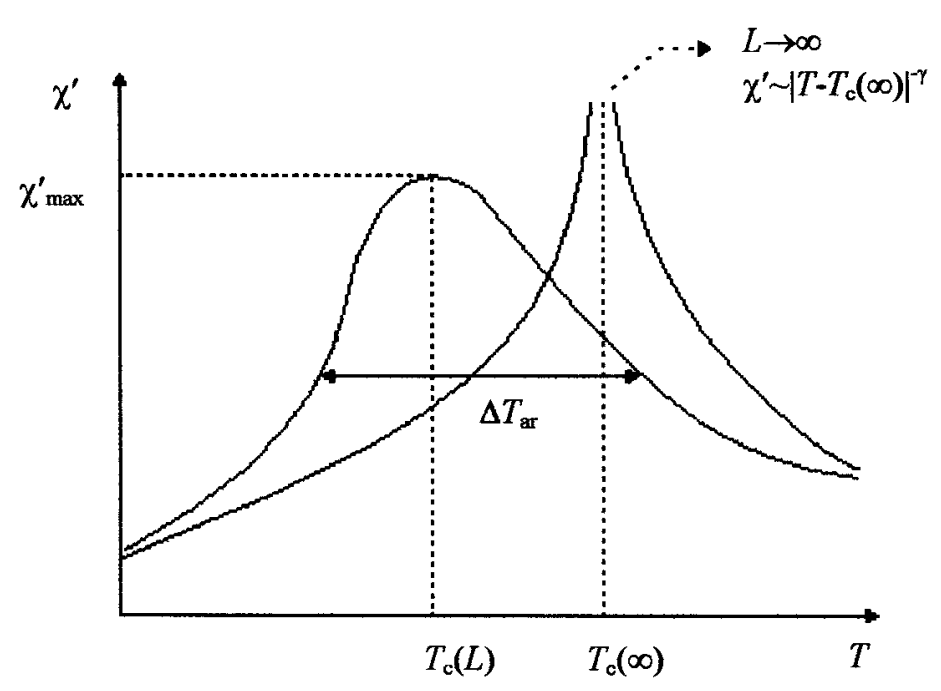

Figura 9.1: Esboço qualitativo da susceptibilidade $\chi^{\prime}$ de um sistema que sofre uma transição da fase ferromagnética para a fase paramagnética, conforme a temperatura $T$ aumenta. $O$ comportamento no limite termodinâmico é mostrado em vermelho e o comportamento de um sistema finito é mostrado em azul. 
O intervalo $\Delta T_{a r}$ ocorre em torno de $T_{c}(L)$, a temperatura onde a curva de transiçāo de um sistema finito apresenta um pico. Esta temperatura está deslocada de $T_{c}(\infty)$ de acordo com

$$
T_{c}(L)-T_{c}(\infty) \sim L^{-\lambda} \quad .
$$

Uma quantidade que no limite termodinâmico apresenta uma divergência critica é a susceptibilidade $\chi^{\prime}$ em uma transição de um estado paramagnético para um estado ferromagnético, e expressa-se em termos da flutuação da magnetização $m$ do sistema,

$$
\chi^{\prime}=\frac{L^{d}}{k_{B} T}\left(\left\langle m^{2}\right\rangle_{T}-\langle|m|\rangle_{T}^{2}\right) \sim\left|T-T_{c}(\infty)\right|^{-\gamma}
$$

Num sistema finito, $\chi^{\prime}$ apresenta um máximo de altura finita $\chi_{\max }^{\prime}$,

$$
\chi_{\max }^{\prime} \sim \chi\left(L, T=T_{c}\right) \sim L^{\gamma_{c}}
$$

Similarmente, o parâmetro de ordem $\langle|m|\rangle_{T, L}$ não se anula em $T_{c}$, comportando-se como

$$
\langle|m|\rangle_{T_{c}, L} \sim L^{-\beta_{c}}
$$

Através destas equaçōes, vários expoentes críticos foram introduzidos: o expoente de arredondamento $\theta$, o expoente de deslocamento $\lambda \mathrm{e}$ os expoentes descrevendo a dependência de tamanho em $T_{c}$ para várias quantidades criticas, tais como $\beta_{c}$ para a magnetização, $\gamma_{0}$ para a susceptibilidade, etc.

A compreensão dos efeitos de tamanho finito é devida à teoria de “finite size scaling” (Fisher, 1971; Fisher e Barber, 1972). A idéia básica desta teoria é a seguinte: próximo ao ponto crítico, hâ somente um comprimento característico importante, o comprimento de correlação $\xi$ das flutuações do parâmetro de ordem; então é plausível que os efeitos de tamanho finito sejam controlados por uma comparação de 
comprimentos, a dimensão linear $L$ e este comprimento de correlação $\xi$.

Para $T \rightarrow T_{c}$, o comprimento de correlação diverge como

$$
\xi=\xi_{ \pm}\left|1-\frac{T}{T_{c}}\right|^{-v}
$$

onde $T_{c} \equiv T_{c}(\infty)$ e $\xi_{+}\left(\xi_{-}\right)$é a amplitude critica para $T>T_{c} \quad\left(T<T_{c}\right)$. Obviamente, esta divergência é limitada se as dimensões lineares do sistema forem finitas.

Se $L \approx \xi$, a hipótese de "finite size scaling" estabelece que

$$
\Delta T_{a r} \sim T_{c}(L)-T_{c} \sim\left|T-T_{c}\right|
$$

Logo, de acordo com (9.1), (9.2), (9.6) e (9.7) podemos escrever

$$
L^{-\theta} \sim L^{-\lambda} \sim L^{-1 / v}
$$

o que implica

$$
\theta=\lambda=1 / v
$$

A magnetizaçāo espontânea $M_{\text {esp }}=\langle|m|\rangle_{T, L \rightarrow \infty}$ comporta-se como

$$
M_{\text {esp }}=B\left(1-\frac{T}{T_{c}}\right)^{\beta},
$$

quando $T \rightarrow T_{c}$.

Expressando as singularidades de $\chi^{\prime}$ (equação (9.3)) e de $M_{\text {esp }}$ (equação (9.10)) em termos de $\xi$,

$$
\chi^{\prime} \sim \xi^{\gamma / v} \quad \text { e } \quad\langle|m|\rangle_{T, L \rightarrow \infty} \sim \xi^{-\beta / v},
$$

a idéia de que o crescimento de $\xi$ próximo a $T_{c}$ é limitado por $L$ imediatamente implica em 


$$
\chi_{\max }^{\prime} \sim L^{\gamma / v} \quad \text { e } \quad\langle|m|\rangle_{T_{c}, L} \sim L^{-\beta / v} \text {. }
$$

Comparando as equaçōes (9.4), (9.5) e (9.12), concluímos

$$
\gamma_{c}=\frac{\gamma}{v} \quad \text { e } \quad \beta_{c}=\frac{\beta}{v}
$$

\subsection{Função de distribuição de probabilidade do PARÂMETRO DE ORDEM}

A afirmação de que num sistema finito uma transição de fase não pode ocorrer é equivalente a dizer que uma quebra de simetria espontânea não pode ocorrer em sistemas finitos. Portanto, na ausência de campos que possam quebrar a simetria, a média térmica da magnetização é identicamente zero em todas temperaturas não nulas,

$$
\langle m\rangle_{T, L} \equiv 0
$$

Obviamente, nāo há contradição entre as equações (9.5) e (9.14), pois na primeira utiliza-se o valor absoluto do parâmetro de ordem: a anulação do valor médio da magnetização $m$, em (9.14), é devida ao fato de que ambos os sinais da magnetização são igualmente prováveis. Isto é verdade tanto acima quanto abaixo de $T_{c}$ : em ambos os casos a distribuição de probabilidade $P_{L}(m)$ da magnetização $m$, no volume finito $L^{d}$, è simétrica em torno de $m=0$, Figura 9.2, ainda que $P_{L}(m)$ mude de formato apreciavelmente quando $T$ aumenta de $T<T_{c}$ para $T>T_{c}$. Em modelos do tipo Ising, $P_{L}(m)$ apresenta uma estrutura formada por dois picos, que incidem sobre os dois valores $\left( \pm M_{e s p}\right)$ da magnetização espontânea. Deveras, para $T<T_{c}$ e próximo a estes picos, $P_{L}(m)$ pode ser escrita como aproximadamente igual à soma de duas gaussianas,

$$
P_{L}(m) \approx C_{0}\left[e^{-\omega_{0}\left(m-M_{e p p}\right)^{2}}+e^{-\omega_{0}\left(m+M_{\text {eep }}\right)^{2}}\right]
$$


onde $\omega_{0}=L^{d} /\left(2 k_{B} T \chi^{\prime}\right)$ (aqui $\chi^{\prime}$ é a susceptibilidade definida em (9.3), em uma temperatura $T<T_{c}$ ) e

$$
C_{0}=\frac{1}{2} \sqrt{\frac{\omega_{0}}{\pi}}=\frac{1}{2} \sqrt{\frac{L^{d}}{2 \pi k_{B} T \chi^{\prime}}}
$$

é a constante de normalização.

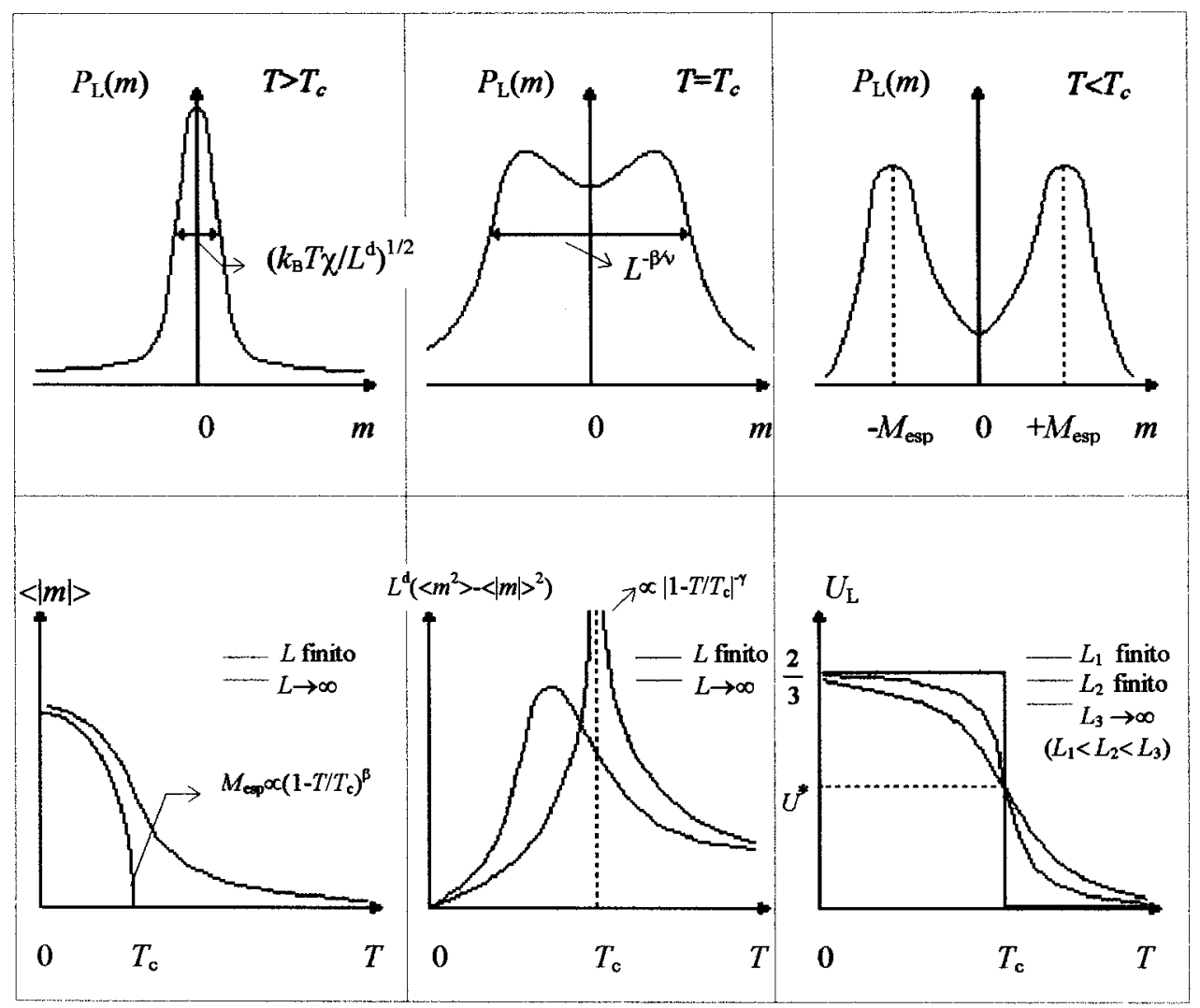

Figura 9.2: Evolução esquemática da distribuição de probabilidade do parâmetro de ordem $P_{\mathrm{L}}(m)$ (os três gráficos superiores correspondem, em sequência, a $T>T_{c}, T=T_{c}$ e $T<T_{c}$ ) e dependência, do parâmetro de ordem médio $\left\langle|m|>\right.$, da susceptibilidade do parâmetro de ordem $k_{\mathrm{B}} T \chi^{\prime}=L^{\mathrm{d}}\left(\left\langle m^{2}\right\rangle-\right.$ $\left.\langle|m|\rangle^{2}\right)$, e do cumulante de quarta ordem reduzido $\left.U_{L}=1-\left[\left\langle m^{4}\right\rangle \mid\left(3<m^{2}\right\rangle^{2}\right)\right]$, como funções da temperatura $T$ (três gráficos inferiores). As curvas em vermelho indicam a variação singular no limite termodinâmico $L \rightarrow \infty$.

Conforme $T$ aumenta em direção a $T_{c}$, os dois picos descritos pela equação (9.15) se aproximam, desde que $M_{\text {esp }} \rightarrow 0$. Muito próximo a $T_{c}$, onde $\xi \approx L$, os picos fundem-se em uma função de distribuição 
critica não trivial, que será discutida adiante. Para $T \gg T_{c}$ (onde novamente $L>>\xi$ ), $P_{L}(m)$ é uma gaussiana centrada em $m=0$,

$$
P_{L}(m) \approx C_{1} e^{-\omega_{1} m^{2}} \quad,
$$

onde $\omega_{1}=L^{d} /\left(2 k_{B} T \chi\right) \mathrm{e}$

$$
C_{1}=\sqrt{\frac{\omega_{1}}{\pi}}=\sqrt{\frac{L^{d}}{2 \pi k_{B} T \chi}}
$$

é a constante de normalização, com $\chi$ (acima de $T_{c}$ ) satisfazendo a relação de flutuação termodinâmica padrão,

$$
\chi=\frac{L^{d}}{k_{B} T}\left(\left\langle m^{2}\right\rangle_{T}-\langle m\rangle_{T}^{2}\right)
$$

Desde que para sistemas finitos, na ausência de campos que possam quebrar a simetria, podemos utilizar a equação (9.14), a equação acima é equivalente a

$$
\chi=\frac{L^{d}}{k_{B} T}\left\langle m^{2}\right\rangle_{T}
$$

O comportamento de $P_{L}(m)$ próximo a $T_{c}$ (onde, num sistema infinito, $\xi$ diverge e ultrapassa a dimensão $L$ ) obedece à hipótese de escala (Binder, 1981):

$$
P_{L}(m)=L^{y} \widetilde{P}\left(m L^{y}, L / \xi\right)
$$

A função de escala $\widetilde{P}$ é normalizada tal que $\int_{-\infty}^{+\infty} P_{L}(m) d m=1$. Tal normalização justifica a presença do fator $L^{y}$ (que antecede $\widetilde{P}$ ) em (9.21). O valor de $y$ é fixo se considerarmos o primeiro momento (note que $\widetilde{P}$ é uma função par em $m$ e que denotamos $m L^{y}=z$ ):

$$
\langle|m|\rangle_{T, L}=\int_{-\infty}^{+\infty}|m| P_{L}(m) d m=L^{-y} \int_{-\infty}^{+\infty}|z| \widetilde{P}(z, L / \xi) d z=L^{-y} \widetilde{m}(L / \xi) .
$$


Para $T=T_{c}$, no limite termodinâmico $\xi$ diverge tal que $L / \xi \rightarrow 0$, de modo que $\langle|m|\rangle_{T_{c}, L}=\widetilde{m}(0) L^{-y}$, onde $\tilde{m}(0)$ é apenas um fator de proporcionalidade. A comparação desta última expressão com (9.12) implica em

$$
y=\frac{\beta}{v}
$$

Por outro lado, para $T$ próximo a $T_{c}$ e $L / \xi \rightarrow \infty$, o valor de $y$ estabelecido acima também pode ser obtido se considerarmos que a expressão (9.22) deve tender a (9.10) conforme $L / \xi \rightarrow \infty$ : neste caso, o fator $L^{-y}$ em (9.22) deve ser cancelado e, para isto, devemos ter $\widetilde{m}(L / \xi) \rightarrow(L / \xi)^{y}$, o que implica $\langle|m|\rangle_{T, L \rightarrow \infty} \sim \xi^{-y} \sim\left|1-T / T_{c}\right|^{\nu y}$. Comparando este resultado com (9.10), obtemos $y=\beta / v$.

Um raciocinio similar pode ser aplicado ao segundo momento,

$$
\left\langle m^{2}\right\rangle_{T, L}=\int_{-\infty}^{+\infty} m^{2} P_{L}(m) d m=L^{-2 y} \int_{-\infty}^{+\infty} z^{2} \widetilde{P}(z, L / \xi) d z=L^{-2 y} \widetilde{\chi}(L / \xi)
$$

que substituído em (9.20) permite reescrever a susceptibilidade como

$$
\chi=\frac{L^{d-2 y}}{k_{B} T} \tilde{\chi}(L / \xi)
$$

Sobre $T_{c}, \chi=\chi\left(L, T=T_{c}\right)=\left[\widetilde{\chi}(0) / k_{B} T_{c}\right] L^{d-2 y}$ e a comparação com a expressão (9.4) conduz à relação $d-2 y=\gamma_{c}$, onde substituimos (9.13) e (9.23), obtendo então a relação de hiperescala entre os expoentes críticos

$$
d v=2 \beta+\gamma
$$

A relaçāo (9.26) é vâlida somente para $d \leq d^{*}$, onde $d^{*}$ é a dimensão crítica superior a partir da qual a teoria de Landau se aplica (Amit, 1987). Por exemplo, no modelo de Ising temos $d^{*}=4$ e se utilizarmos os expoentes da teoria de Landau, $\gamma=1, \beta=1 / 2, \nu=1 / 2$ (Amit, 1987), a relação de hiperescala (9.26) falha para $d \geq 5$ dimensões. 
Para $T=T_{c}$, no limite termodinâmico $\xi$ diverge tal que $L / \xi \rightarrow 0$, de modo que $\langle|m|\rangle_{T_{c}, L}=\widetilde{m}(0) L^{-y}$, onde $\widetilde{m}(0)$ é apenas um fator de proporcionalidade. A comparação desta última expressão com (9.12) implica em

$$
y=\frac{\beta}{v}
$$

Por outro lado, para $T$ próximo a $T_{c}$ e $L / \xi \rightarrow \infty$, o valor de $y$ estabelecido acima também pode ser obtido se considerarmos que a expressão (9.22) deve tender a (9.10) conforme $L / \xi \rightarrow \infty$ : neste caso, o fator $L^{-y}$ em (9.22) deve ser cancelado e, para isto, devemos ter $\widetilde{m}(L / \xi) \rightarrow(L / \xi)^{y}$, o que implica $\langle|m|\rangle_{T, L \rightarrow \infty} \sim \xi^{-y} \sim\left|1-T / T_{c}\right|^{v y}$. Comparando este resultado com (9.10), obtemos $y=\beta / \nu$.

Um raciocínio similar pode ser aplicado ao segundo momento,

$$
\left\langle m^{2}\right\rangle_{T, L}=\int_{-\infty}^{+\infty} m^{2} P_{L}(m) d m=L^{-2 y} \int_{-\infty}^{+\infty} z^{2} \widetilde{P}(z, L / \xi) d z=L^{-2 y} \widetilde{\chi}(L / \xi)
$$

que substituído em (9.20) permite reescrever a susceptibilidade como

$$
\chi=\frac{L^{d-2 y}}{k_{B} T} \widetilde{\chi}(L / \xi)
$$

Sobre $T_{c}, \chi=\chi\left(L, T=T_{c}\right)=\left[\widetilde{\chi}(0) / k_{B} T_{c}\right] L^{d-2 y}$ e a comparação com a expressão (9.4) conduz à relação $d-2 y=\gamma_{c}$, onde substituímos (9.13) e (9.23), obtendo então a relação de hiperescala entre os expoentes criticos

$$
d v=2 \beta+\gamma
$$

A relação (9.26) é válida somente para $d \leq d^{*}$, onde $d^{*}$ è a dimensão crítica superior a partir da qual a teoria de Landau se aplica (Amit, 1987). Por exemplo, no modelo de Ising temos $d^{*}=4$ e se utilizarmos os expoentes da teoria de Landau, $\gamma=1, \beta=1 / 2, v=1 / 2$ (Amit, 1987), a relação de hiperescala (9.26) falha para $d \geq 5$ dimensões. 
A explicação é a seguinte: o tratamento que nos conduziu à relação de hiperescala (9.26) é baseado na hipótese de que, em sistemas isotrópicos, hả um único comprimento relevante próximo ao ponto critico, o comprimento de correlação $\xi$, e esta hipótese é somente verdadeira para $d \leq d^{*}$ (Binder, 1990). O caso $d>d^{*}$ pode ser compreendido por generalizações apropriadas da teoria de Landau, onde um novo comprimento relevante é definido, o comprimento termodinâmico $l_{T}$, que tem uma dependência com a temperatura diferente da dependência de $\xi$ (Binder, 1990).

\subsection{CUMULANTE DA DISTRIBUIÇÃo}

Para localizar a temperatura crítica nas simulações, é conveniente utilizar o cumulante de quarta ordem normalizado da distribuição

$$
U_{L}=1-\frac{\left\langle m^{4}\right\rangle_{L}}{3\left\langle m^{2}\right\rangle_{L}^{2}}
$$

Para $T \gg T_{c}$, a função de distribuição $P_{L}(m)$ é uma gaussiana (expressões (9.17) e (9.18)) e

$$
\left\langle m^{2}\right\rangle_{L}=\int_{-\infty}^{+\infty} m^{2} P_{L}(m) d m=C_{1} \int_{-\infty}^{+\infty} m^{2} e^{-\omega_{1} m^{2}} d m=\frac{1}{2 \omega_{1}}
$$

enquanto que

$$
\left\langle m^{4}\right\rangle_{L}=\int_{-\infty}^{+\infty} m^{4} P_{L}(m) d m=C_{1} \int_{-\infty}^{+\infty} m^{4} e^{-\omega_{1} m^{2}} d m=\frac{3}{4 \omega_{1}^{2}}
$$

Substituindo (9.28) e (9.29) em (9.27), obtemos $U_{L}=0$.

Para $T<<T_{c}$, utilizamos a funçāo de distribuiçāo $P_{L}(m)$ expressa em (9.15) e (9.16) e calculamos: 


$$
\begin{gathered}
\left\langle m^{2}\right\rangle_{L}=\int_{-\infty}^{+\infty} m^{2} C_{0}\left[e^{-\omega_{0}\left(m-M_{e s p}\right)^{2}}+e^{-\omega_{0}\left(m+M_{e p}\right)^{2}}\right] d m=\frac{1}{2 \omega_{0}}+M_{e s p}^{2} \\
\left\langle m^{4}\right\rangle_{L}=\int_{-\infty}^{+\infty} m^{4} C_{0}\left[e^{-\omega_{0}\left(m-M_{e s p}\right)^{2}}+e^{-\omega_{0}\left(m+M_{e s p}\right)^{2}}\right] d m=\frac{3}{4 \omega_{0}^{2}}+\frac{3}{\omega_{0}} M_{e s p}^{2}+M_{e s p}^{4}
\end{gathered}
$$

No limite $T \rightarrow 0,1 / \omega_{0} \rightarrow 0,\left\langle m^{2}\right\rangle_{L} \rightarrow M_{e s p}^{2}$ e $\left\langle m^{4}\right\rangle_{L} \rightarrow M_{e s p}^{4}$, o que implica (de acordo com (9.27)) em $U_{L} \rightarrow 2 / 3$.

Em $T \approx T_{c}$, de acordo com (9.24), $\left\langle m^{2}\right\rangle_{T, L}=L^{-2 y} \tilde{\chi}(L / \xi)$ e, de modo análogo, obtemos $\left\langle m^{4}\right\rangle_{T, L}=L^{-4 y} \psi(L / \xi)$. O cumulante de quarta ordem normalizado (de acordo com (9.27)) é uma função de $L / \xi: U_{L}=\widetilde{U}(L / \xi)$. Exatamente sobre $T_{c}, U_{L}\left(T=T_{c}\right)=\widetilde{U}(L / \xi \rightarrow 0)=\widetilde{U}(0)=U^{*}$.

Portanto, a curva do cumulante $U_{L}$ em função da temperatura $T$ tende a zero para $T \gg T_{c}$ e tende a $2 / 3$ para $T<<T_{c}$. Para diferentes escolhas de $L$, as curvas $U_{L}$ versus $T$ devem ter um único ponto de intersecção $U^{*}$ e a temperatura onde isto ocorre é $T_{c}$ - deste modo, uma estimativa de $T_{c}$ pode ser obtida, e tal estimativa não é influenciada por quaisquer hipóteses sobre os expoentes críticos (ver, na Figura 9.2, gráfico inferior à direita). Originalmente, este método foi demonstrado com sucesso no modelo de Ising (Binder, 1981), tendo se mostrado útil também no estudo de outros modelos.

Considerando que $U_{L}$ deve ser uma funçāo regular da temperatura, desde que para sistemas finitos todas propriedades são funçōes regulares da temperatura, concluimos que, para $T \approx T_{c}$,

$$
\begin{aligned}
U_{L} & =\widetilde{U}(L / \xi)=\bar{U}\left[L^{1 / v}\left(1-T / T_{c}\right)\right] \\
& =U^{*}+U_{1}^{*} L^{1 / v}\left(1-T / T_{c}\right)+U_{2}^{*} L^{2 / v}\left(1-T / T_{c}\right)^{2}+\cdots
\end{aligned},
$$

onde $U_{1}^{*}$ e $U_{2}^{*}$ são constantes. A inclinação da curva $U_{a L}$ versus $U_{L}$ sobre o ponto crítico é 


$$
\left.\frac{\partial U_{a L}}{\partial U_{L}}\right|_{U^{*}}=\left.\frac{\partial U_{a L} / \partial T}{\partial U_{L} / \partial T}\right|_{T=T_{c}}=a^{1 / v}
$$

onde $a>0$ é algum fator de escala. De (9.33) podemos estimar o expoente $v$ : para $L$ e $a L$ fixos, traçamos o gráfico $U_{a L}$ versus $U_{L}$, obtendo a inclinação $\left[\partial U_{a L} / \partial U_{L}\right]_{u^{*}}$ da curva sobre o ponto crítico; o gráfico $\log \left[\partial U_{a L} / \partial U_{L}\right]_{u^{*}}$ versus $\log a$ deve ser uma reta com inclinaçāo $1 / v$.

Similarmente, o expoente $\beta / v$ pode ser obtido a partir da razão dos momentos de segunda ordem em $T_{c}$ (ver expressāo (9.24)),

$$
W_{\beta}\left(T=T_{c}\right) \equiv \frac{-\ln \left[\left\langle m^{2}\right\rangle_{T_{c}, a L} /\left\langle m^{2}\right\rangle_{T_{c}, L}\right]}{\ln a}=\frac{-\ln \left[a^{-2 \beta / v}\right]}{\ln a}=\frac{2 \beta}{v} .
$$

Um mérito particular desta técnica consiste em se poder considerar as correções de "finite size scaling" sistematicamente (Binder, 1981). Lembremos que as expressões apresentadas para $T \rightarrow T_{c}$ e $L / \xi$ finito são leis assintóticas válidas no limite $L \rightarrow \infty$. Para $L$ finito fixo, termos de correção são esperados. Com as correções, o momento de segunda ordem pode ser escrito como

$$
\left\langle m^{2}\right\rangle_{T_{c}, L}=L^{-2 \beta / v} \tilde{\chi}(0)\left[1+\chi_{c} L^{-x_{c}}\right]
$$

onde $x_{c}$ é o expoente de correção dominante e $\chi_{c}$ é o fator de amplitude associado. Utilizando a equação (9.35) na definição de $W_{\beta}\left(T=T_{c}\right)$ (equação (9.34)), obtemos

$$
W_{\beta}\left(T=T_{c}\right) \approx \frac{-1}{\ln a} \ln \left[a^{-2 \beta / v} \frac{\left(1+\chi_{c} a^{-x_{c}} L^{-x_{c}}\right)}{\left(1+\chi_{c} L^{-x_{c}}\right)}\right] .
$$

Notando que, para grandes valores de $L$, podemos expandir $\ln \left(1+\lambda \chi_{c} L^{-x_{c}}\right) \approx \lambda \chi_{c} L^{-x_{c}} \quad$ (com $\lambda=1$ ou $\left.\lambda=a^{-x_{c}}\right)$, reescrevemos (9.36) como 


$$
W_{\beta}\left(T=T_{c}\right) \approx \frac{2 \beta}{v}+\frac{\chi_{c} L^{-x_{c}}}{\ln a}\left(1-a^{-x_{c}}\right)
$$

Portanto, o procedimento para estimar $\beta / v$ consiste em avaliar $W_{\beta}\left(T=T_{c}\right)$ (de acordo com a definição (9.34)) para muitos pares de tamanhos $(L, a L)$ e extrapolar $W_{\beta}$ como função de $1 / \ln a$, tratando $L$ como um parâmetro. Neste caso, a equação (9.37) implica que $W_{\beta}$ deve ser linear em $(\ln a)^{-1}$ para grandes valores de $a$ e a intersecção com o eixo $(\ln a)^{-1}=0$ deve ser independente de $L$. Logo, as curvas obtidas para diferentes escolhas de $L$ devem todas se interceptar em $(\ln a)^{-1}=0$ no mesmo valor, que é então a estimativa final de $2 \beta / v$. 


\section{REFERÊNCIAS}

Amit, D. J. (1987). Field Theory, the Renormalization Group and Critical Phenomena, McGraw Hill, New York.

Andrade Jr., J. S. , Lucena, L. S. , Alencar, A. M. e Freitas, J. E. (1996). A ser publicado.

Bak, P. , Tang, C. e Wiensenfeld, K. (1987). Phys. Rev. Lett. 59, 381. Baker, G. A., Jr. (1961). Phys. Rev. 124, 768.

Baker, G. A., Jr. (1965). Ad. Theor. Phys. 1, 1.

Baker, G. A., Jr. (1975). Essentials of Padé Approximants, Academic Press, New York.

Baker, G. A., Jr. e Gammel, J. L. (1961). J. Math. Anal. and Appl. 2, 21. Barma, M. e Fisher, M. E. (1985). Phys. Rev. B 31, 5954.

Baumgärtner, A. (1982). J. Physique 43, 1407.

Binder, K. (1981). Z. Phys. B 43, 119.

Binder, K. (1987). Ferroelectrics 73, 43.

Binder, K. (1990). Finite Size Scaling and Numerical Simulation of Statistical Systems (ed. V. Privman). World Scientific, Singapore, p. 173.

Binney, J. J. , Dowrick, N. J. , Fisher, A. J. e Newman, M. E. J. (1992). The Theory of Critical Phenomena - An Introduction to the Renormalization Group, Clarendon Press, Oxford.

Broeck, J. M. van den e Schwartz, L. W. (1979). SIAM J. Math. Anal. 10, 658.

Bulirsch, R. e Stoer, J. (1964). Numer. Math. 6, 413.

Camacho, C. J. , Fisher, M. E. e Straley, J. P. (1992). Phys. Rev. A. 46, 6300. - Conjuntos de dados disponiveis no documento AIP No. PAPS PRLAA-466300-49, Ref. 9212C-1307.

Chang, I. S. e Shapir, Y. (1988). Phys. Rev. B. 38, 6736.

Chen, J. -H., Fisher, M. E. e Nickel, B. G. (1982). Phys. Rev. Lett. 48, 630.

Chisholm, J. S. R. (1973). Math. Comp. 27, 841.

Chisholm, J. S. R. e Jones, R. H. (1975). Proc. R. Soc. Lond. A344, 365.

Chisholm, J. S. R. e McEwan, J. (1974). Proc. R. Soc. Lond. A336, 421.

Chisholm, J.S.R. e Roberts, D.E. (1976). Proc. R. Soc. Lond. A351, 585.

Davidson, N. (1962). Statistical Mechanics, McGraw-Hill, New York. 
Derrida, B. (1991). Phys. Scripta T38, 6.

Derrida, B. e Herrmann, H. J. (1983). J. Physique 44, 1365.

Dhar, D. (1987). J. Phys. A 20, L847.

Dickman, R. e Schieve, W. C. (1984). J. Physique 45, 1727.

Domb, C. e Sykes, M. F. (1956). Proc. Phys. Soc. A235, 247.

Domb, C. e Sykes, M. F. (1957). Proc. Phys. Soc. A240, 214.

Duplantier, B. (1982). J. Physique 43, 991.

Feder, J. (1988). Fractals (ed. Plenum). New York.

Fisher, M. E. (1971). Critical Phenomena, (ed. M. S. Green). Academic

Press, New York and London.

Fisher, M. E. e Barber, M. N. (1972). Phys. Rev. Lett. 28, 1516.

Fisher, M. E. (1977). Physica 86-88, 590.

Fisher, M. E. , Guttmann, A. J. e Whittington, S. G. (1991). J. Phys. A 24, 3095.

Fisher, M. E. e Kerr, R. M. (1977). Phys. Rev. Lett. 39, 667.

Fisher, M. E. e Nelson, D. R. (1974). Phys. Rev. Lett. 34, 1634.

Fisher, M. E. e Styer, D. F. (1982). Proc. R. Soc. Lond. A 384, 259.

Flesia, S. e Gaunt, D. S. (1992). J. Phys. A 25, 2127.

Flesia, S. , Gaunt, D. S. , Soteros, C. E. e Whittington, S. G. (1992). J. Phys. A 25, L1169.

₹ Flesia, S. , Gaunt, D. S. , Soteros, C. E. e Whittington, S. G. (1993). J. Phys. A 26, L993.

Flory, P. J. (1969). Principles of Polymer Chemistry, Cornell Univ. Press, Ithaca, NY.

Gaunt, D. S. (1991). Physica A 177, 146.

Gaunt, D. S. e Flesia, S. (1990). Physica A 168, 602.

Gaunt, D. S. , Lipson, J. E. G. , Martin J. L., Sykes, M. F. , Torrie, G. M., Whittington, S. G. e Wilkinson, M. K. (1984). J. Phys. A 17, 211.

Gennes, P. G. de (1975). J. Physique-Lett. 36, L55.

Gennes, P. G. de (1978). J. Physique-Lett. 39, L299.

Gennes, P. G. de (1979). Scaling Concepts in Polymer Physics, Cornell Univ Press, Ithaca, NY.

Guttmann, A. J. (1989). Phase Transitions and Critical Phenomena, Vol. 13, (ed. C. Domb and J. L. Lebowitz). Academic Press, London.

Henkel, M. e Schütz, G. (1988). J. Phys. A 21, 2617.

Herrmann, H. J. (1984). Kinetics of Aggregation and Gelation, (ed. F. Family and D. P. Landau). North-Holland, Amsterdam.

Huang, K. (1963). Statistical Mechanics, (ed. Wiley \& Sons). New York.

Hunter, D. L. e Baker, G. A. Jr. (1973). Phys. Rev. B 7, 3346.

Ikehara, T. e Nishi, T. (1993). Phys. Rev. Lett. 71, 2497.

Isaacson, J. e Lubensky, T. C. (1981). J. Physique 42, 175.

Kaski, K. K. , Binder, K. e Gunton, J. D. (1984). Phys. Rev. B. 29, 3996.

Lam, P. M. (1987). Phys. Rev. B 36, 6988.

Lam, P. M. (1988). Phys. Rev. B 38, 2813.

Landau, D. P. e Binder, K. (1985). Phys. Rev. B. 31, 5946.

Lubensky, T. C. e Isaacson, J. (1979). Phys. Rev. A 20, 2130. 
Lucena, L. S. , Araújo, J. M. , Tavares, D. M. , Silva, L. R. e Tsallis, C. (1994). Phys. Rev. Lett. 72, 230.

Lyklema, J. W. (1986). Fractals in Physics (ed. L. Pietronero and E. Tosati). North-Holland, Amsterdam.

Madras, N. , Soteros, C. E. e Whittington, S. G. (1988). J. Phys. A 21, 4617.

Madras, N. , Soteros, C. E. , Whittington, S. G. , Martin, J. L. , Sykes, M. F., Flesia, S. e Gaunt, D. S. (1990). J. Phys. A 23, 5327.

Majid, I. , Jan, N. , Coniglio, A. e Stanley, H. E. (1984). Phys. Rev. Lett. 52, 1257.

Mandelbrot, B. B. (1986). Fractals in Physics (ed. L. Pietronero and E. Tosati). North-Holland, Amsterdam.

Martin, J. L. (1990). J. Stat. Phys. 58, 749.

Meakin, P. (1993). Phys. Rep. 235, 189.

Moore, M. A. (1977). J. Phys. A 10, 305.

Neves, U. P. C. e Onody, R. N. (1995). Physica A 218, 1.

Nierlich, M. , Cotton, J. P. e Farnoux, B. (1978). J. Chem. Phys. 69, 1379.

Nishio, I. e Sun, S. T. ; Swislow, G. e Tanaka, T. (1979). Nature 281, 208.

ł Onody, R. N. e Neves, U. P. C. (1996a). J. Stat. Phys. 84, 399.

Onody, R. N. e Neves, U. P. C. (1996b). J. Phys. A 29, L527.

Orr, W. J. (1947). Trans. Faraday Soc. 43, 12.

Ortega, J. M. e Poole, W. G. (1981). Numerical Methods for Differencial

Equations, (ed. Pitman). Massachusetts.

Padé, H. (1892). Thesis, Ann. École Nor. 9, Suppl., 1.

Privman, V. e Redner, S. (1987). Z. Phys. B 67, 129.

Randeria, M. e Fisher, M. E. (1988). Proc. R. Soc. Lond. A 419, 181.

Roberts, D. E., Griffiths, H. P. e Wood, D. W. (1975). J. Phys. A. 8, 1365.

Stanley, H. E. (1971). Introduction to Phase Transitions and Critical

Phenomena (ed. Oxford Univ. Press). New York and Oxford.

Stauffer, D. (1985). Introduction to Percolation Theory (ed. Taylor and Francis). London.

Stilck, J. F. e Salinas, S. R. (1981). J. Phys. A 14, 2027.

Styer, D. F. e Fisher, M. E. (1983). Proc. R. Soc. Lond. A 388, 75.

Swendsen, R. H. e Wang, J. S. (1987). Phys. Rev. Lett. 58, 86.

Sykes, M. F. (1986). J. Phys. A 19, 1007; 1027; 2425; 2431.

Tanaka, T. (1981). Sci. American, Jan., 124.

Vanderzande, C. (1993). Phys. Rev. Lett. 70, 3595.

Wessel, R. e Ball, R. C. (1992). Phys. Rev. A. 45, 2177.

Witten, T. A. e Sander, L. M. (1981). Phys. Rev. Lett. 47, 1400.

Wolff, U. (1989). Phys. Rev. Lett. 62, 361. 


\section{APÊNDICE: REALIZAÇÃO EXPERIMENTAL DA TRANSIÇÃO DE COLAPSO EM POÚMEROS RAMIFICADOS}

Experimentalmente, os polímeros ramificados são realizados em géis. O gel é uma forma de matéria intermediária entre o sólido e o liquido. Consiste de uma rede de longas cadeias poliméricas ligadas entre si e imersas em um meio líquido. As propriedades do gel dependem fortemente da interação destes dois componentes: o líquido impede que a rede de cadeias poliméricas colapse em uma massa compacta enquanto que a rede impede o líquido de fluir. Alguns exemplos de géis são: a gelatina, o humor vítreo que preenche o interior do olho, o material da córnea e o fluido que lubrifica as articulações. Os géis também são intermediários importantes na manufatura de borrachas, plásticos, colas e membranas. Géis contendo medicamentos sensiveis a ácidos têm sido desenvolvidos. $\mathrm{Na}$ presença de um meio ácido (estômago), esses géis estão numa fase comprimida e não deixam o medicamento sair. Na presença de um meio mais básico (intestino), o gel expande-se e permite a saida do medicamento.

O grupo liderado por T. Tanaka, no M.I.T., observou que o gel pode sofrer uma expansão ou compressão quando a temperatura varia. Isto pode ser compreendido no contexto de transiçōes de fase $\mathrm{e}$ fenômenos críticos (Tanaka, 1981). Tal como muitas substâncias podem existir como líquido ou vapor sob diferentes circunstâncias, um gel pode ter duas fases, que são distinguidas por diferentes configurações da rede de polimeros. A mudança descontinua no volume do gel constitui uma transição abrupta entre as fases, análoga à ebulição de um líquido. A altas temperaturas, as duas fases do gel não podem mais ser distinguidas. No ponto crítico onde ocorre a separação das fases do gel, a rede polimérica exibe flutuações de larga escala na densidade e outras propriedades. 
Esta transição de colapso foi verificada através de experimentos envolvendo um gel contendo poliacrilamida. A Figura I ilustra a preparação do gel. Inicialmente, dois tipos de monômeros ("acrylamide" e "bisacrylamide") são dissolvidos em água. Então, duas substâncias ("ammonium persulfate" e "tetramethyl ethylene diamine") são adicionadas a esta solução para iniciar o processo de polimerização. Como resultado, uma rede de poliacrilamida, contendo "loops" e ramos, forma-se em cerca de 30 minutos. Após algumas horas, o gel é removido do recipiente que o contém e embebido em água para a retirada dos monômeros que não tenham participado da reação ou dos iniciadores da polimerização. O gel é altamente transparente, macio e elástico, com uma superficie delgada e escorregadia. O passo final na preparação é uma modificação química da rede polimérica: parte das cadeias laterais $\left(-\mathrm{CONH}_{2}\right)$ são convertidas por hidrólise em grupos - $\mathrm{COOH}$. A hidrólise é a separação de um grupo químico pela ação de uma molécula de água. É obtida ao imergir o gel por um periodo de dias ou semanas numa solução básica com $\mathrm{pH} \approx 12$. O número de cadeias hidrolisadas depende do tempo de hidrólise e tem grande influência na natureza das transiçōes de fase observadas no gel.

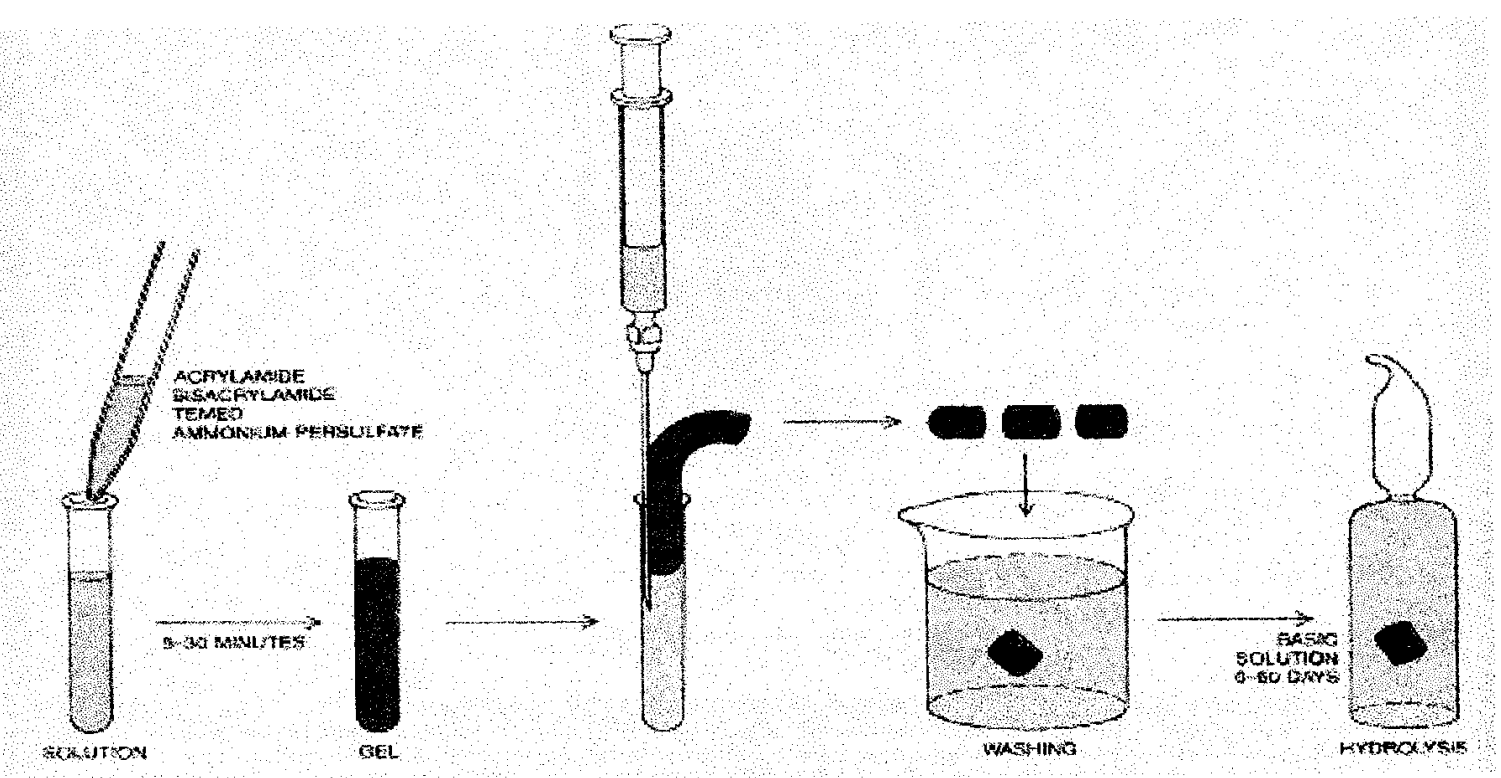

Figura I: Preparação do gel poliacrilamida. Os monômeros "acrylamide" e "bisacrylamide" săo dissolvidos em água e duas outras substâncias ("ammonium persulfate" e "tetramethyt ethylene diamine - TEMED") são adicionadas para iniciar a polimerização. O gel se forma, é lavado em água e então hidrolisado por dias ou semanas em soluçăo básica de $\mathrm{pH} \approx 12$.

As transições de fase observadas em géis poliacrilamida podem ser ilustradas pela seguinte série de experimentos. Uma porção de géis idênticos é preparada e os espécimes são hidrolisados numa solução básica por vários periodos de dias (até um máximo de 60 dias). Neste estado, os géis estão expandidos na água. Deveras, um gel completamente hidrolisado tem 30 vezes seu volume inicial. Os géis são então colocados em misturas de acetona e água e observados por muitos dias. Dependendo do tempo de hidrólise e das proporções de acetona e água, alguns dos géis são encontrados colapsados. O abrupto colapso de um gel acrilamida é interpretado como uma transição de fase. A Figura Il mostra gêis preparados identicamente (inicialmente 
com o mesmo tamanho) e que foram sujeitos à hidrólise pelo mesmo periodo de tempo (15 dias). Os espécimes foram colocados em misturas de água e acetona com diferentes concentrações de acetona. É aparente que solventes com menos de $47 \%$ de acetona têm pouco efeito no volume do gel. Em qualquer mistura que exceda esta concentração, o gel é reduzido a uma pequena fração de seu volume inicial. Assim, quando o gel é colocado em soluções com concentraçōes de acetona crescentes (à temperatura fixa), observa-se uma transição de colapso. Inversamente, os resultados obtidos com a diminuição da temperatura em uma solução com concentraçāo de acetona constante são absolutamente semelhantes.

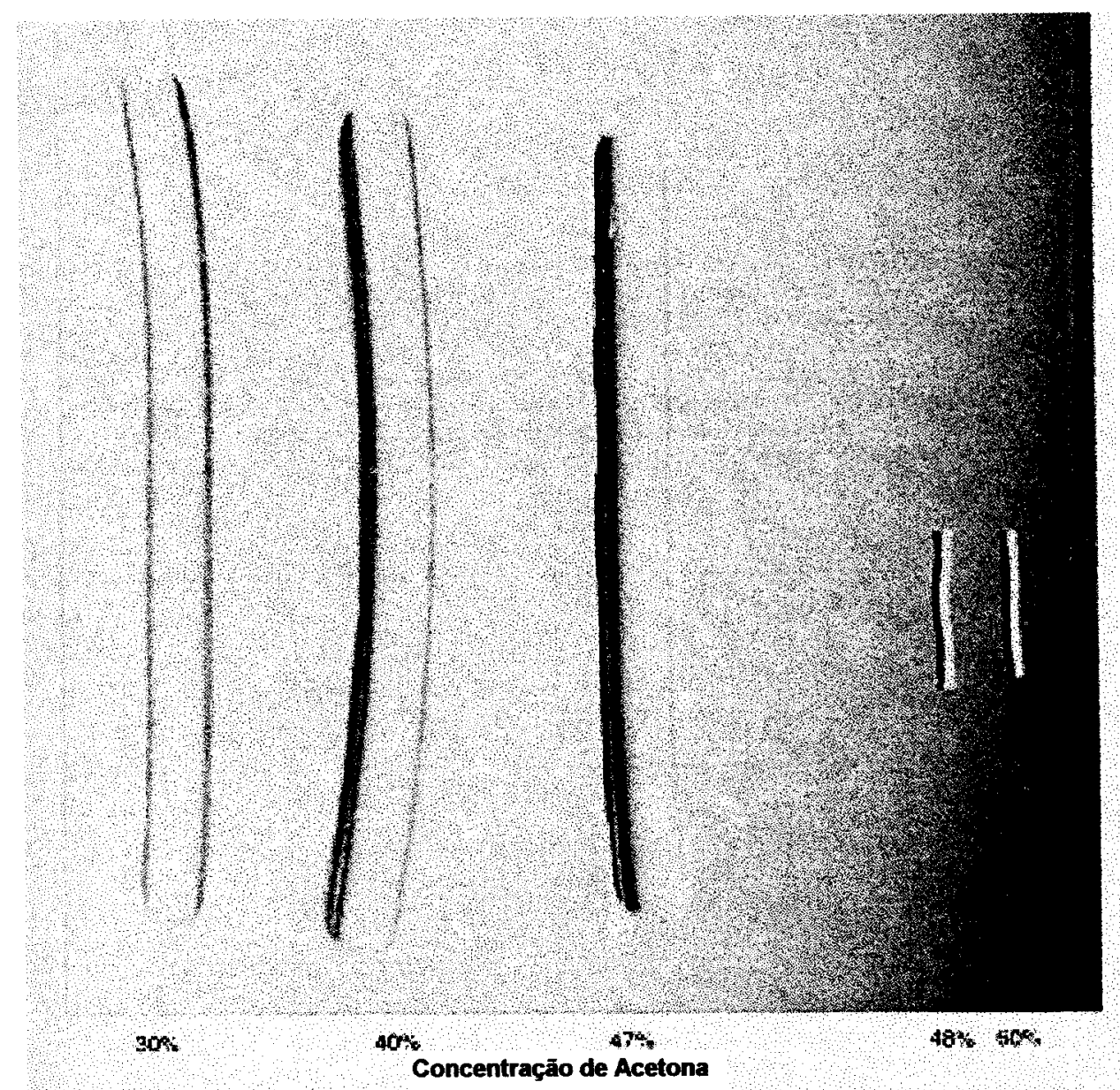

Figura II: Colapso abrupto do gel poliacrilamida. Géis preparados identicamente e sujeitos a 15 dias de hidrólise, quando colocados em diferentes concentraçסes de acetona (à temperatura fixa) sofrem uma transição de colapso. Os resultados såo absolutamente semelhantes se variarmos a temperatura (com a concentração de acetona mantida constante).

Os gráficos da Figura III mostram a variação do volume do gel conforme a concentração de acetona aumenta, para diversos tempos de hidrólise. Para o gel sem hidrólise, o gráfico é uma curva suave. Para o gel hidrolisado por dois dias, a curva é ainda suave, mas apresenta um ponto de inflexão. Géis expostos à hidrólise durante tempos progressivamente maiores, apresentam curvas descontínuas que representam transições de fase discretas e que tendem a uma função degrau. Portanto, o aumento do tempo de hidrólise tem como efeito a 
transformação de uma transição de segunda ordem em uma de primeira ordem!
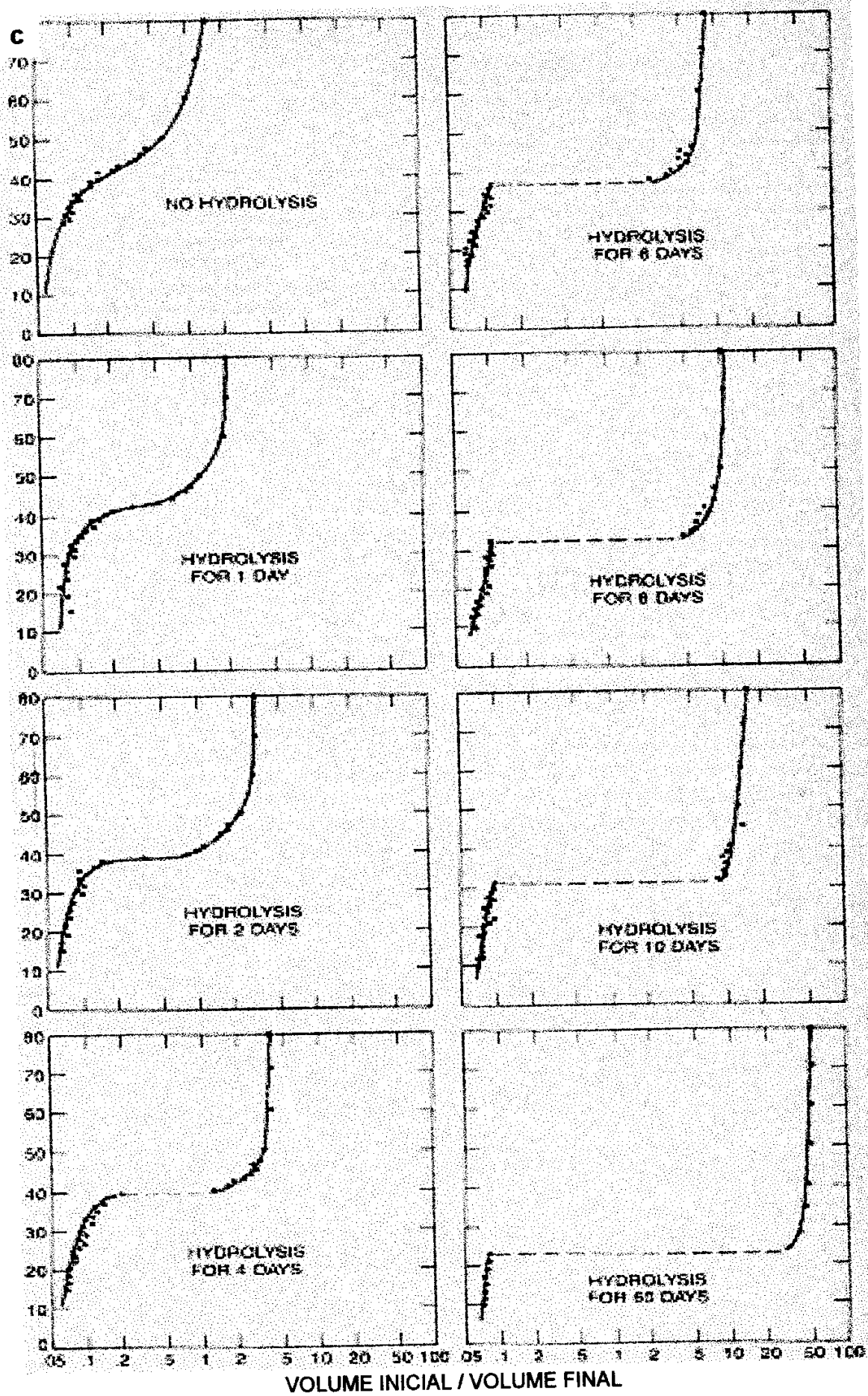

Figura III: Taxa de expansão do volume de um gel quando este é colocado em solventes com diferentes concentraçöes $c$ de acetona $(\%)$, para tempos de hidrólise progressivamente maiores.

Todos os mesmos fenômenos podem ser observados mantendo-se a mistura acetona-água constante e variando-se a temperatura. A altas temperaturas o gel está na fase expandida enquanto a baixas temperaturas está na fase colapsada. Além disso, se o grau de hidrólise for suficientemente grande, a transição é descontínua. Por exemplo, a 
transição de colapso de um gel hidrolisado por 4 dias e colocado num solvente com $42 \%$ de acetona ocorre a uma temperatura aproximadamente igual a $22^{\circ} \mathrm{C}$. Se a concentração de acetona for aumentada, a temperatura de transição aumenta em compensação. 